Identificação da cobertura espacial de documentos usando mineração de textos 

SERVIÇO DE PÓS-GRADUAÇÃO DO ICMC-USP

Data de Depósito: 27/08/2012

Assinatura:

\title{
Identificação da cobertura espacial de documentos usando mineração de textos
}

\author{
Rosa Nathalie Portugal Vargas
}

Orientadora: Profa. Dra. Solange Oliveira Rezende

Dissertação apresentada ao Instituto de Ciências Matemáticas e de Computação - ICMC-USP, como parte dos requisitos para obtenção do título de Mestre em Ciências - Ciências de Computação e Matemática Computacional. VERSÃO REVISADA 
Ficha catalográfica elaborada pela Biblioteca Prof. Achille Bassi e Seção Técnica de Informática, ICMC/USP, com os dados fornecidos pelo(a) autor(a)

\begin{tabular}{|c|c|}
\hline \multirow[t]{3}{*}{ P839i } & $\begin{array}{l}\text { Portugal Vargas, Rosa Nathalie } \\
\quad \text { Identificação da cobertura espacial de documentos } \\
\text { usando mineraço de textos / Rosa Nathalie Portugal } \\
\text { Vargas; orientadora Solange Oliveira Rezende. -- São } \\
\text { Carlos, } 2012 \text {. } \\
\quad 140 \text { p. }\end{array}$ \\
\hline & $\begin{array}{l}\text { Dissertação (Mestrado - Programa de Pós-Graduação en } \\
\text { Ciências de Computação e Matemática Computacional) -- } \\
\text { Instituto de Ciências Matemáticas e de Computação, } \\
\text { Universidade de São Paulo, } 2012 \text {. }\end{array}$ \\
\hline & $\begin{array}{l}\text { 1. Resolução de Topônimos. 2. Ambiguidade de } \\
\text { Entidades. 3. Reconhecimento de Entidades } \\
\text { Mencionadas. I. Oliveira Rezende, Solange, orient. } \\
\text { II. Título. }\end{array}$ \\
\hline
\end{tabular}




\section{Agradecimentos}

Aos meus pais, Rosa María e Ricardo Enrique, pelo grande apoio, amor, carinho, incentivo incondicional e por me estimular aos estudos desde os primeiros anos de vida e a seguir sempre para frente. Sempre penso no poema que vocês me ensinaram e que se tornou parte do meu dia a dia, sobretudo quando penso que não posso mais.

Se acha que está derrotado, o está.

Se pensa que não consegue, não conseguira.

Se acha que gostaria de ganhar mas não pode, não terá exito.

Por que no mundo encontrara, que o sucesso começa com o pensamento do homem.

Tudo está no estado mental.

Por que muitas carreiras foram perdidas antes de serem executadas e muitos covardes falham antes de seu trabalho ter começado.

Pense grande, e suas ações vão crescer.

Pense pequeno, e você ficará para trás.

Pense que pode, e poderá.

Na batalha da vida nem sempre vence o homem mais forte ou mais rápido, por que mais cedo ou mais tarde, o homem que ganha é aquele que pensa que pode fazê-lo.

Dr. Christian Barnard

Às minhas irmãs Angela, Claudia e Stephanie pelo apoio incondicional desde sempre, por me dar ânimos para seguir e nunca desistir e por sempre lembrar de mim e estar atentas a qualquer coisa que aconteça comigo. À minha sobrinha Jazmin por sempre estar me esperando quando volto para casa para me ouvir, brincar comigo, e me contar das novas experiências na escola. Ao meu anjinho de sempre, meu irmãozinho Jean Paul que sempre esteve cuidando de mim desde o céu. Aos meus avôs Rodolfo e Carmen, os quais sempre me motivaram, apoiaram e incentivaram em seguir meus estudos e são agora meus anjos da guarda que cuidam de mim desde o céu. À minha avó Dora que sempre me espera em casa com um sorriso imenso esperando que lhe conte tudo o que eu vivi no Brasil.

À Arturo Urquizo, um homem muito especial na minha vida, pelo apoio, confiança, paciência e compreensão. Obrigada por estar sempre comigo nas boas e nas más horas. Obrigada por não me deixar desistir em nenhum momento e me apoiar sempre. Obrigada por estar sempre ali para me escutar e 
cuidar. Agradeço muito pelo tempo vivido com você e por todas as aventuras que vivemos juntos até o momento e por todas aquelas aventuras que estão por vir.

À minha orientadora e amiga, Dra. Solange Oliveira Rezende, que com sua paciência, generosidade e força tem me auxiliado muito durante o desenvolvimento do mestrado. Muito obrigada por estar ali para me orientar, ajudar e poder conversar sobre tudo em qualquer momento. Obrigada por me receber sempre com um sorriso, mesmo que o dia não tinha sido bom para você ou para mim. Estou muito agradecida com você por ter me aceitado como aluna e como amiga e ter me ajudado em tudo durante estes dois anos.

A todos os amigos e companheiros do Labic, pela ajuda brindada em todo momento, sobretudo com o portunhol e algumas palavras difíceis para mim. Obrigada por me aceitar e tentar me entender desde o dia que cheguei. Com todos vocês aprendi muitas coisas e não só português. Agradeço por todos os churrascos de confraternização e por todos os bons momentos vividos dia a dia no laboratório. Agradeço também à Dra. Maria Fernanda Moura, pelo apoio brindado durante todo o decorrer do mestrado.

Às minhas grandes amigas que sempre esperam meu retorno à casa: Cinthia, Ginger, Silvia e Linccy. Aos meus grandes amigos que conheci no Brasil e nunca esquecerei: Lucía, Merley, Paula, Valéria, Poliana, Carla, Yumi, Carlos, Jorge, Victor, Alceu, Daniel e muitos mais. Obrigada por estar sempre presentes para mim e me ajudar em tudo, obrigada pelas aventuras compartilhadas, as palavras de consolo e motivação brindadas.

Ao Anandsing pela enorme contribuição nas correções dos trabalhos escritos em inglês e português e pela generosidade e valiosa ajuda.

Aos professores e funcionários do ICMC-USP.

Á CAPES e Embrapa pelo apoio financeiro.

Finalmente, agradeço a todos que me ajudaram direta ou indiretamente. 


\section{Resumo}

$\mathcal{A}$

tualmente, é comum que usuários levem em consideração a localização geográfica dos documentos, é dizer considerar o escopo geográfico que está sendo tratado no contexto do documento, nos processos de Recuperação de Informação. No entanto, os sistemas convencionais de extração de informação que estão baseados em palavras-chave não consideram que as palavras podem representar entidades geográficas espacialmente relacionadas com outras entidades nos documentos. Para resolver esse problema, é necessário viabilizar o georreferenciamento dos textos, ou seja, identificar as entidades geográficas presentes e associá-las com sua correta localização espacial. A identificação e desambiguação das entidades geográficas apresenta desafios importantes, principalmente do ponto de vista linguístico, já que um topônimo, pode possuir variados tipos de ambiguidade associados. Esse problema de ambiguidade causa ruido nos processos de recuperação de informação, já que o mesmo termo pode ter informação relevante ou irrelevante associada. Assim, a principal estratégia para superar os problemas de ambiguidade, compreende a identificação de evidências que auxiliem na identificação e desambiguação das localidades nos textos. O presente trabalho propõe uma metodologia que permite identificar e determinar a cobertura espacial dos documentos, denominada SpatialCIM. A metodologia SpatialCIM tem o objetivo de organizar os processos de resolução de topônimos. Assim, o principal objetivo deste trabalho é avaliar e selecionar técnicas de desambiguação que permitam resolver a ambiguidade dos topônimos nos textos. Para isso, foram propostas e desenvolvidas as abordagens de (1)Desambiguação por Pontos e a (2)Desambiguação Textual e Estrutural. Essas abordagens, exploram duas técnicas diferentes de desambiguação de topônimos, as quais, geram e desambiguam os caminhos geográficos associados aos topônimos reconhecidos para cada documento. Assim, a hipótese desta pesquisa é que o uso das técnicas de desambiguação de topônimos viabilizam uma melhor localização espacial dos documentos. A partir dos resultados obtidos neste trabalho, foi possivel demonstrar que as técnicas de desambiguação melhoram a precisão e revocação na classificação espacial dos documentos. Demonstrou-se também o impacto positivo do uso de uma ferramenta linguística no processo de reconhecimento das entidades geográficas. Assim, foi demostrada a utilidade dos processos de desambiguação para a obtenção da cobertura espacial dos documentos. 



\title{
Abstract
}

\begin{abstract}
C
urrently, it is usual that users take into account the geographical localization of the documents in the Information Retrieval process. However, the conventional information retrieval systems based on key-word matching do not consider which words can represent geographical entities that are spatially related to other entities in the documents. To solve this problem, it is necessary to enable the geo-referencing of texts by identifying the geographical entities present in text and associate them with their correct spatial location. The identification and disambiguation of the geographical entities present major challenges mainly from the linguistic point of view, since one location can have different types of associated ambiguity. The ambiguity problem causes noise in the process of information retrieval, since the same term may have relevant or irrelevant information associated. Thus, the main strategy to overcome these problems, include the identification of evidence to assist in the identification and disambiguation of locations in the texts. This study proposes a methodology that allows the identification and spatial localization of the documents, denominated SpatialCIM. The SpatialCIM methodology has the objective to organize the Topônym Resolution process. Therefore the main objective of this study is to evaluate and select disambiguation techniques that allow solving the toponym ambiguity in texts. Therefore, we proposed and developed the approaches of (1) Disambiguation for Points and (2) Textual and Structural Disambiguation. These approaches exploit two different techniques of toponym disambiguation, which generate and desambiguate the associated paths with the recognized geographical toponym for each document. Therefore the hypothesis is, that the use of the toponyms disambiguation techniques enable a better spatial localization of documents. From the results it was possible to demonstrate that the disambiguation techniques improve the precision and recall for the spatial classification of documents. The positive effect of using a linguistic tool for the process of geographical entities recognition was also demonstrated. Thus, it was proved the usefulness of the disambiguation process for obtaining a spatial coverage of the documents.
\end{abstract}





\section{Sumário}

Resumo ...............................

Abstract ...................... . . .

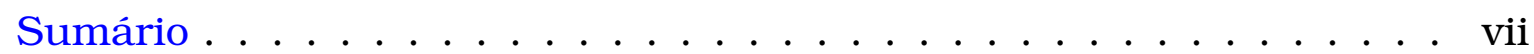

Lista de Figuras . . . . . . . . . . . . . . . . . . . xi

Lista de Tabelas . . . . . . . . . . . . . . . . . xiv

1 Introdução 1

1.1 Objetivos e Hipótese . . . . . . . . . . . . . . . . . . . 3

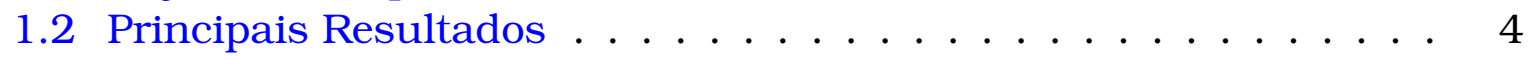

1.3 Organização do Texto ....................... 5

2 Fundamentação Teórica $\quad 7$

2.1 Considerações Iniciais . . . . . . . . . . . . . . . 7

2.2 Mineração de Textos . . . . . . . . . . . . . . . . . . . . . . . . . . . . .

2.2.1 Identificação do Problema . . . . . . . . . . . . . 10

2.2.2 Pré-processamento . . . . . . . . . . . 10

2.2.3 Extração de Padrões . . . . . . . . . . . . . . . . . . 12

2.2.4 Pós-processamento e Utilização do conhecimento . . . . . . 14

2.3 Recuperação de Informação Geográfica . . . . . . . . . . . . . . . 15

2.3.1 Geo-Parsing . . . . . . . . . . . . . . 16

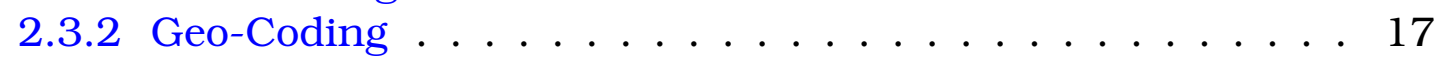

2.3.3 Avaliação ................... . . 19

2.4 Reconhecimento e Classificação de Entidades Nomeadas . . . . . 20

2.4.1 Ferramentas Linguísticas . . . . . . . . . . . . . . . 24

2.5 Resolução de Topônimos . . . . . . . . . . . . . . . . . . . 28

2.5.1 Características dos Topônimos . . . . . . . . . . . 29

2.5.2 Estratégias para Resolução de Topônimos . . . . . . . . . . 31

2.6 Considerações Finais ................... 31

3 Trabalhos Relacionados $\quad 33$

3.1 Considerações Iniciais . . . . . . . . . . . . . . . . . 33

3.2 Abordagem de Resolução de Topônimos baseada em gazetteers ou na Wikipédia . . . . . . . . . . . . . . . . . . . 34

3.2.1 Biblioteca digital PERSEUS (Smith e Crane, 2001) . . . . . 34 
3.2.2 Atribuição de probabilidades e expansão da expressão da consulta geográfica (Yi et al., 2006) . . . . . . . . . . . 36

3.2.3 Modelos de coocorrência com Wikipédia (Overell et al., 2006) 38

3.2.4 Extração de informação considerando o foco geográfico (Zubizarreta et al., 2008) . . . . . . . . . . . . . . . . 39

3.2.5 Minimalidade Espacial (Leidner, 2008) . . . . . . . . . 40

3.2.6 Estudo dos topônimos e dificuldade de desambiguação (Buscaldi e Magnini, 2010) . . . . . . . . . . . . . . . . . . . 41

3.2.7 Abordagem baseada em evidências geográficas e uso da teoria Dempster-Shafer (Xingguang et al., 2010) . . . . . . 42

3.2.8 Classificação do texto em categorias geográficas usando a Wikipédia (De Alencar et al., 2010) . . . . . . . . . . . . 43

3.3 Abordagem de Resolução por Ontologia Geográfica . . . . . . . . . 44

3.3.1 OnLocus, uma ontologia de lugar (De Vasconcelos Borges, 2006) . . . . . . . . . . . . . . . . 45

3.3.2 Abordagem baseada em ontologia, gazetteers e WordNet para o processo de desambiguação (Volz et al., 2007) . . . . 47

3.3.3 Densidade Conceitual da WordNet (Buscaldi e Rosso, 2008) 49

3.3.4 Extração de conhecimento geográfico (Campelo e Baptista, 2009) .

3.3.5 Relações arborescentes entre topônimos calculando a Densidade Geográfica (DG) da WordNet (Bensalem e Kholladi, 2010) . . . . . . . . . . . . . . . . .

3.3.6 Desambiguação de Topônimos usando eventos (Roberts et al., 2010) . . . . . . . . . . . . . . . 53

3.3.7 Gazetteer Ontológico para Recuperação de Informação Geográfica (Ribeiro Machado, 2011) . . . . . . . . . . . .

3.3.8 Desambiguação de topônimos por uma ontologia em espanhol (López et al., 2012) . . . . . . . . . . . . . . . 58

3.4 Síntese de trabalhos relacionados . . . . . . . . . . . . . . . 59

3.5 Considerações Finais . . . . . . . . . . . . . . . . . . . 64

4 Metodologia para a Descoberta da Cobertura Espacial dos Documentos: SpatialCIM

4.1 Considerações Iniciais . . . . . . . . . . . . . . . . . . . 65

4.2 A Metodologia SpatialCIM . . . . . . . . . . . . . . . . 66

4.2 .1 Pré-Processamento . . . . . . . . . . . . . . . 67

4.2.2 Expansão dos Dados . . . . . . . . . . . . . 70

4.2 .3 Desambiguação . . . . . . . . . . . . . . . . . 72

4.3 Materiais e Métodos . . . . . . . . . . . . . . . . . 79

4.3.1 O Gazetteer Brasileiro . . . . . . . . . . . . . . . . . . . 79

4.3.2 Ontologia Geográfica do Brasil . . . . . . . . . . . . . . 81

4.3.3 Vocabulário Controlado AGRI-BR . . . . . . . . . . . . 82

4.3.4 Ferramentas Desenvolvidas . . . . . . . . . . . . . . . 83

4.4 Considerações Finais . . . . . . . . . . . . . . . . . 85 
5 Avaliação Experimental $\quad 87$

5.1 Considerações Iniciais . . . . . . . . . . . . . . . . . . . 87

5.2 Visão Geral da Avaliação . . . . . . . . . . . . . . . . . 87

5.2.1 Coleções de Documentos Textuais utilizadas nos experimentos .................. . 90

5.2.2 Estabilidade no Tamanho dos Documentos . . . . . . . 92

5.2.3 Avaliação das Abordagens de Desambiguação . . . . . . . . 94

5.3 Avaliação da Abordagem de Desambiguação por Pontos . . . . . . 95

5.3.1 Avaliação Global . . . . . . . . . . . . . . . . . 997

5.3.2 Avaliação por partes da Hierarquia . . . . . . . . . . . . . 100

5.4 Avaliação da Abordagem de Desambiguação Textual e Estrutural 104

5.4.1 Avaliação Global . . . . . . . . . . . . . . . . . . 107

5.4.2 Avaliação por partes da Hierarquia . . . . . . . . . . . 110

5.5 Avaliação da Abordagem de Aprendizado de

Máquina - Classificação hierárquica multirrótulo . . . . . . . . . 113

5.6 Comparação entre a Desambiguação por Pontos e a Desambigua-

ção Textual e Estrutural usando o Paired T-Teste . . . . . . . . . . 119

5.7 Considerações Finais . . . . . . . . . . . . . 121

6 Conclusões 123

6.1 Principais Resultados e Contribuições . . . . . . . . . . . 125

6.2 Principais Limitações . . . . . . . . . . . . . . . . . 128

6.3 Trabalhos Futuros . . . . . . . . . . . . . . 128 



\section{Lista de Figuras}

2.1 Áreas associadas aos conceitos relacionados à Resolução de Topô-

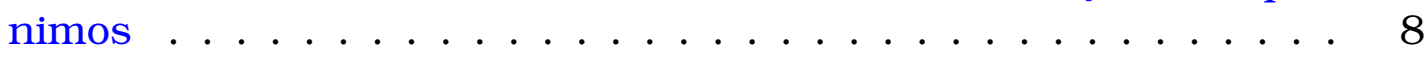

2.2 Etapas da mineração de dados (Rezende, 2003) . . . . . . . . . . 9

2.3 Representação do conjunto de classes planas e hierárquicas (Metz,

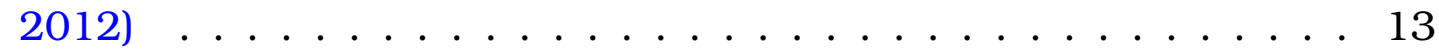

2.4 Principais componentes da RIG. Adaptado de (Gouvêa, 2009) . . . 16

2.5 Representação de uma localização usando pontos e polígonos (Larson e Frontiera, 2004) . . . . . . . . . . . . . . . 18

2.6 Exemplo de marcação de Entidades Mencionadas no texto (Mikheev et al., 1999) . . . . . . . . . . . . . . . . . 20

2.7 Classes dos processo de Reconhecimento de Entidades Mencionadas (REM). Adaptado de (Aranha, 2007) . . . . . . . . . . . 24

2.8 Funcionamento do sistema Rembrandt (Cardoso, 2008) . . . . . . 27

4.1 Visão geral da metodologia SpatialCIM . . . . . . . . . . . . 66

4.2 Exemplo de um documento pré-processado pela ferramenta Rem-

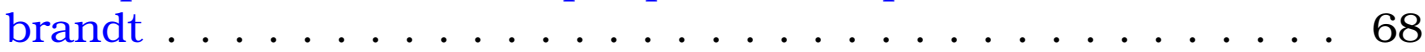

4.3 Exemplo de Reconhecimento e filtro de entidades geográficas para um documento . . . . . . . . . . . . . . . 70

4.4 Extração das coordenadas geográficas para as entidades reconhecidas ........................ 73

4.5 Exemplo da construção de polígonos para o processo de Desambiguação por Pontos . . . . . . . . . . . . . . . . 74

4.6 Exemplo de Termos Especiais nos documentos . . . . . . . . . . 75

4.7 Exemplo de Desambiguação estrutural das entidades . . . . . . . 77

4.8 Exemplo dos dados obtidos com o gazetteer GeoNames . . . . . . 80

4.9 Exemplo das coordenadas e mapeamento das Meso-Regiões da Região centro-oeste ............... . 81

4.10 A dimensão Território da ontologia agrícola (Venâncio et al., 2003) 82

4.11 Relação entre conceitos e instâncias (Venâncio et al., 2003) . . . . 82

4.12 Processo de criação do Vocabulário Controlado AGRI-BR . . . . . 83

4.13Tela principal do programa de Marcação de Corpus Geográfico 84

5.1 Visão Geral da Avaliação . . . . . . . . . . . . . . . . . 89 
5.2 Documento da coleção de notícias da cana-de-açúcar . . . . . . . 91

5.3 Comportamento dos processos não-desambiguado e desambiguado para documentos com poucas entidades reconhecidas e pré-processados com o Rembrandt e o AGRI-BR . . . . . . . . . . . . . . 93

5.4 Comportamento dos processos não-desambiguado e desambiguado para os documentos com várias entidades reconhecidas e préprocessados com o Rembrandt e o AGRI-BR . . . . . . . . . . . 93

5.5 Precisão e Cobertura para os processos não-desambiguados e desambiguados usando o Rembrandt e o AGRI-BR na Desambiguação por Pontos . . . . . . . . . . . . . . . . . . 98

5.6 F-Score para os processos não-desambiguados e desambiguados usando o Rembrandt e o AGRI-BR na Desambiguação por Pontos

5.7 Avaliação Hierárquica entre os documentos pré-processados com o Rembrandt e o AGRI-BR para os processos não-desambiguado e desambiguado . . . . . . . . . . . . . . . . 103

5.8 Precisão e Cobertura para os processos não-desambiguados e desambiguados usando o Rembrandt e o AGRI-BR na Desambiguação Textual e Estrutural . . . . . . . . . . . . . . . . 108

5.9 F-Score para os processos não-desambiguados e desambiguados usando o Rembrandt e o AGRI-BR na Desambiguação Textual e Estrutural . . . . . . . . . . . . . . . . . . 109

5.10 Avaliação Hierárquica entre os documentos pré-processados com o Rembrandt e o AGRI-BR para os processos não-desambiguado e desambiguado . . . . . . . . . . . . . . . . . . . . 112

5.11 Exemplo da hierarquia utilizada para a abordagem de classificação hierárquica multirrótulo . . . . . . . . . . . . . . . . . 115

5.12 Distribuição de exemplos para as classes de País, Região e Estado 117

5.13 Distribuição de exemplos para as classes de Município e Usina . 117

5.14 Percentagem da distribuição de exemplos para as classes de Região e Estado . . . . . . . . . . . . . . . . . . . . . 118

5. 15 Comparação do F-Score entre a Desambiguação por Pontos (DePP) e a Desambiguação Textual e Estrutural (DeTE) . . . . . . . . . . 120 


\section{Lista de Tabelas}

2.1 Exemplos multirrotulados no formato atributo-valor (Metz, 2012) 14

2.2 Avaliação de Sistemas de Recuperação de Informação . . . . . . . 19

2.3 Estado da Arte: Comparação dos resultados globais, observando as tarefas de identificação e classificação (Correia de Oliveira, 2010) 26

2.4 Tipos de Ambiguidade para a Resolução de Topônimos . . . . . . 30

3.1 Correspondência entre ontologia e elementos do gazetteer (Ribeiro Machado, 2011) . . . . . . . . . . . . . 56

3.2 Síntese dos trabalhos baseados na resolução de topônimos fazendo uso de gazetteers, a Wikipédia ou na WordNet . . . . . . . . 62

3.3 Síntese dos trabalhos baseados na resolução de topônimos fazendo uso de ontologias geográficas . . . . . . . . . . . . . . 64

4.1 Exemplo dos caminhos geográficos extraídos para as entidades reconhecidas de um documento . . . . . . . . . . . 71

5.1 Descrição de Legenda das Tabelas de Avaliação Global e Hierárquica para a Desambiguação por Pontos e Desambiguação Textual e Estrutural . . . . . . . . . . . . . . . . . . . . 94

5.2 Comparação entre entidades corretas e incorretas dos processos não-desambiguado e desambiguado usando o Rembrandt para os 15 primeiros documentos da coleção para a abordagem de Desambiguação por Pontos . . . . . . . . . . . . 96

5.3 Comparação entre entidades corretas e incorretas dos processos não-desambiguado e desambiguado usando o Vocabulário Controlado AGRI-BR para os 15 primeiros documentos da coleção para a abordagem de Desambiguação por Pontos . . . . . . . . . 97

5.4 Avaliação da Precisão, Cobertura e F-Score dos processos nãodesambiguado e desambiguado para a Desambiguação por Pontos 98

5.5 Avaliação hierárquica da coleção de documentos usando Rembrandt para o processo não-desambiguado para a Desambiguação por Pontos . . . . . . . . . . . . . . 101 
5.6 Avaliação hierárquica da coleção de documentos usando Rembrandt para o processo desambiguado para a Desambiguação por

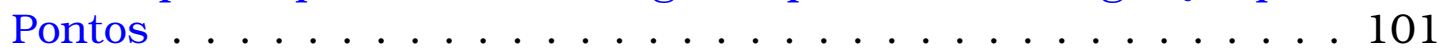

5.7 Avaliação hierárquica da coleção de documentos usando o AGRIBR para o processo não-desambiguado para a Desambiguação por Pontos . . . . . . . . . . . . . . . . . . . .

5.8 Avaliação hierárquica da coleção de documentos usando o AGRIBR para o processo não-desambiguado para a Desambiguação por Pontos ......................

5.9 Comparação entre entidades corretas e incorretas dos processos não-desambiguado e desambiguado usando o Rembrandt para os 15 primeiros documentos da coleção para a abordagem de Desambiguação Textual e Estrutural . . . . . . . . . . .

5.10 Comparação entre entidades corretas e incorretas dos processos não-desambiguado e desambiguado usando o Vocabulário Controlado AGRI-BR para os 15 primeiros documentos da coleção para a abordagem de Desambiguação Textual e Estrutural . . . .

105

5. 11 Configuração de parâmetros para a Desambiguação Textual e Es-

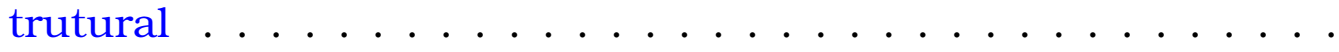

5.12 Avaliação da Precisão, Cobertura e F-Score dos processos nãodesambiguado e desambiguado para a Desambiguação Textual e Estrutural . . . . . . . . . . . . . . . .

5.13Avaliação hierárquica da coleção de documentos usando Rembrandt para o processo não-desambiguado para a Desambiguação Textual e Estrutural . . . . . . . . . . . . . . . .

5.14 Avaliação hierárquica da coleção de documentos usando Rembrandt para o processo desambiguado para a Desambiguação Textual e Estrutural . . . . . . . . . . . . . . . . . . 110

5. 15Avaliação hierárquica da coleção de documentos usando o AGRIBR para o processo não-desambiguado para a Desambiguação Textual e Estrutural . . . . . . . . . . . . . . . . . . 111

5.16Avaliação hierárquica da coleção de documentos usando o AGRIBR para o processo desambiguado para a Desambiguação Textual e Estrutural . . . . . . . . . . . . . . .

5.17 Resultados da classificação hierárquica multirrótulo para as 10 primeiras classes . . . . . . . . . . . . . . 116

5. 18 Exemplificação da quantidade de exemplos de treinamento e teste para cada classe da hierarquia . . . . . . . . . . . . . 116

5.19F-Score para os documentos pré-processados com o Rembrandt e AGRI-BR no processo desambiguado usando a Desambiguação por Pontos e a Desambiguação Textual e Estrutural . . . . . . . . 119

5.20Amostra de documentos utilizadas para o teste estatístico Paired

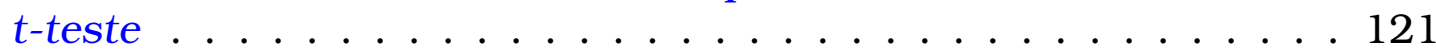

5.21 Valores calculados para o Paired t-teste . . . . . . . . . 121 


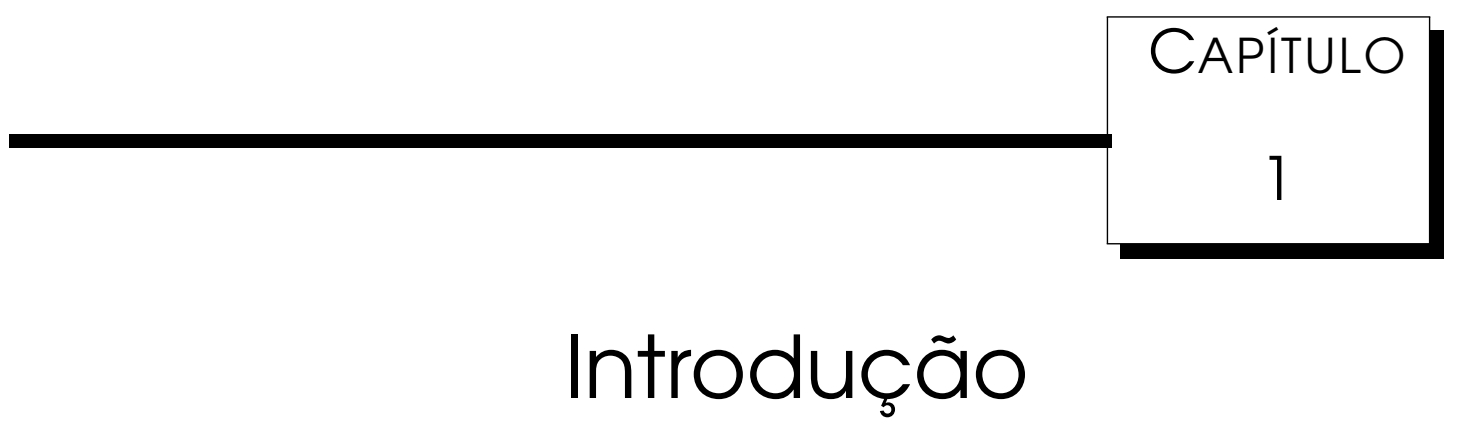

A contínua evolução da tecnologia computacional tem possibilitado gerar e processar uma grande quantidade de dados. Como consequência, e aliada ao crescente aumento da capacidade de armazenamento, se tornou comum a utilização de grandes bases de dados em diversas áreas da atividade humana. Contudo, esses avanços tecnológicos têm causado um problema conhecido como superabundância de dados, pois nossas capacidades de coletar e armazenar dados têm superado a habilidade de analisar e extrair conhecimento dos mesmos (Fayyad et al., 1996; Cardoso, 2011). Nesse sentido, se faz necessária a aplicação de técnicas e ferramentas que sejam capazes de extrair, dos dados disponíveis, de forma inteligente e automática, as informações úteis que representem conhecimento (Brachman e Anand, 1996; Overell, 2009). Apesar de haver algumas iniciativas recentes, os mecanismos de extração de informação apresentam deficiência na recuperação de conteúdos semânticos (Baeza-Yates et al., 2008), como informações geográficas relacionadas ao contexto (Jones e Purves, 2008; Martins e Calado, 2011).

O processo de identificação do contexto geográfico de textos é denominado geotagging (Amitay et al., 2004) e envolve duas etapas principais, geo-parsing e geo-coding (McCurley, 2001). A etapa de geo-parsing envolve a identificação das entidades geográficas, também conhecidas como topônimos, presentes nos textos por meio da análise do seu conteúdo. Esses processos são complicados dado que as palavras analisadas podem apresentar diversos tipos ambiguidade. Por exemplo, a entidade "Paris" pode ser mapeada como parte 
da "França" ou como parte dos "Estados Unidos". Já a etapa de geo-coding tem o objetivo de identificar o contexto ou extensão geográfica do texto por meio de coordenadas geográficas.

A ambiguidade é uma expressão de linguagem (palavra ou frase) que tem diferentes significados e pode ser entendida de diversas formas por um receptor. Esse problema de ambiguidade causa ruido nos processos de recuperação de informação, já que o mesmo termo pode ter informação relevante ou irrelevante associada (Fuchs, 1987; Cardoso, 2011). Segundo Silva (2006), a ambiguidade está relacionada com o contexto. Ou seja, é possível extrair diversos significados de uma frase ou palavra. Assim, é necessário distinguir um desses significados determinado segundo o contexto do documento. A resolução de ambiguidades por meio do processamento da língua natural enfrenta vários problemas de difícil resolução como o conhecimento de contexto que não está explícito no texto analisado, e, os diversos tipos de ambiguidade presentes nos textos. Neste trabalho, a ambiguidade estudada está referida à ambiguidade das entidades geográficas associadas aos documentos. Por exemplo, se uma entidade reconhecida dentro de um documento tem diversos caminhos geográficos associados, podemos dizer que a entidade é ambígua.

Para resolver os problemas de ambiguidade, devem ser aplicados processos de desambiguação de entidades, os quais são responsáveis por encontrar a correta localização geográfica (espacial) no texto por meio de padronização das entidades numa representação estruturada (Roberts et al., 2010). Segundo Clough et al. (2004) os tipos de ambiguidade no contexto geográfico podem ser: com outra localidade homônima (ambiguidade do referente), com outro tipo de entidades não-geográfica, por exemplo, nomes de pessoas ou organizações (ambiguidade da classe do referente) ou com nomes sinônimos, por exemplo, siglas da cidade (ambiguidade da referência). A área que estuda a identificação e desambiguação de topônimos é definida por Leidner (2006) como Resolução de Topônimos.

As pesquisas focadas em obter a localização geográfica dos documentos usualmente trabalham com as características geográficas extraídas da estrutura dos documentos (D'hondt et al., 2011), imagens (Lee et al., 2011), hiperlinks (Mantratzis et al., 2005) ou ontologias (Farazi et al., 2011), com o intuito de determinar de forma mais precisa a correta localização das entidades. As técnicas mais comuns de desambiguação fazem uso de gazetteers para prover de coordenadas geográficas para cada entidade e a ontologia geográfica provê as relações entre entidades (Câmara et al., 2000). 
Na literatura, a maioria das pesquisas segue uma série de passos para resolver a ambiguidade de topônimos. Esses passos estão baseados no reconhecimento de entidades, obtenção dos dados associados à entidade usando recursos externos, e, finalmente, o processo de desambiguação das entidades candidatas. No entanto, não é apresentada uma metodologia que indique os passos e etapas a serem seguidos antes de realizar os processos de desambiguação. Assim, neste projeto é proposta a metodologia SpatialCIM (Spatial Coverage Identification Methodology) que proporciona uma série de etapas com o objetivo de organizar os processos de resolução de topônimos. As etapas propostas envolvem os processos de geo-parsing e geo-coding.

\subsection{Objetivos e Hipótese}

O objetivo principal deste trabalho é avaliar e selecionar técnicas de desambiguação que permitam resolver a ambiguidade dos topônimos nos textos considerando a estrutura hierárquica das entidades. Outro objetivo, é aplicar as técnicas de desambiguação de topônimos considerando os topônimos brasileiros para obter dessa forma uma representação hierárquica das entidades brasileiras.

Os métodos existentes de desambiguação de topônimos podem ser divididos em três categorias: (1) baseados em mapas, (2) baseados em conhecimento, e (3) dirigido a dados. Na literatura, existem várias pesquisas que consideram, como base para a resolução de topônimos, os métodos baseados em conhecimento. A utilização desses métodos é devido à disponibilidade de recursos externos que permitem resolver o problema de ambiguidade dos topônimos. Os recursos externos mais utilizados são gazetteers (Yi et al., 2006; Leidner, 2008; Xingguang et al., 2010; Buscaldi e Magnini, 2010), Wikipédia (Overell et al., 2006; De Alencar et al., 2010; Roberts et al., 2010), WordNet (Volz et al., 2007; Buscaldi e Rosso, 2008; Bensalem e Kholladi, 2010) e ontologias geográficas (De Vasconcelos Borges, 2006; Campelo e Baptista, 2009; Roberts et al., 2010; Ribeiro Machado, 2011 ; López et al., 2012).

O presente trabalho busca superar o problema da ambiguidade dos topônimos com uma abordagem que permite realizar a desambiguação dos mesmos, considerando como fonte de conhecimento externo: gazetteers, Sistemas de Informação Geográficos ou ontologias geográficas. Para isso, foram propostas e desenvolvidas as abordagens de (1) Desambiguação por Pontos e a (2) Desambiguação Textual e Estrutural. Essas abordagens, exploram duas téc- 
nicas diferentes de desambiguação de topônimos, as quais, geram e desambiguam os caminhos geográficos associados aos topônimos reconhecidos para cada documento. Assim, a hipótese deste trabalho é que o uso das técnicas de desambiguação de topônimos viabilizam encontrar uma melhor localização espacial dos documentos.

A partir disso, o presente trabalho busca responder as seguintes questões:

1. A técnica de desambiguação selecionada influência na localização espacial dos documentos?;

2. Os processos de reconhecimento de entidades mencionadas influenciam os processos de desambiguação?;

3. A desambiguação de topônimos está influenciada pelo número de topônimos reconhecidos para os documentos?

É importante ressaltar que este projeto de mestrado também tem o objetivo de apoiar um projeto maior, denominado TIENA (Tecnologia Inovadoras em mineração de textos para a Espacialização de Notícias Agrícolas - piloto canade-açúcar), que está em desenvolvimento na Embrapa (Empresa Brasileira de Pesquisa Agropecuária) e no Laboratório de Inteligência Computacional (LABIC), do Instituto de Ciências Matemáticas e de Computação (ICMC-USP). O TIENA tem o objetivo de organizar notícias agrícolas sobre uma dada cultura, por meio de técnicas de Mineração de Textos, em três dimensões: tópicos ou assuntos, cobertura temporal e cobertura espacial. A incorporação de métodos de identificação da cobertura espacial é importante, pois irá permitir a descoberta da localização geográfica dos documentos, que por sua vez estão caracterizados pela alta ambiguidade de entidades geográficas.

\subsection{Principais Resultados}

De forma a cumprir os objetivos propostos neste projeto de mestrado, inicialmente foi realizado um estudo sobre as técnicas e métodos existentes de desambiguação de topônimos. Esse estudo permitiu adaptar alguns métodos reconhecidos na literatura que permitem efetuar uma desambiguação dos topônimos brasileiros. As principais contribuições e resultados alcançados com este projeto de mestrado foram:

- Desenvolvimento de um método que permite a realização da Desambiguação por Pontos. A abordagem proposta, adaptada de Leidner (2008), 
possibilita a desambiguação das entidades geográficas utilizando as coordenadas geográficas das entidades para um mapeamento e posterior desambiguação usando os polígonos formados entre as entidades.

- Proposta e desenvolvimento de um método que permite a realização da Desambiguação Textual e Estrutural. Esta abordagem possibilita a desambiguação das entidades considerando o documento no qual a entidade foi encontrada e considerando também a estrutura hierárquica das entidades não ambíguas presentes nos documentos.

- Proposta da metodologia para a identificação e determinação da cobertura espacial dos documentos, denominada SpatialCIM, que define uma série de etapas que visam identificar a correta localização geográfica dos documentos, usando para isso métodos que permitam fazer um Reconhecimento das Entidades Mencionadas, expansão dos caminhos geográficos e desambiguação dos mesmos.

- Análise e construção de um gazetteer brasileiro que proporciona uma lista de entidades geográficas brasileiras. O gazeteer está organizado de tal forma que permita obter a estrutura hierárquica da forma "País, Macro-Região, Região, Estado, Meso-Região, Micro-Região, Município e Usina" e as respetivas coordenadas geográficas em cada nível da hierarquia.

- Adaptação de uma ontologia geográfica brasileira. Esta ontologia, obtida do trabalho de Venâncio et al. (2003) foi modificada para permitir uma estrutura até o nível de usina. Foi adicionado também o nível de País, que considera os principais países e cidades do mundo.

- Avaliação da precisão dos caminhos geográficos obtidos para cada documento usando os processos de desambiguação propostos e sem usar a desambiguação, assim como a análise da influencia das ferramentas de Reconhecimento de Entidades nos processos de desambiguação.

\subsection{Organização do Texto}

O restante desta dissertação de mestrado está dividido em 4 Capítulos. No Capítulo 2 são apresentadas as etapas do processo de Mineração de Texto e 
conceitos sobre as técnicas de Recuperação de Informação geográfica, com ênfase nas tarefas de Reconhecimento e classificação de Entidades Mencionadas e na Resolução de Topônimos.

No Capítulo 3 é apresentada uma revisão dos principais trabalhos relacionados com a Resolução de Topônimos. Nesse capítulo são descritos os métodos encontrados na literatura, assim como são mostrados os principais resultados obtidos em cada trabalho.

No Capítulo 4 é apresentada a metodologia SpatialCIM proposta neste trabalho. São descritas as etapas que formam a metodologia, assim como são apresentados os dois métodos de desambiguação propostos neste projeto de mestrado.

No Capítulo 5 são apresentados os resultados obtidos considerando a Desambiguação por Pontos e a Desambiguação Textual e Estrutural. Foram avaliados também o desempenho de cada abordagem considerando a ferramenta linguistica Rembrandt e o vocabulário controlado AGRI-BR para o processo de Reconhecimento de entidades.

Por fim, no Capitulo 6 são feitas as conclusões sobre este projeto de mestrado e são apresentados os trabalhos futuros. 


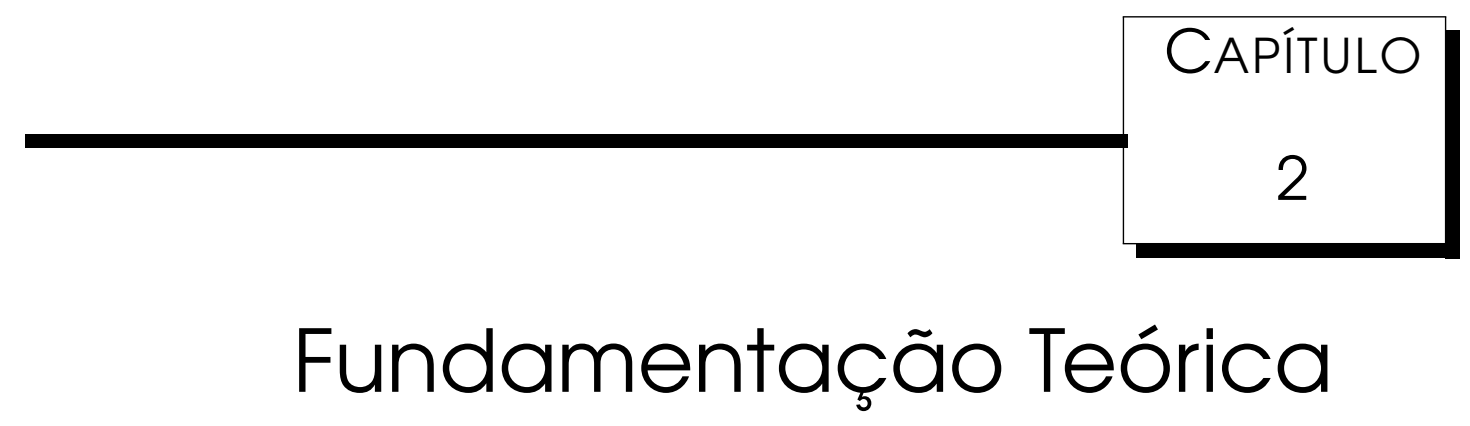

\subsection{Considerações Iniciais}

Grande parte das informações dispersas na Internet possuem algum tipo de contexto geográfico. Podem fazer parte deste contexto, por exemplo, o local onde a informação foi criada, os locais aos quais os conteúdos se referem ou onde estão os maiores interessados por estas informações. No entanto, os sistemas de busca tradicional não consideram esse contexto nos processos de organização e recuperação da informação. A adição de contextualização geográfica nos processos envolvidos com a Recuperação de Informação pode proporcionar resultados mais interessantes ao usuário.

Na Figura 2.1 são ilustradas as diversas áreas que foram exploradas neste trabalho. Observa-se que a Resolução de Topônimos trabalha em conjunto com as áreas de: (i) Linguística, utilizando o reconhecimento de entidades mencionadas nos documentos; (ii) Processamento automático de textos, utilizando a mineração de textos; e (iii) Recuperação de Informação, utilizando a recuperação de Informação Geográfica.

Para poder contextualizar o problema do trabalho, é preciso compreender alguns termos e conceitos relacionados. Assim, o restante deste capítulo está estruturado da seguinte forma: inicialmente, apresentam-se, na Seção 2.2, os principais conceitos de Mineração de Textos. Em seguida, descreve-se o processo dos sistemas de Recuperação de Informação geográfica, apresentado na Seção 2.3, e aprofunda-se na tarefa de Reconhecimento de Entidades Men- 


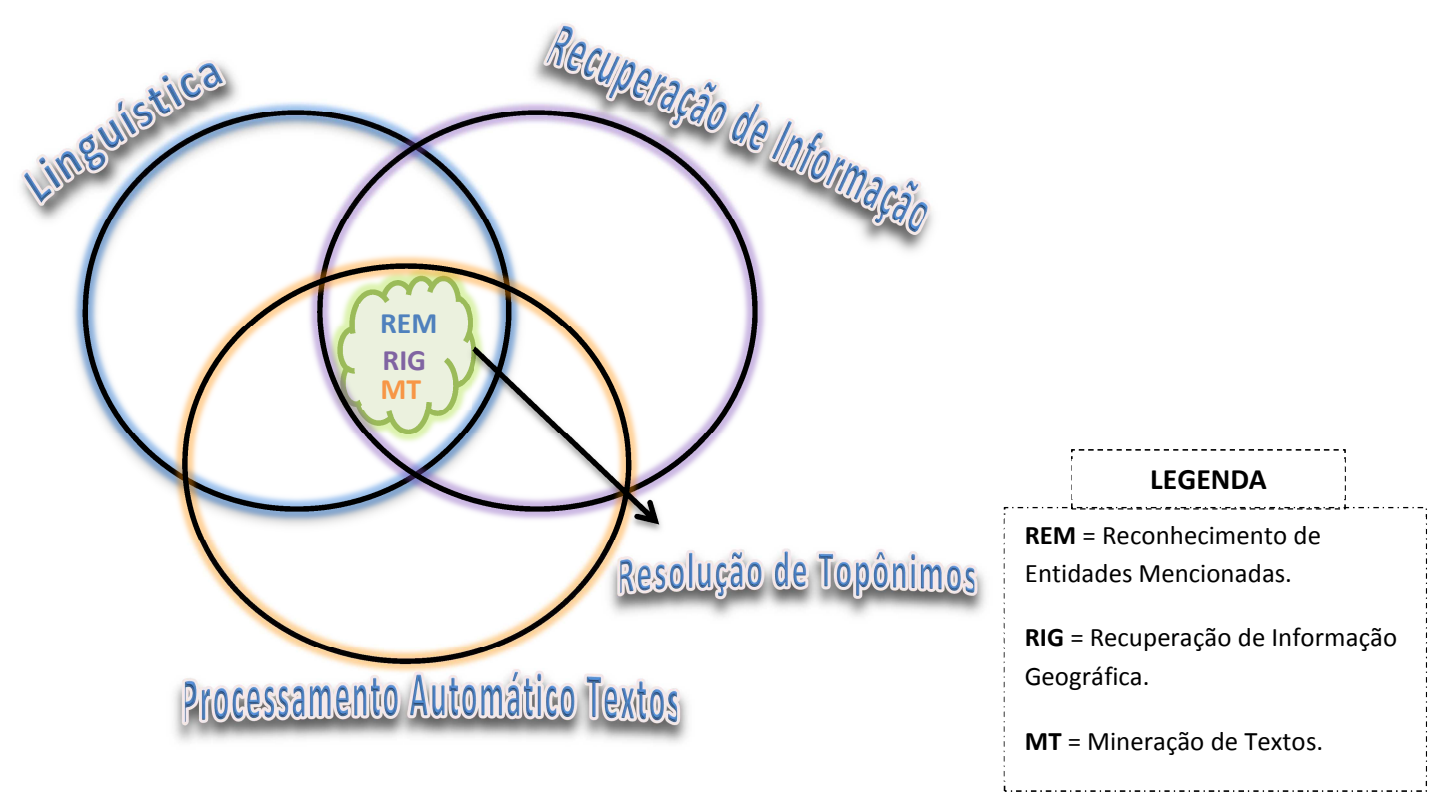

Figura 2.1: Áreas associadas aos conceitos relacionados à Resolução de Topônimos

cionadas na Seção 2.4, assim como também os problemas de ambiguidade presentes nos documentos na Seção 2.5.

\subsection{Mineração de Textos}

Um dos maiores tesouros da humanidade é o conhecimento. Grande parte desse conhecimento existe na forma de linguagem natural em livros, revistas, relatórios técnicos, artigos e notícias na internet. A utilização eficiente de todo esse conhecimento depende da habilidade para fazer algumas operações com a informação como, por exemplo, encontrar a informação necessária, comparação de fontes de informação diversas para obter conclusões e manipulação de textos para tradução.

Segundo Tan (1999); Buscaldi e Magnini (2010), 80\% das informações de uma empresa estão contidas em documentos textuais. Chen (2001) afirma, ainda, que o $80 \%$ do conteúdo online estão em formato não estruturado, entre eles texto. Há, então uma necessidade de organizar e explorar estes dados a fim de descobrir conhecimento útil de forma automática, como padrões ou anomalias. Mineração de textos é um conjunto de métodos usados para essa finalidade, auxiliando a navegação, organização e descoberta de conhecimento em bases de textos.

Segundo Aranha e Passos (2006); Rezende (2003), a Mineração de Textos 
é um campo multidisciplinar que inclui conhecimentos de áreas como Recuperação de Informação, Aprendizado de Máquina, Estatística e Linguística. Muitos autores concordam que a Mineração de Textos provem da área de processamento automático de textos. Recursos de processamento automático de textos permitem localizar e extrair a informação e conhecimento mais significativo e essencial dos documentos, assim como informação e conhecimento implícito em grandes corporas textuais eletrônicos geralmente não estruturados, como mensagens de correios eletrônicos, artigos e notícias.

A Mineração de Textos é um processo muito semelhante à Mineração de Dados e pode ser considerada como uma especialização desta. A principal diferença entre os dois processos é que a Mineração de Textos lida com dados não-estruturados, como e-mails, relatórios e artigos científicos, além de dados semi-estruturados, como páginas HTML ou arquivos XML. Assim, na Mineração de Textos, o primeiro desafio é obter alguma estrutura que represente bem os documentos textuais.

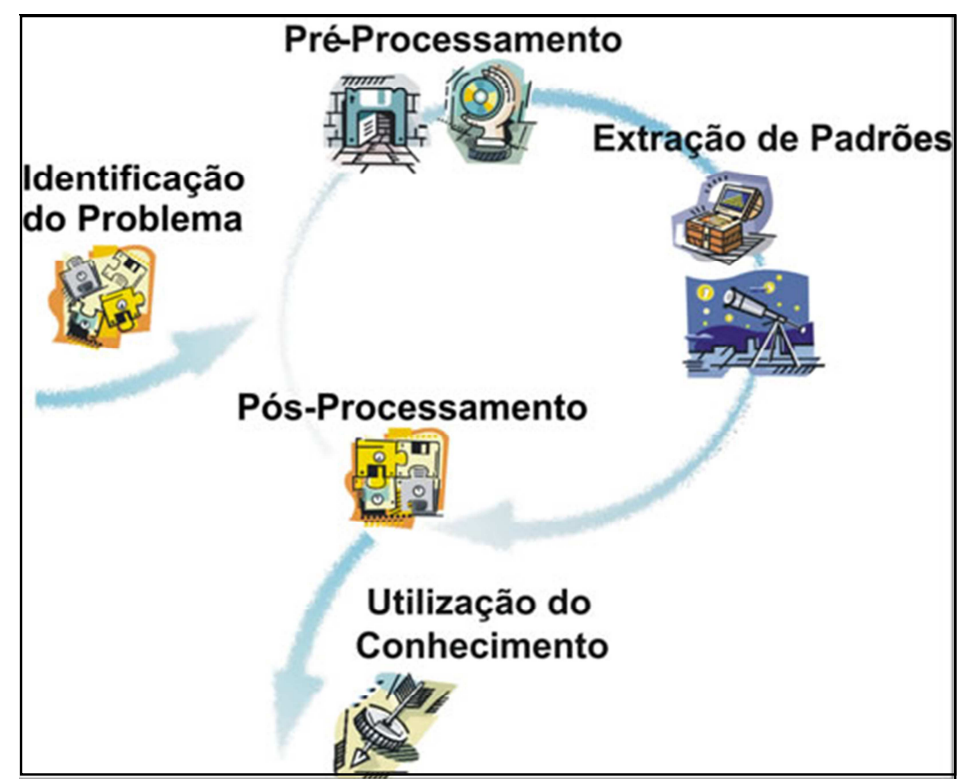

Figura 2.2: Etapas da mineração de dados (Rezende, 2003)

O processo de Mineração de Dados pode ser dividido em cinco etapas como ilustrado na Figura 2.2. A primeira etapa é de Identificação do Problema que busca delimitar o problema e selecionar as ferramentas apropriadas. A segunda etapa de Pré-processamento que permite fazer uma padronização, seleção e redução de dados, a fim de gerar uma representação dos textos de forma matriz atributo-valor. Na etapa de Extração de padrões, podem ser aplicadas diferentes técnicas de Aprendizado de Máquina como Agrupamento de Dados, Classificação, Regras de Associação e Sumarização com a 
finalidade de extrair padrões ou comportamentos desses dados. Na etapa de Pós-processamento do conhecimento validam-se os conhecimentos obtidos por alguma técnica de extração de padrões e pode-se fazer refinamento do conhecimento. Finalmente, a última etapa é responsável pela disponibilização e uso do conhecimento (Rezende, 2003).

Nas próximas subseções, serão detalhadas as etapas da Mineração de Textos.

\subsubsection{Identificação do Problema}

Nesta etapa, delimita-se o escopo do problema e o objetivo da aplicação do processo da Mineração de Textos. Basicamente são definidas as coleções textuais que serão utilizadas, o que se espera obter com o processo de Mineração de Textos, quais técnicas serão utilizadas e como os resultados obtidos serão utilizados. Esta é uma etapa que demanda muito esforço, tanto do especialista do domínio, quanto do especialista em Mineração de Textos, pois a mesma fornece subsídios em todo o processo, permitindo identificar requisitos e possiveis ferramentas para cada passo.

No contexto deste trabalho, o objetivo do processo de Mineração de Textos é extrair um conjunto de entidades geográficas de um conjunto de documentos. Uma vez extraídas essas entidades, aplicam-se técnicas de expansão e desambiguação de dados, as quais, permitem classificar os documentos de acordo com seu contexto geográfico. Os resultados obtidos pelas técnicas de classificação e desambiguação geográfica visam auxiliar nas tarefas de organização da informação textual e nos processos de Recuperação de Informação.

Outro aspecto de grande importância nesta etapa do processo de Mineração de Textos é a definição do conjunto de documentos que serão utilizados, bem como a conversão destes documentos para um formato adequado para as ferramentas de extração de entidades. Assim, é possível iniciar a etapa de pré-processamento, conforme discutida a seguir.

\subsubsection{Pré-processamento}

Nesta etapa, se encontra a principal diferença entre os processos de Mineração de Textos e os processos de Mineração de Dados: a estruturação dos textos em um formato adequado para a extração de conhecimento. O objetivo do pré-processamento é extrair de textos escritos em língua natural, inerentemente não estruturados, uma representação estruturada, concisa e 
manipulável (Rezende, 2003).

As atividades de tratamento da coleção de documentos textuais podem compreender a eliminação de documentos repetidos; a verificação de uma estrutura prévia nos documentos, a fim de utilizar esta informação para atribuição de pesos; a análise dos tamanhos e a verificação da necessidade de atribuição de pesos de acordo com o tamanho de cada documento; e a remoção de caracteres que não serão utilizados, como números e carácteres não alfabéticos. De modo geral, esta etapa tem por finalidade melhorar a qualidade dos dados disponíveis e organizá-los.

No primeiro parágrafo foi explicado o pré-processamento no nível de documentos. No segundo parágrafo, foi abordado o pré-processamento ao nível de palavras. Em Mineração de Textos, pré-processamento normalmente significa dividir o texto em palavras, aplicar técnicas de simplificação como stemming, remover as stop-words e classificá-las segundo a classe gramatical. No entanto, é necessário transformar os textos em uma representação estruturada adequada para que, a partir disso, os dados possam ser submetidos os processo como um todo. Um desafio ao obter essa representação é minimizar a perda de informação. A etapa de pré-processamento em um processo de Mineração de Textos é, portanto, fundamental para o desempenho de todo o processo (Martins, 2004).

Segundo (Martins, 2004; Rezende, 2003), as técnicas comumente utilizadas para padronização dos termos nesta etapa são stemming, remoção de stopwords e a utilização do Modelo espaço vetorial, descritas a seguir:

Remoção de Stop-Words - as palavras comuns são elementos de textos que não possuem uma semântica significativa; sua presença não agrega nenhuma indicação do conteúdo ou do assunto do texto correspondente. Normalmente as palavras comuns são constituídas de artigos, preposições e verbos auxiliares;

Obtenção dos Radicais (Stems) - em língua natural, diversas palavras designam variações indicando plural, flexões verbais ou variantes que são sintaticamente similares. Por exemplo, as palavras "real", "realidade", "realeza" e "realizado" têm sua semântica relacionada. O objetivo de aplicar a stemização é obter um elemento único que permita considerar as palavras relacionadas como um único termo, portanto com uma semântica única;

Modelo de Espaço Vetorial - o objetivo é transformar um documento em um 
vetor. Formalmente, seja $C=\left(d_{1}, d_{2}, \ldots, d_{n}\right)$ uma coleção qualquer nãoordenada de documentos $d_{i}$, contendo $m$ diferentes termos, então a representação de um documento será $d_{i}=\left(f_{i 1}, f_{i 2}, \ldots, f_{i m}\right)$ para $i=1$ até $N$, no qual $f_{i j}$ é uma função de avaliação associada ao termo $j$ do documento $i$.

\subsubsection{Extração de Padrões}

Nesta etapa são definidas as tarefas a serem realizadas de acordo com o objetivo do processo. Essas tarefas podem ser preditivas ou descritivas (Conrado et al., 2009).

Tarefas Preditivas, que consistem na generalização de exemplos ou experiências passadas com respostas conhecidas. Essas tarefas utilizam os chamados modelos de Aprendizado de Máquina supervisionado, uma vez que as categorias são sempre pré-conhecidas e encontram-se disponíveis junto aos dados. Entre estas tarefas encontram-se os modelos de classificação e regressão. Tarefas Descritivas, que consistem na identificação de comportamentos intrínsecos da coleção de textos, sendo que esses dados são exemplos não rotulados ou tratados como não rotulados. Nestas tarefas são utilizados modelos de Aprendizado de Máquina não-supervisionado. Os principais modelos são regras de associação, agrupamento, sumarização e visualização.

Como parte deste projeto de mestrado, foi realizada uma comparação dos processos de desambiguação baseados em conhecimento e uma abordagem de Aprendizado de Máquina, apresentado no Capítulo 5. Após fazer uma análise do conjunto de documentos a ser utilizado neste trabalho, observou-se que cada documento pode ter $n$ caminhos geográficos associados e cada caminho considera a hierarquia geo-política do Brasil. Assim, constata-se que a técnica de Aprendizado de Máquina compativel com este problema é a classificação hierárquica multirrótulo, explicada a seguir.

\section{Classificação Hierárquica Multirrótulo}

A grande maioria dos problemas de classificação descritos na literatura diz respeito a problemas de classificação não hierárquica (Flat Classification). Nesta, cada exemplo é associado a uma classe pertencente a um conjunto finito de classes, não considerando assim relacionamentos hierárquicos. No entanto, existe um grande número de problemas em que uma ou mais classes podem ser divididas em subclasses ou agrupadas em superclasses. Nesse 
caso, as classes são dispostas em uma estrutura hierárquica de forma que representem uma árvore ou um Grafo Acíclico Direcionado (DAG). Esses problemas são conhecidos como problemas de classificação hierárquica, e têm como objetivo a classificação de cada novo exemplo em um dos nós-folha. No entanto, pode ocorrer o classificador ter uma baixa confiança na classificação em uma das classes desse nível, sendo mais seguro classificá-lo em uma das classes dos níveis mais elevados da hierarquia (Metz, 2012).

\begin{tabular}{|l|l|}
\hline Headlamp & Window \\
\hline Nonild & Float \\
\hline Non-Window & Glass \\
\hline Tableware & Container \\
\hline
\end{tabular}

(a) Classes sem qualquer tipo de organização estrutural

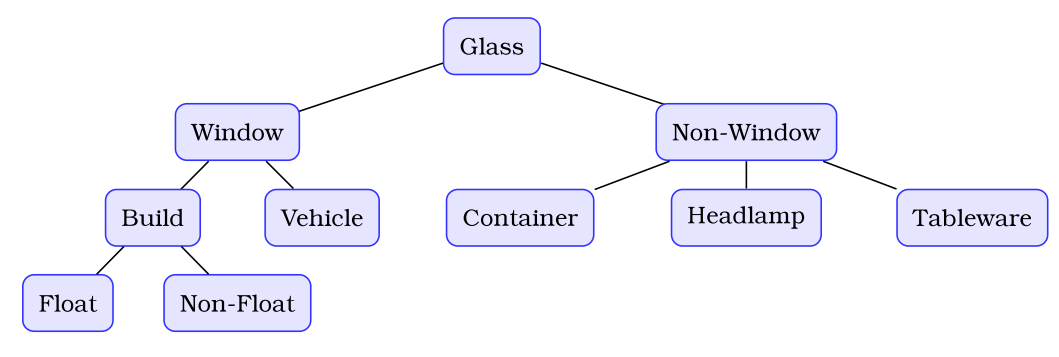

(b) Classes hierarquicamente organizadas

Figura 2.3: Representação do conjunto de classes planas e hierárquicas (Metz, 2012)

Na Figura 2.3 é ilustrada a diferença entre a classificação plana e a classificação hierárquica. Observe que na Figura 2.3(a) os rótulos são apresentados sem qualquer relacionamento. Por outro lado, na Figura 2.3(b) existem arestas que conectam pares de classes formando dessa forma uma árvore. Os nós mais próximos da raiz da hierarquia representam classes mais gerais e os nós mais próximos das folhas representam classes mais específicas.

A organização das classes de maneira hierárquica implica que um exemplo não pode estar associado a uma classe $y_{j}$ qualquer sem que esteja também associado com às classes ancestrais de $y_{j}$. Alem disso, o conjunto de rótulos associados a cada exemplo deve formar um caminho com origem no nó da raiz da hierarquia terminando no nó que representa a classe mais específica associada ao exemplo. Desse modo, dada uma hierarquia de classes pré-definida, 
uma maneira bastante simples para construir um classificador hierárquico é transformar a tarefa em um ou mais problemas de classificação plana, construindo um ou mais classificadores planos em cada nível da hierarquia de classes (Metz, 2012).

Grande parte dos métodos de aprendizado supervisionado considera que cada um dos exemplos do conjunto de treinamento está associado a um único rótulo. Entretanto, existem diversos domínios de aplicação nos quais os exemplos são rotulados com mais de uma classe ao mesmo tempo, os quais são chamados de exemplos multirrótulo (Tsoumakas et al., 2010). Na classificação monorrótulo, a entrada do algoritmo de aprendizado consiste em um conjunto de $N$ exemplos no formato atributo-valor, e cada exemplo $E_{i}$ está associado a um único rótulo $y_{i}$ contido no conjunto de rótulos $L$. Para o caso de algoritmos de classificação multirrótulo, os dados são também representados no formato atributo-valor. Porém, nesse caso, o atributo classe admite mais de um rótulo associado a cada exemplo ao mesmo tempo. Assim, um exemplo $E_{i}$ é representado por $\left(x_{i}, Y_{i}\right)$, onde $Y_{i} \subseteq L$ e $L=y_{j}: j=1 . . q$ é o conjunto dos $q$ monorrótulos que constituem os multirrótulos $Y_{i}, i=1 . . N$ (Tsoumakas et al., 2010), como representado na Tabela 2.1.

Tabela 2.1: Exemplos multirrotulados no formato atributo-valor (Metz, 2012)

\begin{tabular}{c|cccc|c}
\hline Exemplo & $X_{1}$ & $X_{2}$ & $\ldots$ & $X_{M}$ & $Y$ \\
\hline$E_{1}$ & $x_{11}$ & $x_{12}$ & $\ldots$ & $x_{1 M}$ & $Y_{1}=y_{1}, y_{4}$ \\
\hline$E_{2}$ & $x_{21}$ & $x_{22}$ & $\ldots$ & $x_{2 M}$ & $Y_{2}=y_{1}, y_{2}, y_{4}$ \\
\hline$E_{3}$ & $x_{31}$ & $x_{32}$ & $\ldots$ & $x_{3 M}$ & $Y_{3}=y_{1}, y_{3}$ \\
\hline$\ldots$ & $\ldots$ & $\ldots$ & $\ldots$ & $\ldots$ & $\ldots$ \\
\hline$E_{N}$ & $x_{N 1}$ & $x_{N 2}$ & $\ldots$ & $x_{N M}$ & $Y_{N}=y_{2}, y_{3}$ \\
\hline
\end{tabular}

Como mostrado na Tabela 2.1, todos os exemplos do conjunto de treinamento estão associados a conjuntos de rótulos unitários, tornando dessa forma o problema em monorrótulo. Nesse sentido, a representação atributovalor dos dados monorrótulo é uma especialização do caso multirrótulo.

\subsubsection{Pós-processamento e Utilização do conhecimento}

O Pós-processamento é a etapa de validação das descobertas efetuadas. É a etapa de avaliação do conhecimento obtido e a apresentação do mesmo, seja por ferramentas de visualização ou simplesmente por tabelas de resultados. Deve-se avaliar aspectos do conhecimento extraído de acordo com o contexto 
do problema, como a representatividade do conhecimento obtido, a novidade contida nos resultados e a maneira que o conhecimento deve ser utilizado.

Se os dados foram extraídos usando aplicações que envolvam tarefas preditivas, pode-se avaliar os modelos com medidas relativas à erro, precisão e revocação na predição de dados não vistos. Por outro lado, em aplicações que envolvem tarefas descritivas são um pouco mais difíceis de avaliar, uma vez que o critério de avaliação varia de acordo com o objetivo do processo. Algumas vezes podem não existir medidas objetivas para avaliar o resultado do processo, ficando a avaliação a cargo de um especialista do domínio, denominada avaliação subjetiva.

$\mathrm{Na}$ etapa de Utilização do conhecimento os resultados estão validades e aptos para serem utilizados. Dessa forma, o conhecimento extraído pode ser aplicado para apoiar algum processo de tomada de decisão, conforme o objetivo pré-estabelecido na etapa de Identificação do Problema.

\subsection{Recuperação de Informação Geográfica}

Segundo Larson (1996) a área de Recuperação de Informação Geográfica (RIG) pode ser vista como um ramo da área de Recuperação de Informação tradicional, incluindo todas suas áreas de pesquisa, mas enfatizando a recuperação e indexação de informações geográficas e espaciais. De acordo com Santos e Chaves (2006), a RIG pressupõe o seguinte:

- A possibilidade de associar à coleção de documentos informações geográficas;

- A existência ou a possibilidade de criação de repositórios semânticos (Gazetteers) que permitam a inferência geográfica.

O processo de georreferenciamento de textos possui de forma geral os componentes apresentados na Figura 2.4, na qual observa-se que os documentos passam primeiro por um processo de Geo-Parsing e Geo-Coding. Esses processos permitem reconhecer o contexto geográfico dos textos e a definição das coordenadas espacias (McCurley, 2001).

Segundo Amitay et al. (2004) o processo de identificação do contexto geográfico de textos é denominado como Geo-tagging e envolve duas etapas principais: (i)Geo-Parsing que tem como objetivo reconhecer as referências geográficas nos textos ignorando nomes de localidades que não possuam sentido geográfico, como nomes de pessoas com o mesmo nome de localidade; e 


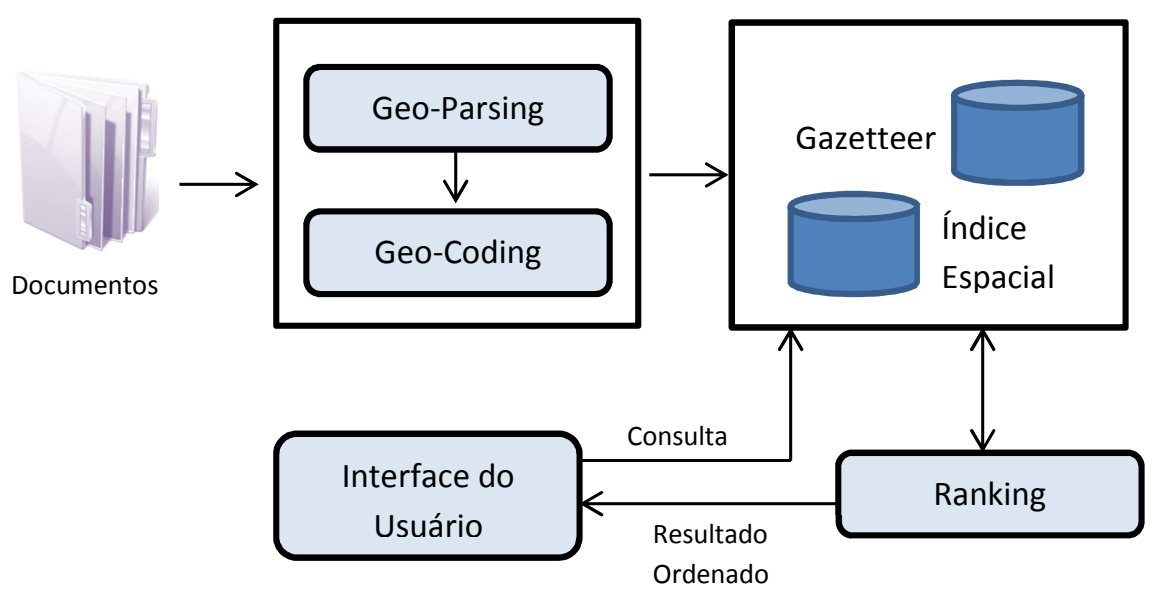

Figura 2.4: Principais componentes da RIG. Adaptado de (Gouvêa, 2009)

(ii)Geo-Coding que busca desambiguar as localidades recuperadas, isto é associar cada localidade a apenas uma única localização geográfica (footprint).

O componente mais importante do processo é o Gazetteer, o qual busca estruturar os relacionamentos semânticos relacionados às localidades, sendo organizado geralmente de forma hierárquica. A localização por meio de coordenadas geográficas e outras descrições relacionadas a elas, sendo que dependendo da complexidade de sua estrutura, pode ser vista como uma ontologia geográfica. A partir da utilização de Gazetteers, torna-se possível, por exemplo, reconhecer palavras e frases que se relacionam a alguma localidade, auxiliando também na desambiguação desses termos (Gouvêa, 2009).

\subsubsection{Geo-Parsing}

O Geo-Parsing pode ser considerado como uma aplicação mais específica da tarefa de Reconhecimento de Entidades Mencionadas (REM).

Para entender como é possivel extrair o contexto geográfico dos textos a partir da análise de seu conteúdo, é necessário, primeiro, analisar como as relações espaciais são determinadas para especificar lugares ou espaços geográficos na Terra (Gouvêa, 2009). As relações espaciais são comumente agrupadas em três categorias (Egenhofer e Franzosa, 1991):

- Topológicas: descrevem os conceitos de vizinhança, incidência, sobreposição sem variar com escalas e rotações, como "dentro de".

- Métricas: são consideradas em termos de direções, como "ao leste”, "ao oeste". 
- De Ordem: expressam a ordem, total ou parcial, dos objetos espaciais, como "em frente", "acima de".

Segundo Leidner e Lieberman (2011), existem fundamentalmente três métodos que são atualmente utilizados para o reconhecimento de entidades geográficas no texto.

Baseado em Gazetteers, nesta abordagem, o texto é percorrido palavra por palavra ou caractere por caractere, e procura-se por ocorrências de um conjunto predefinido de topônimos. Esses topônimos são armazenados no gazetteer, um banco de dados de nomes de lugar e metadados associados. Por exemplo, a palavra "Berlim" seria reconhecida como topônimo por alguns gazetteers mundiais.

Baseado em Regras, nesta abordagem, um conjunto de regras simbólicas de um domínio específico codificam as decisões que permitem a um interprete decidir se a palavra é um topônimo ou não. Usualmente, são usadas expressões regulares, autômatos finitos ou gramáticas livres de contexto.

Baseado em Aprendizado de Máquina , os métodos que utilizam essa abordagem geralmente utilizam uma janela deslizante, a qual é movida sobre o texto. Em cada posição, um conjunto de propriedades denominadas de características são computadas. Baseadas no corpus de treinamento que contem a coleção dourada (golden collection), as características são configuradas para serem o mais altamente correlacionadas com os topônimos extraídos.

\subsubsection{Geo-Coding}

O processo de transformar uma descrição textual de um nome de lugar em coordenadas em uma referência espacial é geralmente conhecida como geocoding (Amelunxen, 2009). Segundo Goldberg (2008) geo-coding é o ato de transformar um texto descritivo localizado espacialmente em uma representação válida espacial por meio de um processo pré-definido.

Segundo Goldberg et al. (2007), o fato de tornar dados em localizações descritivas como endereços ou entidades mencionadas em uma referência geográfica absoluta virou uma peça fundamental nos processos de Recuperação de Informação Geográfica (GIS). 
Para Davis et al. (2003), o geo-coding compreende a localização de pontos na superfície da terra a partir de informações alfanuméricas, envolvendo três etapas:

1. Tratamento do endereço alfanumérico semi-estruturado (parsing);

2. Estabelecimento de uma correspondência entre o endereço estruturado e o banco de dados (matching);

3. Atribuição das coordenadas geográficas com a extensão geográfica (footprint) da entidade que esta sendo alvo da geo-codificação.
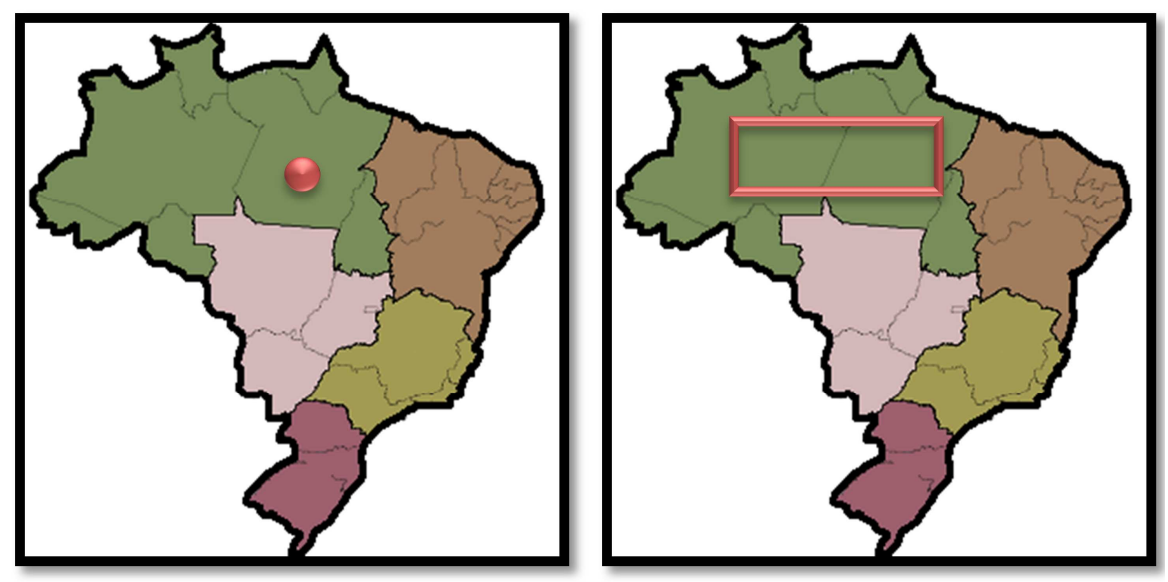

Figura 2.5: Representação de uma localização usando pontos e polígonos (Larson e Frontiera, 2004)

O footprint é uma representação geométrica da extensão do conteúdo geográfico do objeto que está sendo descrito e expressado na forma de coordenadas geográficas (Gouvêa, 2009). A localização referida por um footprint, conforme mostrada na Figura 2.5 é geralmente dada de acordo com Larson e Frontiera (2004) por:

- Pontos: mantém um senso geral da localização sem extensões ou formas;

- Polígonos: identificação da localização, extensão e forma com grau variável de precisão. O retângulo de limite mínimo é a representação espacial poligonomial mais usada em sistemas de RIG.

A representação de conteúdos por meio de coordenadas geográficas tem ganhado cada vez mais importância com o surgimento de padrões para representação de informações geográficas e a existência de serviços de navegação geo-espacial presentes na web, por exemplo, aplicações com Google Maps (Gouvêa, 2009). 


\subsubsection{Avaliação}

Geralmente, para avaliar um Sistema de Recuperação de Informação, são associadas três métricas com o objetivo de mensurar a eficiência do processo de avaliação da relevância de documentos: precisão (precision), cobertura (recall) e $f$-score. Na Tabela 2.2 são apresentados os quatro possiveis efeitos de uma consulta sobre o espaço total de documentos.

Tabela 2.2: Avaliação de Sistemas de Recuperação de Informação

\begin{tabular}{ccc}
\hline & Recuperados & Não Recuperados \\
\hline Relevantes & $\mathrm{Rr}$ & $\mathrm{Rnr}$ \\
\hline Não Relevantes & $\mathrm{NRr}$ & $\mathrm{NRnr}$ \\
\hline
\end{tabular}

Essas medidas citadas anteriormente podem ser expressas segundo as Equações 2.1, 2.2 e 2.3.

$$
\begin{gathered}
\text { Precisão }=\frac{\text { Nro_relevantes_recuperados_ }(R r)}{\text { Total_recuperados }} \\
\text { Cobertura }=\frac{\text { Nro_relevantes_recuperados_ }(R r)}{\text { Total_relevantes_existentes }} \\
F-\text { Score }=2 * \frac{\text { Precisao } * \text { Cobertura }}{\text { Precisao }+ \text { Cobertura }}
\end{gathered}
$$

A precisão mede a eficiência da recuperação para uma consulta considerando apenas os resultados que foram obtidos dessa consulta. Por exemplo, uma precisão de $70 \%$ significa que $30 \%$ de documentos não relevantes foram recuperados. A cobertura serve para demonstrar, em uma determinada consulta, quão hábil foi a recuperação de documentos considerados como relevantes, considerando todos os documentos possiveis de serem recuperados. Por exemplo, uma cobertura de $20 \%$ significa que $80 \%$ de documentos relevantes não foram recuperados. A medida $F$-score é uma medida que combina os resultados obtidos de precisão e cobertura para assim dar um valor médio entre as duas medidas de avaliação (Campelo e Baptista, 2009).

Como foi apresentado nesta seção, o processo de identificação do contexto geográfico de textos envolve duas etapas principais: (i) Geo-Parsing, que busca reconhecer as referências geográficas e (ii) Geo-Coding que busca desambiguar as localidades recuperadas. Na Seção 2.4 é detalhado o processo de GeoParsing no processo de Reconhecimento de entidades geográficas. Já na Seção 
2.5, é apresentada uma análise do processo de Geo-Coding para resolução da ambiguidade.

\subsection{Reconhecimento e Classificação de Entidades No- meadas}

O pré-processamento comum à maioria das atividades em Recuperação e Extração de Informações tem por responsabilidade principal o Reconhecimento de Entidades Mencionadas (REM) no texto. Por entidades podemos entender pessoas, lugares, instituições, entre outros. Porém, existe a necessidade de reconhecer essas entidades de forma eficiente no texto (Aranha, 2007).

O processo REM pode ser considerado como uma sub-tarefa dos processos de Extração de Informação (EI) que buscam localizar e classificar elementos atômicos no texto em categorias predefinidas, como nome de pessoas, organizações, localizações, expressões de tempo, quantidades, valores monetários e percentagens. O REM, que é muito usado em tarefas de Processamento da Língua Natural (PLN), foi cunhado pela Sixth Message Understanding Conference (MUC-6) (Grishman e Sundheim, 1996). Na Figura 2.6 observa-se um exemplo marcado com quatro tipos de entidades $<$ Data $>$, $<$ Pessoa $>$, $<$ Organização $>$ e $<$ Localização $>$.

On $<$ Date $>$ Jan $13^{\text {th }}<$ /Date $>$, $<$ Person $>$ John Briggs Jr $</$ Person $>$ contacted $<$ Organization > Wonderful Stockbrokers Inc. </Organization> in <Location> New York $<$ /Location $>$ and instructed them to sell all his shares in $<$ Organization> Acme </Organization>.

Figura 2.6: Exemplo de marcação de Entidades Mencionadas no texto (Mikheev et al., 1999)

O processo REM é um dos pontos principais do PLN pois eles nomeiam os objetos do mundo real do trabalho. O processo começa pela avaliação dos candidatos a Entidade Nomeada (EN), essa avaliação consiste em uma serie de filtros. Os candidatos que persistem são agrupados por proximidade e considerados nomes de entidades (Aranha, 2007).

Segundo Sarmento et al. (2006), uma Entidade Nomeada (EN) refere-se a uma entidade que possui um nome próprio que é usado na sua individualiza- 
ção, ainda que esse nome próprio seja utilizado por outras entidades, podendo gerar situações ambíguas. As ENs são palavras da classe de substantivos próprios e definem nomes para lugares, pessoas, organizações, acontecimentos, coisas, obras, entre outros. Por exemplo, "Porto" nomeia uma cidade, ou seja, é uma entidade que é um local geográfico/administrativo. Por outro lado, uma Entidade Mencionada (EM) têm a mesma definição de Entidade Nomeada, porém as EMs dependem do contexto em que se encontram para que sejam resolvidas.

Para uma EM existem situações em que no contexto é atribuído um determinado papel semântico diferente do seu papel intrínseco, ou quando uma entidade é usada para mencionar implicitamente outras entidades. Por exemplo, "Porto candidata-se aos Jogos Olímpicos", “A presença do Porto em Macau", "Brasil e Portugal jogam amanhã". No exemplo anterior se pega-se o termo "Brasil" e interpreta-se ele sozinho, representa o país mais populoso da América Latina. No entanto, se a frase inteira é considerada, o termo "Brasil" refere-se à seleção brasileira de futebol. É assim que pode-se interpretar que o termo "Brasil" sem contexto é considerado uma Entidade Nomeada, e já com contexto é considerada uma Entidade Mencionada (Sarmento et al., 2006).

O termo "Entidades Mencionadas" (EM), no âmbito do PLN, é a adaptação do conceito "Named Entities" e pode ser compreendido como referente a entidades expressas em textos por meio de nomes próprios (Santos e Cardoso, 2007). As EMs são instâncias de classes ontológicas que possuem alto poder de informação e por isso seu reconhecimento é fundamental para extração de informação em textos. A palavra "Mencionada" tem como objetivo restringir a tarefa apenas às entidades para as quais são usadas um ou vários designadores rígidos como definido em Kripke (1980). Por exemplo, "A companhia de automóveis criada por Henry Ford em 1903" refere "Ford" ou "Companhia de motores Ford". Os designadores rígidos includem nomes próprios e certos termos naturais. Existe um acordo geral para incluir expressões temporais e algumas expressões numéricas nas tarefas de REM. Segundo Nadeau (2007) algumas instâncias de números e tempo são bons exemplos de designadores rígidos, por exemplo:

1. O ano 2001, que refere-se a um ano do calendário gregoriano;

2. Férias em Junho, refere-se a um mês de um ano indefinido, podendo ser junho passado, próximo junho, etc. 
Ceci et al. (2010) explicam que existem muitas técnicas automáticas que podem auxiliar no processo de reconhecimento de entidades, como a aplicação de expressões regulares, gazetteers, thesauros, heurísticas, modelos estatísticos e ontologias. Segundo Kozareva (2006), a tarefa de identificar as entidades consiste em determinar suas fronteiras, ou seja, identificar o início e o fim. Isso é importante para entidades compostas como, por exemplo, "Universidade Federal de Santa Catarina”. Segundo Konchady (2006), a técnica de extração de entidades pode ser vista como um problema de classificação em que as palavras são atribuídas para uma ou mais classes semânticas. No trabalho de Amancio (2011), explica-se que as meta palavras representam as palavras das vizinhanças das entidades. Essas palavras, muitas vezes, são indicadores de localização e são geralmente usadas na etapa de desambiguação. Por exemplo, na sentença "A produção de açúcar aumentou $20 \%$ no estado de São Paulo" a presença da meta palavra "estado" ajuda a identificar que a entidade "São Paulo" refere-se ao nome de um estado, que podería ser confundido com um município ou um time de futebol.

Segundo Nadeau (2007), uma boa parte do trabalho em pesquisa de REM é dedicado a textos em língua inglesa. Uma proporção ainda maior dos trabalhos, trata sobre a independência de linguagem e problemas do multilinguismo. Por exemplo, na Conference on Computational Natual Language Learning (CONLL-2003) o alemão foi estudado para problemas de reconhecimento de entidades. Na CONLL-2002 foi estudado espanhol e holandês, assim como várias outras línguas foram estudadas em diferentes versões do CONLL. Palmer e Day (1997) examinaram a tarefa do REM para o português. Após, foi criada a conferencia HAREM (Avaliação e Reconhecimento de Entidades Mencionadas) com o propósito de incentivar o desenvolvimento de sistemas voltados para a tarefa de identificar e classificar automaticamente nomes próprios em categorias previamente definidas, em textos escritos em portuguese (Santos e Cardoso, 2007).

O problema de Reconhecimento de Entidades Mencionadas é uma tarefa bem conhecida na área de Extração de Informação Geográfica. Segundo Leidner (2006), o objetivo é mais do que anotar uma expressão de textos como uma localização, é fazer uma anotação de forma a que a expressão geográfica seja inequivocamente descrita. O processo de REM é o primeiro passo na análise semântica de um texto. Este reconhecimento está dividido em duas sub tarefas:

1. Identificação das entidades, na qual uma dada sequência de palavras 
constitui uma entidade;

2. Classificação, que determina a que categoria semântica essa entidade pertence naquele contexto.

A principal dificuldade para o processo de REM assim como para outros processos que trabalham com textos é a ambiguidade das palavras. Em Aranha (2007) e Amancio (2011), estes problemas são descritos usando as seguintes sentenças de exemplos:

1. Fernando H. Cardoso;

2. Juiz Nicolau dos Santos Neto;

3. Presidente da Câmara dos Vereadores Alcides Barroso;

4. Hollywood.

No exemplo (1) encontra-se um problema importante para o REM que é a abreviação no meio de um nome, o qual pode ser entendida pelo computador como fim de sentença. No exemplo (2) a presença de "dos" pode induzir a um sistema REM a separar os nomes "Juiz Nicolau" e "Santos Neto", os quais fazem parte de um mesmo nome. No exemplo (3) existem duas entidades, mas a ortografia (presença de maiúscula) pode confundir os sistemas REM, pois a heurística geralmente adotada é o agrupamento de todas as palavras que iniciam em maiúscula em uma mesma entidade. Finalmente, o exemplo (4) representa um nome ambíguo já que não podemos dizer se "Hollywood" significa lugar ou marca de cigarro.

Na Figura 2.7 são apresentadas as classes utilizadas nos processos de REM, assim como o apoio fornecido pelo conhecimento de uma para outra. Por exemplo, as regras de classificação de datas usam perguntas sobre a classificação dos números. As classes que encontram-se no nível mais baixo da árvore tendem a ser mais independentes da língua, como os nomes de pessoa e de organização, em seguida os nomes de locais geográficos e finalmente os formatos de datas (Aranha, 2007).

O processo de classificação pode ser realizado seguindo a mesma lógica do processo de reconhecimento, porém em um nível de abstração maior. A maioria das regras contém perguntas sobre o resultado do reconhecimento. Além disso, existe a meta informação. São utilizadas também regras que utilizam de palavras adjacentes que circunscrevem a classificação dos nomes. Por exemplo, em "Isso aconteceu próximo litoral da ilha de Sumatra” , as palavras 


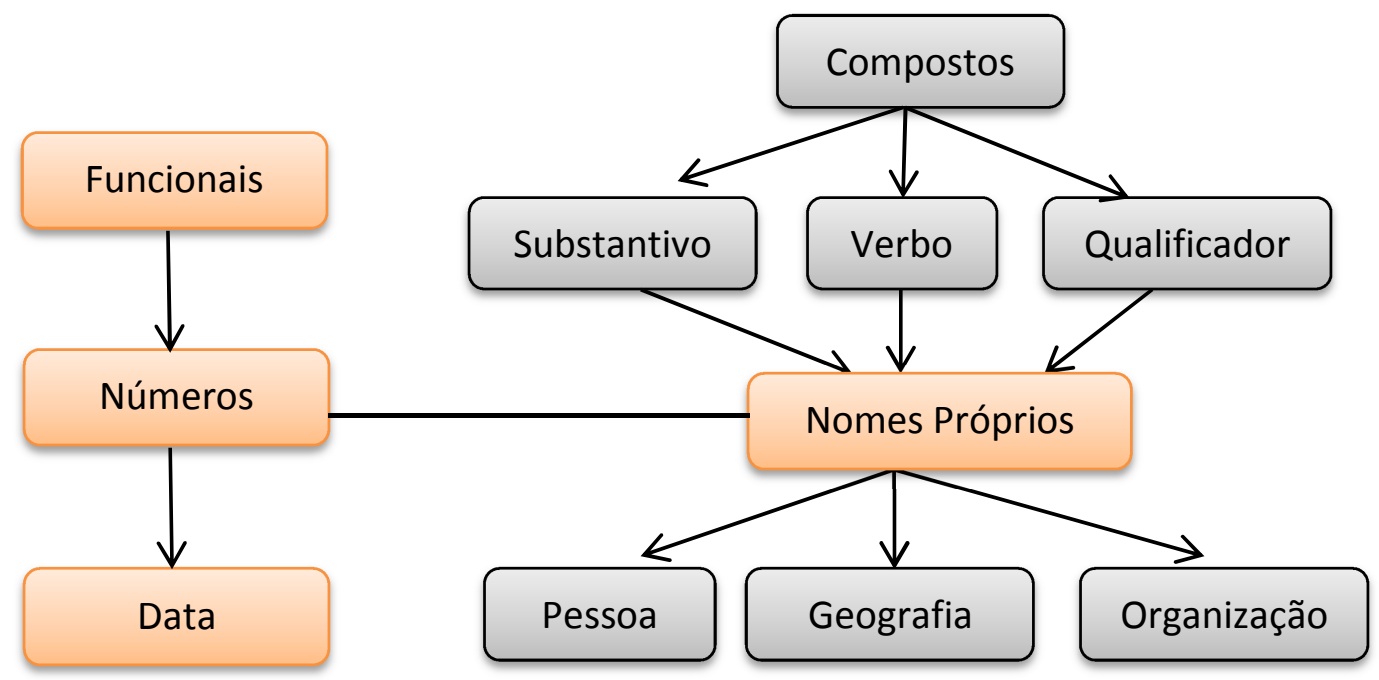

Figura 2.7: Classes dos processo de Reconhecimento de Entidades Mencionadas (REM). Adaptado de (Aranha, 2007)

"litoral" e "ilha" ditam a classificação de localização geográfica para a entidade "Sumatra" (Aranha, 2007).

\subsection{Ferramentas Linguísticas}

A avaliação conjunta do HAREM trouxe vários sistemas que estão envolvidos no processo de REM para a língua portuguesa. O HAREM é uma avaliação conjunta na área do reconhecimento de entidades mencionadas em português. O HAREM é uma iniciativa que pretende avaliar o sucesso na identificação e consequente classificação automática dos nomes próprios na língua portuguesa (Santos e Cardoso, 2006). O objetivo comum de todos os trabalhos foi identificar e classificar corretamente as entidades em um determinado texto. Tipicamente esses textos são um conjunto de notícias, artigos Web e muitas outras fontes manualmente marcadas. Nessa avaliação o resultado foi uma compilação de 1,040 documentos (15,737 parágrafos, 670,610 palavras).

No trabalho de Correia de Oliveira (2010), é feita uma comparação entre todos os sistemas que participaram da segunda avaliação conjunta do HAREM. A seguir é apresentada uma breve visão dos sistemas explorados nesse trabalho.

Sistema CAGE - trabalha com o reconhecimento e desambiguação das EM geográficas. São usadas informações geográficas como coordenadas de latitude e longitude; 
Sistema PorTexTo - sistema focado na identificação de expressões temporais embutidas nos documentos. Essas expressões podem ser usadas para ordenar os resultados providos por um sistema de recuperação de informação;

Sistema Priberam - foi desenvolvido como base de um sistema REM construído em uma plataforma linguística própria. Essa plataforma inclui um conjunto de recursos linguísticos (léxico, ontologia e gramática) e ferramentos de software que cobrem provas, processamento de texto e ferramentas de Recuperação de Informação;

Sistema R3M - foi desenvolvido para identificar e classificar unicamente pessoas, organizações e localizações. O autor deste sistema adotou uma abordagem de aprendizado semi supervisionada usando o menos possível recursos linguísticos manualmente anotados;

Sistema REMBRANDT - este sistema realiza tarefas de REM e detecção de relações entre entidades. Foi criado para detectar todos os diferentes tipos de entidades que acontecem em textos em português, usando a Wikipédia como fonte de conhecimento;

Sistema REMMA - é um sistema de REM parecido ao REMBRANDT que também usa a Wikipédia como fonte de conhecimento externo. Foi desenvolvido para o projeto MedAlert. Segundo Ferreira e Teixeira (2008) o objetivo do MedAlert é usar técnicas de Recuperação de Informação em textos médicos para deduzir automaticamente irregularidades ou dúvidas sobre uma decisão feita por um médico, enfermeira ou algum oficial da saúde;

Sistema SEI-Geo - é um sistema de REM que realiza unicamente a identificação e classificação de entidades do tipo "LOCAL" e esta essencialmente baseado em padrões e ontologias geográficas;

Sistema XIP - é um compilador de regras que permite análise de textos da forma sintáctica e semântica e é usada para identificar e classificar entidades. Esse sistema identifica e classifica todas as EMs com exceção das entidades "Coisa" e "Abstração".

Na Tabela 2.3 é apresentada uma visão geral dos resultados gerados pelos sistemas apresentados anteriormente e estudados em Correia de Oliveira (2010). Como apresentado na Tabela 2.3 o sistema Priberam está em primeiro 
lugar se comparamos a F-measure de todos os sistemas, o segundo lugar é ocupado pelos sistemas REMBRANDT e R3M na parte da Identificação e o REMBRANDT em segundo lugar na parte de classificação. Porém, o sistema Priberam não foi escrito especificamente para o HAREM e atualmente é usado como um módulo independente em alguns produtos Priberam.

Tabela 2.3: Estado da Arte: Comparação dos resultados globais, observando as tarefas de identificação e classificação (Correia de Oliveira, 2010)

\begin{tabular}{c|ccc|ccc}
\hline Sistema & \multicolumn{3}{|c|}{ Identificação } & \multicolumn{3}{c}{ Classificação } \\
\hline & Precisão & Cobertura & F-score & Precisão & Cobertura & F-score \\
\hline CaGE & 0.5108 & 0.3773 & 0.4340 & 0.4499 & 0.2757 & 0.3419 \\
\hline PorTexTO & 0.7003 & 0.0898 & 0.1592 & 0.6790 & 0.0882 & 0.1562 \\
\hline Priberam & 0.6994 & $\mathbf{0 . 7 2 2 9}$ & $\mathbf{0 . 7 1 1 0}$ & 0.6417 & $\mathbf{0 . 5 1 4 6}$ & $\mathbf{0 . 5 7 1 1}$ \\
\hline R3M & 0.7644 & 0.6170 & $\mathbf{0 . 6 8 2 8}$ & & & \\
\hline REMBRANDT & 0.7577 & 0.6214 & $\mathbf{0 . 6 8 2 8}$ & 0.6497 & 0.5036 & $\mathbf{0 . 5 6 7 4}$ \\
\hline REMMA & 0.7083 & 0.4516 & 0.5515 & 0.6050 & 0.3615 & 0.4526 \\
\hline SEI-Geo & $\mathbf{0 . 8 9 6 3}$ & 0.1358 & 0.2359 & $\mathbf{0 . 7 4 8 5}$ & 0.1166 & 0.2017 \\
\hline XIP & 0.7214 & 0.5315 & 0.6121 & 0.6566 & 0.4652 & 0.5445 \\
\hline
\end{tabular}

$O$ resultado da ferramenta REMBRANDT mostrá-se boa em termos de $F$ score, já que balanceia a precisão e a cobertura dos documentos. No decorrer deste trabalho de mestrado, foram utilizadas duas ferramentas para ajudar no processo de Reconhecimento de Entidades Mencionadas: a ferramenta linguística REMBRANDT e um vocabulário controlado de termos do domínio dos documentos. Escolheu-se o REMBRANDT devido à disponibilidade e aos bons resultados apresentados anteriormente. Por outro lado escolheu-se o vocabulário controlado do domínio dos documentos como uma alternativa à ferramenta linguística. A seguir é descrito o funcionamento das duas ferramentas.

\section{REMBRANDT}

O Reconhecimento de Entidades Mencionadas Baseado em Relações e ANálise Detalhada do Texto (Rembrandt ${ }^{1}$ ) é um sistema de Reconhecimento de Entidades Mencionadas (REM) e de Detecção de Relações entre Entidades (DRE). Este sistema foi criado originalmente para a anotação de textos em Português mas está sendo adaptado para outras línguas (Cardoso, 2008).

O sistema REMBRANDT aborda duas técnicas principais:

1. Utilização da enciclopédia Wikipédia;

\footnotetext{
${ }^{1}$ http://xldb.di.fc.ul.pt/Rembrandt
} 
2. Utilização de Regras gramaticais durante a fase de identificação e classificação das Entidades Mencionadas.

A classificação do REMBRANDT é baseada em 9, categorias as quais foram definidas para a Coleção dourada (Santos e Cardoso, 2007): (1) pessoa, (2) lugar, (3) organização, (4) obra, (5) acontecimento, (6) abstração, (7) valor, (8) tempo e (9) coisa. Essas categorias são compostas por 47 subcategorias.

O funcionamento do REMBRANDT pode ser subdividido em três etapas principais como apresentado na Figura 2.8:

1. Reconhecimento de Expressões numéricas e geração de EM candidatas;

2. Classificação das EM;

3. Repescagem das EM sem classificação.

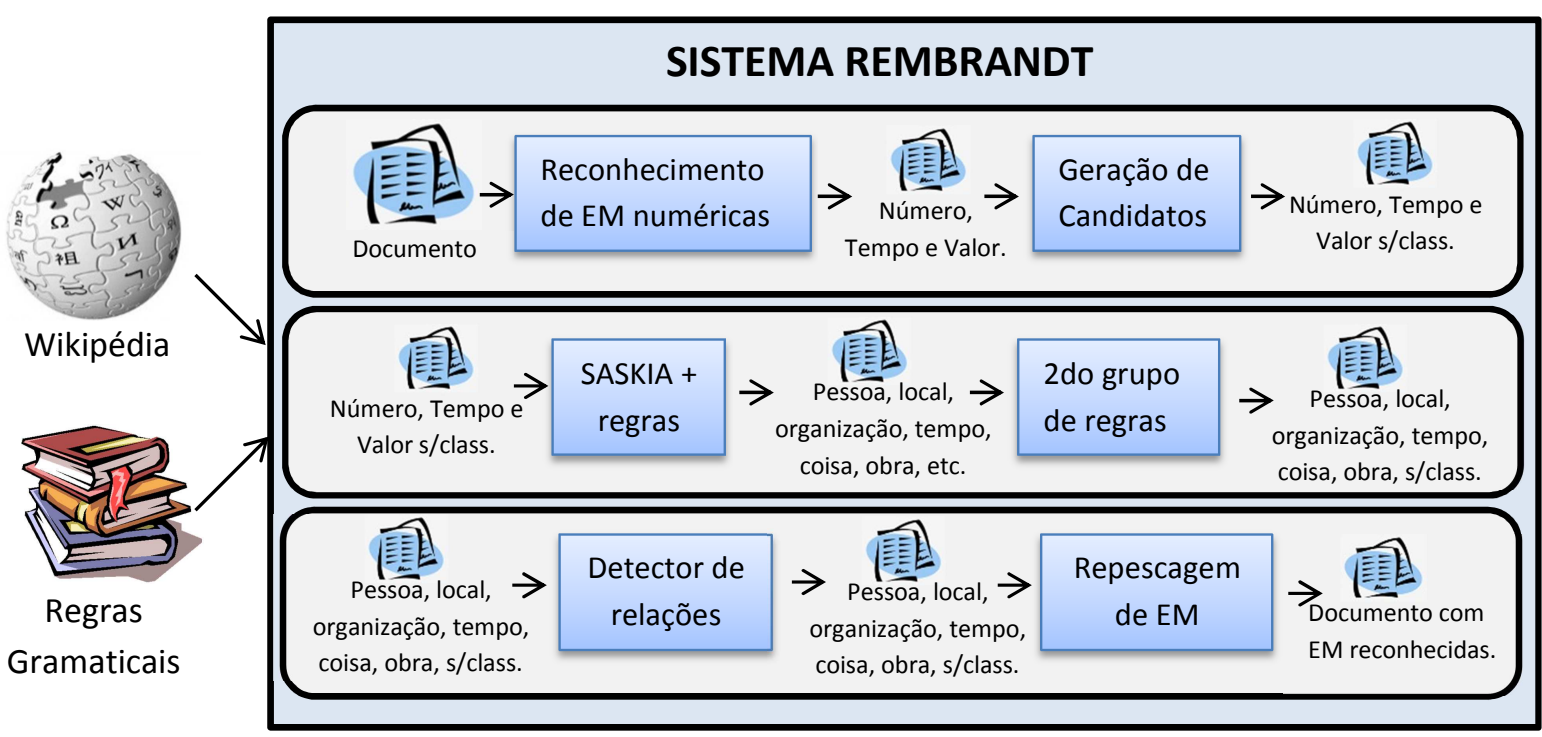

Figura 2.8: Funcionamento do sistema Rembrandt (Cardoso, 2008)

Na etapa (1), um conjunto de regras são encarregadas de identificar todas as expressões numéricas. Após, são aplicadas regras para reconhecer expressões temporais e para gerar EM candidatas. Na etapa (2), as EM candidatas são classificadas primeiro pelo SASKIA (interface do REMBRANDT que serve para interagir com Wikipédia), e depois novamente classificadas por meio de regras gramaticais para detectar as EM com uma morfologia mais elaborada. Finalmente, na etapa (3) realiza-se a detecção das relações entre as EM usando um conjunto de regras específicas para essa tarefa. Após isso, é feita uma última repescagem das EM com nomes de pessoas usando uma listas de nomes 
comuns. Por último, as EM que persistem sem classificação são eliminadas, bem como números por extenso sem uma letra maiúscula (Cardoso, 2008).

\section{Vocabulário Controlado Agrícola Brasileiro (AGRI-BR)}

Para Ebecken et al. (2005), um dicionário ou thesaurus pode ser definido como um vocabulário controlado que representa sinônimos, hierarquias e relacionamentos associativos entre termos para ajudar os usuários a encontrar a informação que eles precisam.

Segundo Finch e Gardner (2009), o thesaurus é uma ferramenta de controle de palavras que utiliza-se para organizar termos e expressar relações entre conceitos. Durante muito tempo os especialistas dependem dos thesauros para contribuir e padronizar a terminologia em sistemas de recuperação de informação. Além disso, o thesauro constitui um vocabulário controlado no qual cada termo representa um conceito.

O objetivo do vocabulário controlado agrícola brasileiro, denominado como AGRI-BR, é proporcionar uma lista de palavras agrícolas e geográficas relacionadas aos documentos. Essa lista de palavras visa permitir a identificação das entidades geográficas nos documentos, como uma fonte não linguística alternativa de reconhecimento de entidades. A construção do vocabulário controlado AGRI-BR, proposto neste trabalho é apresentado no Capítulo 4

\subsection{Resolução de Topônimos}

A resolução de topônimos pode ser definida como a tarefa de atribuir a um nome de lugar ambíguo uma única localização na qual está representada a entidades segundo o contexto do documento (Leidner, 2006). Por exemplo, a entidade "Cambridge" representa uma entidade ambígua e pode ser usada para representar as seguintes localizações segundo a WordNet:

- Cidade no leste de Inglaterra perto do rio Cam;

- Universidade de Cambridge;

- Cidade em Massachusetts ao norte de Boston;

- Site da Universidade de Harvard e o MIT (Massachusetts Institute of Technology). 
Normalmente, existem dicas dentro do próprio texto que poderiam ajudar no processo de desambiguação, essas dicas estão baseadas no contexto do documento. Por exemplo, se no texto encontra-se a referência "Boston" esta poderia ser utilizada para determinar a referência correta da entidade "Cambridge", no caso, o termo desambiguado seria Cambridge que é uma cidade em Massachusetts ao norte de Boston.

Devido ao fato de poder identificar de forma precisa um determinado espaço geográfico, a utilização de técnicas para identificação correta de topônimos (também conhecidas como entidades geográficas) apresenta-se como uma possibilidade importante para a inferência do contexto geográfico abordado pelos textos. No entanto, devido às características dos espaços geográfico e textual surge a necessidade de lidar com vários tipos de ambiguidade para a correta identificação das localidades. Por exemplo, no aspecto geográfico um topônimo como entidade geo-política pode mudar de nome ou extensão ao longo do tempo, já no âmbito linguístico lugares distintos da Terra podem compartilhar o mesmo nome. Segundo Leidner (2006) a área encarregada de estudar estes problemas é definida como Resolução de Topônimos (RT), a qual tem o objetivo de possibilitar o mapeamento correto das localidades referenciadas pelos textos a partir da resolução dos vários tipos de ambiguidades relacionadas a elas.

\subsubsection{Características dos Topônimos}

Para entender como realizar a Resolução de Topônimos em textos é necessário inicialmente compreender como estes podem ser referenciados nos textos e quais são os tipos de ambiguidade que podem estar relacionados. Segundo Garbin e Mani (2005) um topônimo é o nome de uma entidade geográfica na superficie da Terra que pode ser representada por alguma especificação geométrica de um SIG, por exemplo ponto, linha ou polígono.

Do ponto de vista linguístico, as principais dificuldades para capturar as expressões vagas as quais se relacionam a lugares imprecisos relacionam-se a inferência correta das localidades referenciadas nos textos. Assim, Clough et al. (2004) define os seguintes tipos de ambiguidade:

- Ambiguidade da Referência (ARC), acontece quando determinada localidade pode ser referenciada por vários nomes diferentes. Por exemplo, nomes históricos, abreviações e siglas.

- Ambiguidade do Referente (ART), acontece quando o nome pode ser usado 
para referenciar outras localidades. Por exemplo, uma cidade com o mesmo nome de outra como "Belém".

- Ambiguidade da Classe do Referente (ACR), acontece quando o nome pode ser usado para referenciar outros tipos de entidades. Por exemplo, nome de pessoas que são iguais a nomes de empresas.

Segundo Broder (2007) o processo de Resolução de Topônimos traz desafios específicos já que principalmente do ponto de vista linguístico um topônimo pode possuir variados tipos de ambiguidade. Essas ambiguidades são divididas habitualmente em:

- Ambiguidade Geo/Não-Geo, uma localidade possui ambiguidade com outro tipo de entidade não geográfica. Por exemplo, São Paulo cidade e São Paulo time de futebol;

- Ambiguidade Geo/Geo, uma localidade possui ambiguidade com outro tipo de localidade (homonímia) ou quando pode ser identificada por meio de outras definições (sinonímia).

Na Tabela 2.4 pode-se observar alguns exemplos sobre os tipos de ambiguidade, ressaltando assim importância de ter um bom processo que permita a resolução destas ambiguidades.

Tabela 2.4: Tipos de Ambiguidade para a Resolução de Topônimos

\begin{tabular}{c|c|c|c}
\hline & Localização & Ambiguidade \\
\hline \multirow{3}{*}{ Geo/Geo } & ARC & $\begin{array}{c}\text { Pelotas, RS } \\
\text { Rio de Janeiro, RJ }\end{array}$ & $\begin{array}{c}\text { Princesa do Sul } \\
\text { Rio }\end{array}$ \\
\cline { 2 - 4 } & ART & $\begin{array}{c}\text { Bom Jesus, RS } \\
\text { Belém, PA }\end{array}$ & $\begin{array}{c}\text { Bom Jesus, RN } \\
\text { Belém, PB }\end{array}$ \\
\hline Geo/Não Geo & ACR & $\begin{array}{c}\text { Pelotas, RS } \\
\text { Serra, ES }\end{array}$ & $\begin{array}{c}\text { Rua Pelotas } \\
\text { Serra, governador de São Paulo }\end{array}$ \\
\hline
\end{tabular}

Segundo Gouvêa (2009) um outro problema de ambiguidade é quando um nome de lugar pode estar sendo utilizado no texto como metonímico de outro, ou seja, uma localidade referencia a outra entidade que é relacionada a ela. Por exemplo:

- "Rio Grande prepara-se para a construção do dique seco";

- "Pelotas assinou ontem lei para a educação". 
Nesses casos o topônimo não é referenciado no texto como o aspeto propriamente geográfico, mas sim está relacionado com pessoas localizadas na cidade. No primeiro exemplo esta relacionada a população em geral, no segundo exemplo está relacionado ao prefeito.

\subsubsection{Estratégias para Resolução de Topônimos}

Para poder efetuar o processo de Resolução de Topônimos, as entidades geográficas devem ter sido identificadas na etapa de Geo-Parsing. Ao utilizar uma ferramenta que realize a tarefa de Reconhecimento de Entidades Mencionadas (REM) espera-se que as entidades selecionadas não possuam ambiguidades do tipo ACR. Assim, a resolução de topônimos busca lidar com problemas de ambiguidade do tipo ARC e principalmente ART.

Para a de desambiguação utilizam-se técnicas principalmente inspiradas na Desambiguação Lexical de Sentido (Word Sense Disambiguation - WSD). Segundo Ide e Véronis (1998), a WSD consiste de forma geral na classificação de uma palavra ambígua a partir da avaliação do sentido dos candidatos, verificando os diferentes significados de cada palavra, de acordo com um contexto particular. Por exemplo, "Bando de areia" ou "Banco do Brasil".

\subsection{Considerações Finais}

Neste capítulo foram apresentados diversos conceitos relacionados à tarefa de reconhecimento e desambiguação de entidades geográficas, assim como também técnicas de mineração de texto que permitem solucionar o problema. Foi explorado, na parte de Mineração de Textos, a abordagem de Aprendizado de Máquina que visa classificar os documentos usando uma hierarquia e considerando ao mesmo tempo que um documento pode ter $m$ marcações. Após, foram abordados conceitos de Recuperação de Informação geográfica, levando em consideração os processos de geo-parsing e geo-coding respetivamente. Analisou-se também diferentes ferramentas que permitem realizar processos de Reconhecimento de Entidades Mencionadas, detalhando o funcionamento da ferramenta Rembrandt e o vocabulário controlado AGRI-BR. Finalmente, explorou-se os tipos de ambiguidade que podem estar presentes neste tipo de tarefa.

No seguinte capítulo são apresentados os trabalhos relacionados com os principais aspectos da resolução de topônimos. De forma que exploram-se 
os diversos métodos existentes na literatura para resolver a ambiguidade das entidades nos documentos. 


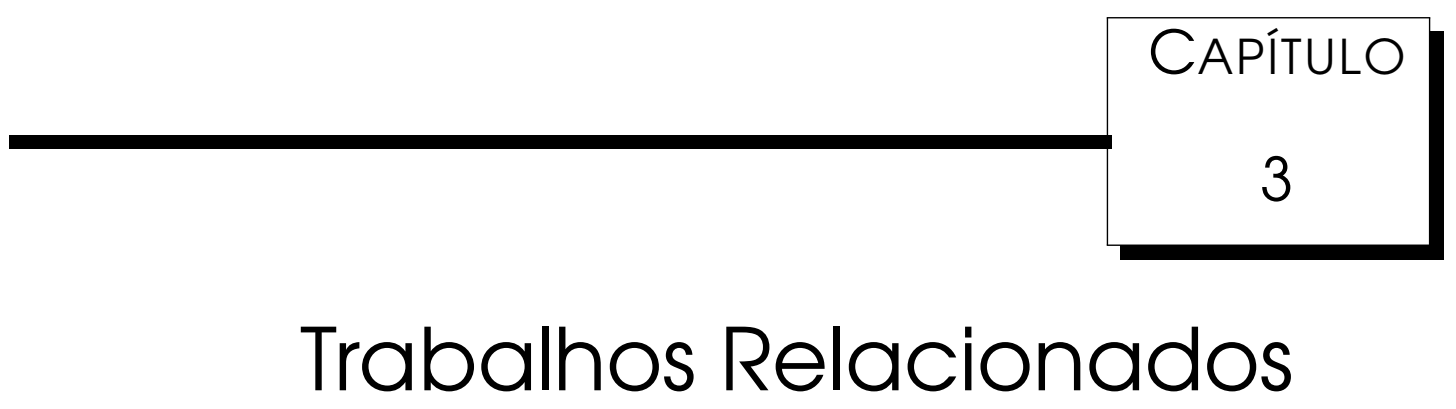

\subsection{Considerações Iniciais}

Um dos principais problemas para obter a espacialidade dos documentos está relacionado com o problema de ambiguidade presente nas entidades geográficas dos documentos. Esse problema é considerado como um problema complexo e tratado em diversas áreas em diferentes aplicações.

Segundo Roberts et al. (2010), a desambiguação de topônimos é a tarefa de determinar as localizações geográficas dos documentos no texto normalizandoos para alguma representação estruturada, por exemplo, coordenadas geográficas, entradas de banco de dados, ou localização usando uma ontologia geográfica. Essa tarefa é difícil porque podem existir topônimos altamente ambíguos.

Segundo Overell e Rüger (2008), a desambiguação de lugares é um subconjunto da desambiguação de nomes próprios, com duas diferenças: (i) existe uma relação espacial implícita entre as localizações, e (ii) existem diversos recursos geográficos que listam as localizações e as relações implícitas. Segundo Buscaldi e Rosso (2008), os métodos existentes para desambiguação podem ser subdivididos em três categorias:

- Baseados em Mapas: são métodos que usam uma representação explícita de lugares em um mapa;

- Baseados em Conhecimento: são métodos que exploram as fontes de 
conhecimento externo como gazetteers, Wikipédia ou ontologias;

- Dirigidos a dados ou supervisionados: são métodos baseados em técnicas de Aprendizado de Máquina.

Na abordagem baseada em conhecimento, a tarefa de se associar um lugar aos documentos é dividida em três subproblemas (De Vasconcelos Borges, 2006), (López et al., 2012):

1. Extração dos nomes de lugares, na qual todas as possíveis referências são extraídas de uma fonte de conhecimento geográfico (gazetteers, ontologias, banco de dados, Wikipédia ou outras fontes externas);

2. Eliminação da ambiguidade, para o qual são aplicados um conjunto de heurísticas para determinar entre todos os potenciais candidatos o mais semelhante, levando em consideração o contexto e os recursos como fonte de evidência;

3. Associação de um lugar aos documentos.

Nesta dissertação são exploradas duas formas de lidar com o problema de ambiguidade por meio de métodos baseados em conhecimento: (i) abordagem baseada em gazetteers ou na Wikipédia e, (ii) abordagem de resolução por ontologia geográfica. Essas abordagens serão exploradas com maior detalhe nas seções seguintes.

\subsection{Abordagem de Resolução de Topônimos base- ada em gazetteers ou na Wikipédia}

Esta abordagem pode ser definida como a tarefa de estabelecer uma única referência a uma entidade ambígua. Essa referência deve estar relacionada com a localização real da entidade representada pelo contexto. Nesse tipo de abordagem geralmente são utilizados Gazetteers ou Sistemas de Informação Geográficos (SIG) para poder extrair as coordenadas associadas a uma determinada entidade. A seguir são apresentados alguns trabalhos relacionados com a área de Resolução de Topônimos em ordem cronológica.

\subsubsection{Biblioteca digital PERSEUS (Smith e Crane, 2001)}

Smith e Crane (2001) descrevem um sistema de desambiguação de topônimos para a biblioteca digital Perseus. Para o processo de desambiguação 
é usada evidência externa e interna relativa aos documentos. A evidência interna inclui o uso de etiquetas geográficas genéricas e um ambiente linguístico. A evidência externa inclui gazetteers, informação bibliográfica e conhecimento geral de linguística. Os autores usaram as seguintes fontes de conhecimento:

- Getty Thesaurus of Geographic Names ${ }^{1}$;

- Cruchley's gazetteer of London;

- Lista de autores do Dictionary of National Biography.

\section{Método}

- O sistema produz uma caracterização do contexto do documento.

- Todas as possíveis localizações para todos os topônimos do documento são adicionadas uma a uma em um bitmap que representa a Terra.

- Cada topônimo adicionado no bitmap tem um peso associado que representa a frequência do topônimo no documento.

- Depois, o centroide de todos os potenciais referentes é calculado e todos os candidatos com uma distância maior que dois desvios-padrão são descartados. Após o descarte, os centroides são atualizados.

- Cada topônimo ambíguo no documento é analisado usando uma janela deslizante. A janela contém quatro topônimos não ambíguos ou já resolvidos.

Para cada referente, é associado um escore baseado na distância espacial de um topônimo ambíguo a um topônimo na janela. Esse escore considera também a distância do documento com o centroide geográfico e a importância relativa. A importância relativa do documento é determinada usando um conjunto de características. Por exemplo, as interpretações de país tem um peso maior que as interpretações de cidades. Finalmente, os candidatos com os maiores escores são selecionados como os topônimos desambiguados.

\footnotetext{
$1_{\text {http }}:$ / / www $\cdot$ getty $\cdot$ edu/vow/TGNServlet
} 


\section{Resultados}

Para avaliar o sistema, os autores usaram as medidas de precisão e cobertura em cinco corpus históricos representados por Grécia, Roma antiga, Londres, e duas coleções de documentos da Library of Congress representados por Califórnia e Centro-Oeste Americano. A precisão, a cobertura e o F-score deram bons resultados no processo de desambiguação, obtendo-se 0.96 de F-Score para o corpus da Grécia. Este método está focado em maximizar a precisão, diminuindo dessa forma o valor da cobertura.

\subsubsection{Atribuição de probabilidades e expansão da expressão da consulta geográfica (Yi et al. , 2006)}

No trabalho de Yi et al. (2006) é explorado o uso de consultas com referências geográficas para a expansão da expressão da consulta e recuperação de documentos relevantes. Como parte do pré-processamento do Sistema de Recuperação de Informação Geográfica (SIG) foi considerada a identificação e localização dos topônimos. Para solucionar o problema de ambiguidade presente nos topônimos, os autores consideraram os seguintes critérios:

- Utilizou-se uma abordagem baseada em probabilidades que atribui um peso para cada entidade ambígua. Para atribuir esse peso é considerado o nível hierárquico da entidade. Esse nível é extraído usando o World Gazetteer $^{2}$.

- A hierarquia usada é da forma "País-Nação-Estado-Cidade-Outros".

- Adicionalmente, foi usado o Getty Thesaurus para obter informações mais específicas sobre cada entidade. Por exemplo, o Getty Thesaurus indica que o termo "Dublin" corresponde a 25 localizações diferentes em 4 países. Esse thesauro também permite saber se a entidade selecionada é do tipo capital, ou cidade mais populosa.

\section{Método}

Usando a informação do gazetteer e do thesauro é atribuído um valor de probabilidade inicial para cada entidade. Esses valores iniciais de probabilidade vão-se atualizando considerando as seguintes heurísticas:

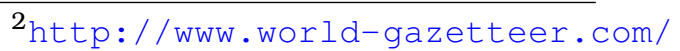


- Informação local de contexto: são identificados os termos geográficos que ocorrem em relativa proximidade no texto, por exemplo, na mesma oração;

- Estatísticas de população: são escolhidas as cidades com maior população;

- Palavras-chave geográficas: considera palavras-chave, como país ou lago, já que elas podem dar um indício de localização;

- Informação contextual global: usa as entidades mencionadas no documento como base para desambiguar. Por exemplo, se em algum lugar do documento foi reconhecida a entidade "Austrália" e em outra parte a entidade "Melbourne", existe uma probabilidade grande que a entidade desambiguada seja o Melbourne que pertence a Austrália em lugar de Melbourne na Flórida.

Depois de atribuir a probabilidade para cada entidade é feita uma expansão de consulta e de documentos.

\section{Resultados}

Os autores usaram como base da avaliação a metodologia proposta pelo "GeoCLEF 2005" e usaram 3 bancos de dados para comparar a Precisão Média (PM). A PM calcula a média do valor de precisão ao longo do intervalo entre 0 e 1 .

1. "TdBaseLine" é o banco de dados base que não usa resolução de topônimos;

2. "TdGeoDexp", e "TdGeoQexp", são as bases que usam os métodos propostos pelos autores.

Os resultados mostraram um ganho mínimo (0.03\% e 1.06\%) do corpus "TdGeoDexp" e "TdGeoQexp" versus "TdBaseLine" para a medida de PM. Esses valores obtidos não mostraram uma significância muito grande para realizar a desambiguação; porém os autores explicam que esses valores foram obtidos devido ao escopo dos documentos, os efeitos da expansão de consultas, e devido ao fato que algumas entidades não eram consideradas no gazetteer ou no thesauro por serem do tipo "regiões gerais". Por exemplo: Sibéria, América Latina ou mar do Norte.

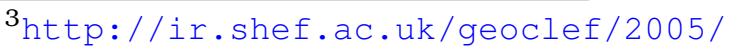




\subsubsection{Modelos de coocorrência com Wikipédia (Overell et al., 2006)}

Overell et al. (2006) exploram métodos para gerar e aplicar modelos de coocorrência no processo de desambiguação de entidades. O sistema proposto pelos autores está dividido em duas etapas:

1. Um conjunto de textos com um indexador geográfico,

2. Mecanismo de consulta em tempo real.

\section{Método}

Na etapa (1) solucionam-se os problemas de ambiguidade, para o qual é aplicado o modelo de coocorrência. Para gerar o modelo de coocorrência foram utilizadas um conjunto de heurísticas que servem para anotar como as localizações geográficas ocorrem na Wikipédia. Esse processo foi nomeado como WikiDisambiguator. O WikiDisambiguator coletou dados da Wikipédia considerando:

- Os links que podem ser classificados como entidades geográficas considerando a ordem em que elas aparecem;

- Links que acredita não podem ser classificados como entidades geográficas, considerando a ordem de aparição;

- Um mapeamento dos artigos da Wikipédia com identificadores únicos providos pelo Getty Thesaurus.

O WikiDisambiguator resolve problemas de sinonímia (várias palavras referenciando à mesma entidade) e homonímia (uma palavra refere-se a varias localizações).

\section{Resultados}

O corpus usado para avaliar o método esta em inglês e considera consultas em inglês. Esse corpus foi obtido do "GeoCLEF 2006". Os resultados mostraram uma melhora nas consultas expandidas e nos documentos que foram extraídos para cada consulta.

\footnotetext{
${ }^{4}$ http://ir.shef.ac.uk/geoclef/2006/
} 


\subsubsection{Extração de informação considerando o foco geográfico (Zubizarreta et al., 2008)}

No trabalho de Zubizarreta et al. (2008) é explorado um método para atribuir um foco geográfico às páginas Web considerando o contexto. Nesse trabalho foram sugeridas varias heurísticas para o processo de desambiguação por topônimos. Os dados são obtidos da Web, extraindo assim dados no formato HTML. Depois da extração, os documentos extraídos são comparados com um dicionário de topônimos. Para tratar as ambiguidades geo/não-geo que pudessem aparecer ao comparar os documentos com o dicionário são aplicados alguns filtros como:

- Remoção dos topônimos que não aparecem com maiúscula;

- Filtro de stop-words;

- Filtro qualificador.

\section{Método}

Depois da extração, os topônimos reconhecidos são organizados como nós em um grafo $k$-partido. Para a criação do grafo são considerados:

- Criação do nó, que adiciona todos os topônimos reconhecidos no texto;

- Criação das arestas, na qual os nós são conectados considerando a distância no texto;

- Poda, na qual cada aresta é verificada com um banco de dados geográfico para remover relações não existentes.

Quando uma localização real é encontrada, os nós são marcados com seus "GeoIDs". Para o processo de desambiguação são usadas uma série de heurísticas:

- Filtro multi caminho, na qual as arestas redundantes são eliminadas e só é conservado o caminho mais longo;

- Desambiguação democrática, na qual localizações coocorrentes servem como evidência para encontrar o sentido de localização correto;

- Atribuição de escores, na qual é usada quando existe um nó com vários possíveis pais, para isso é atribuído um valor que considera a frequência 
no texto e aquele pai com o maior score é considerado como o desambiguado;

- Filtro de população, na qual é escolhida a entidade com maior população.

\section{Resultados}

Para testar a abordagem proposta, os autores usaram o corpus do Open Directory Project $\left(\mathrm{ODP}^{5}\right)$ que contém mais de 1 milhão de páginas marcadas no âmbito geográfico. Além disso, os autores criaram quatro corpus de teste baseados em região geográfica e linguagem:

- Espanha (ES);

- Espanha (ES+EN);

- Reino Unido (EN);

- Estados Unidos (EN).

Nos resultados observou-se um intervalo de confiança de 95\% para a medida de precisão. Os erros foram também classificados e notou-se que $27 \%$ dos erros pertencem à ambiguidade não-geo; as ambiguidades geo/geo representam apenas $13 \%$ dos erros.

\subsubsection{Minimalidade Espacial (Leidner, 2008)}

Em Leidner (2008) é proposto um algoritmo que tenta incrementar o valor da cobertura mantendo um valor de precisão razoável para a localização geográfica dos documentos. Para esse propósito foram criadas duas heurísticas:

1. A heurística conhecida como "um referente por discurso";

2. A heurística de "minimalidade espacial".

A heurística (1) assume que um nome de lugar mencionado no documento refere-se à mesma localização em todo o documento. A heurística (2) assume que quando existe mais de um topônimo mencionado no documento, a menor região que cubra todo o conjunto de topônimos é aquela que da à interpretação.

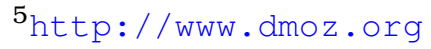




\section{Método}

Neste método, trabalha-se primeiro com os topônimos não ambíguos, os quais são mapeados e um polígono é construído. Depois, cada um dos topônimos ambíguos é mapeado e aquele candidato que pertença ou seja o mais próximo ao polígono é considerado como o topônimo desambiguado. O autor usou técnicas de Aprendizado de Máquina para comparar os resultados com os obtidos pela abordagem dele.

\section{Resultados}

Os experimentos realizados com árvores de decisão mostraram a alta dispersão dos dados e overfitting, o que produz resultados não satisfatórios. É assim que para uma abordagem de Aprendizado de Máquina foi sugerido o uso de um ensemble de classificadores, em que cada classificador participante deve ter um voto para as entidades reconhecidas.

\subsubsection{Estudo dos topônimos e dificuldade de desambiguação (Buscaldi e Magnini, 2010)}

Buscaldi e Magnini (2010) apresentam um estudo sobre os topônimos contidos em um conjunto de notícias italianas para assim determinar o grau de ambiguidade dos topônimos e demostrar como pode ser difícil resolver tais ambiguidades. O conjunto de dados usado consta de artigos da revista L'Adige dos anos 2002 até 2006. Os documentos foram classificados em 11 seções, algumas temáticas como esportes ou internacionais e outras seções dedicadas para regiões específicas. Os documentos foram etiquetados com a ferramenta TextPro (Pianta et al., 2008) que realiza as tarefas de tokenização, divisão de orações, análise morfológica, POS-tagging, Reconhecimento e Classificação de Entidades Mencionadas, entre outras.

\section{Método}

Os autores estudaram como a ambiguidade está distribuída com respeito à frequência. Eles observaram que os topônimos menos frequentes são os que apresentam mais ambiguidade. De forma que a probabilidade de que um topônimo com frequência 100 seja ambíguo é 96\%. Por outro lado, os topônimos com frequência maior a mil tem uma probabilidade de 69\% de serem ambíguos. Observou-se também que os nomes de ruas representam uma alta per- 
centagem de ambiguidade. Foi analisado também o contexto dos topônimos, para isso considerou-se a fonte dos documentos, na qual a revista L'Adige esta localizada em Trento. Foi observado que a maioria de topônimos encontrados nos documentos estavam situados a aproximadamente $400 \mathrm{~km}$ de distância de Trento. Para o processo de desambiguação os autores desenvolveram um método baseado nas caracteristicas geográficas dos topônimos como o descrito em (Smith e Crane, 2001) e incluiram informação sobre a correlação e a frequência dos topônimos ambíguos. Finalmente, foi considerada a distância entre as palavras no texto como a chave para resolver as ambiguidades.

\section{Resultados}

O método que considera a distância das palavras obteve um valor de $88.43 \%$ para a precisão e $88.34 \%$ para a cobertura, já o método que não usa a distância das palavras obteve $88.81 \%$ para a precisão e $88.73 \%$ para a cobertura.

\subsubsection{Abordagem baseada em evidências geográficas e uso da teoria Dempster-Shafer (Xingguang et al., 2010)}

No trabalho de Xingguang et al. (2010) foi proposta uma abordagem baseada em evidências para resolver os problemas de ambiguidade em duas etapas:

1. Calcular a relação semântica entre duas entidades geográficas,

2. Uso da teoria Dempster-Shafer (D-S) para combinar as várias ocorrências de evidências de topônimos.

\section{Método}

Os autores consideraram dois possíveis casos para a desambiguação:

1. Mono evidência;

2. Multi evidências.

No caso da (1) mono-evidência, a forte associação entre objetos geográficos tem um papel significante para determinar a referência exata de um topônimo ambíguo. Por exemplo, a entidade "Huangshan" tem 3 referências: montanha "Huangshan", cidade de "Huangshan" e distrito de "Huangshan", para desambiguar as entidades é considera a entidade "Tianzhunshan" que 
foi mencionada também no documento, para isso calcula-se a relação topológica, semântica e a relação métrica entre todas as entidades ambíguas de "Huangshan" e a entidade não ambígua de "Tianzhunshan". Para os topônimos com (2) multi evidências é usada a teoria D-S que oferece um mecanismo para combinar várias evidências quando dois ou mais topônimos são providos no contexto.

\section{Resultados}

Essa teoria pode ser vista como um modelo de decisão realizado de acordo com as evidências. Infelizmente os autores informaram que a abordagem proposta por eles não deu bons resultados no processo de desambiguação.

\subsubsection{Classificação do texto em categorias geográficas usando a Wikipédia (De Alencar et al. , 2010)}

De Alencar et al. (2010) descrevem algumas estratégias para classificar o texto em categorias geograficamente relacionadas usando como evidência a Wikipédia ${ }^{6}$. A técnica proposta pelos autores não busca usar toda a Wikipédia: ela usa só os títulos e hiperlinks entre as entradas, formado desta forma um grafo da Wikipédia.

\section{Método}

Primeiro é recolhida informação sobre referências de localização da Wikipédia, explorando o grafo formado por links e entidades que referem-se a entidades de interesse. Para cada hiperlink que aponta ou é apontado por uma entidade de lugar é armazenado o título como um termo relacionado às entidades. Depois, é usada uma estratégia que permite obter as características dos termos relacionados com cada entidade, essas características tem associado um valor que é uma estimativa do seu poder discriminativo que pode variar considerando a número de termos associados. Os termos que estão relacionados com menos entidades tem associado um valor maior.

\section{Resultados}

Para testar sua abordagem, os autores usaram o classificador Multinomial Naive Bayes e não incorporaram o modelo proposto por eles no classificador

\footnotetext{
$6_{\text {http: }} / /$ wikipedia.org
} 
obtendo desta forma uma precisão de 92.7\%. Depois, o conjunto de dados passado pelo classificador foi melhorado com o modelo que eles propuseram e rodaram de novo no Multinomial Naive Bayes e a precisão foi de 98\%. Essa melhora demonstrou que ter mais evidência para o processo de classificação melhora os resultados. Para os experimentos foi usado um conjuto de 200 documentos e foram considerados 27 estados brasileiros.

\subsection{Abordagem de Resolução por Ontologia Geográ- fica}

Esta abordagem está baseada no uso de ontologias geográficas como base para obter os conceitos geográficos e as relações. As ontologias geo-espaciais definem classes e indivíduos para representar regiões geográficas, características e as relações entre elas (Jones et al., 2003), (Stuckenschmidt e Van Harmelen, 2004).

Segundo Spaccapietra et al. (2004) a maioria das ontologias existentes não considera as características espaciais e temporais da informação, uma ontologia relacionada ao espaço geográfico difere de outras porque a topologia e os relacionamentos "todo-parte" assumem um papel de destaque no domínio geográfico. O espaço pode participar de uma ontologia de três formas distintas:

1. O espaço é o próprio domínio, descrito por meio de conceitos como os elementos espaciais, tais como ponto, linha e polígono; e os relacionamentos espaciais;

2. O espaço aparece implícito como nas ontologias de domínio geográfico onde as aplicações que lidam com dados geográficos usam o espaço como o local em que elas acontecem, por exemplo, sistema de redes de transporte;

3. O espaço é usado para enriquecer a descrição de conceitos de uma ontologia, descrevendo por exemplo uma localização espacial.

A seguir são apresentados alguns trabalhos relacionados com a área de Resolução de Topônimos em ordem cronológica. 


\subsubsection{OnLocus, uma ontologia de lugar (De Vasconcelos Borges, 2006)}

No trabalho de De Vasconcelos Borges (2006) propõe-se a criação de uma ontologia de lugar denominada OnLocus, que fornece uma estrutura hierárquica e semântica de localização no espaço geográfico urbano e suas interrelações. O objetivo dessa ontologia é auxiliar no processo de extração do contexto geográfico em páginas da Web, possibilitando o reconhecimento e a interpretação de termos referentes a lugares.

OnLocus é considerada como uma ontologia geográfica classificada como uma ontologia de extração e dependente de domínio. OnLocus é considerada uma ontologia de extração por que descreve regras para a identificação dos elementos da ontologia presentes nas páginas da Web como, por exemplo, palavras-chave indicadoras de contexto.

Segundo a classificação de (Stuckenschmidt e Van Harmelen, 2004), OnLocus engloba dois tipos de ontologia: uma ontologia taxonômica e uma descritiva. A ontologia é do tipo taxonômica por que explora a estrutura hierárquica do espaço urbano, na qual as regiões são subdivididas em outras regiões e apresentadas na OnLocus pelo conceito "Divisão Territorial”. A hierarquia é da forma "Cidade, Estado, Região e Pais". Alem disso é também descritiva por conceituar formas de referenciamento a um lugar como feições naturais e pontos de referência que possuem significado de localização.

Além da criação da ontologia de lugar OnLocus, os autores criaram um gazetter digital chamado de Gazetteer do Locus. Esse gazetteer foi projetado para ser uma base de conhecimento sobre locais brasileiros, a ser utilizada no processo de reconhecimento do contexto geográfico em páginas Web. O Gazetteer do Locus implementou conceitos nas classes "Território", "Endereço" e "Referência", que são especializações da classe "Lugar".

\section{Método}

Para o processo de desambiguação são usadas diferentes evidências geoespacias presentes nas páginas Web como, por exemplo, endereço, telefone e código postal. De acordo com o tipo de evidência geo-espacial encontrado nas páginas da Web, somente a combinação com outros tipos definirá com mais certeza se o que foi encontrado é realmente um local ou não. O primeiro elemento reconhecido nas páginas Web são os endereços já que alguns pesquisadores observaram que $20 \%$ das páginas americanas continham endereços 
bem formados. Já para páginas brasileiras mostrou-se que só 10\% das páginas possuem endereços geocodificáveis. Foi observado também que muitos sites de serviços brasileiros omitem o nome da cidade ou estado ao informar um endereço. Nesses casos, o uso de outras evidências como o número de telefone com código de área e o Código de Endereçamento Postal (CEP) são essenciais para saber a exata localização do endereço.

De acordo com a OnLocus, um lugar pode ser reconhecido por meio de:

- Nomes de acidentes geográficos, como Serra do Curral, Praia de Copacabana e Lagoa da Pampulha;

- Nomes das divisões territoriais conhecidas como cidades, estados, regiões do país, regiões dos estados, bairros e regiões administrativas;

- Nomes de logradouros e de locais de referência.

Para evitar falsos positivos e ambiguidades, foram adotadas quatro estratégias no reconhecimento de um endereço:

1. Um número de telefone só é considerado se vier acompanhado do respetivo código de área;

2. Um CEP que não seguir o padrão definido só será considerado se o número vier antecedido pela palavra-chave CEP;

3. Um nome de cidade deve ser sempre seguido do nome ou da sigla de um estado;

4. Todo endereço para ser considerado válido deverá vir acompanhado de um ou mais indicadores de localização (telefone, cidade, estado ou CEP).

\section{Resultados}

Os experimentos realizados pelos autores utilizaram páginas Web brasileiras, entre elas, aquelas que compõem a coleção WBR05 com 4 milhões de páginas. Conisderou-se também os dados armazenados no gazetteer do Locus e o banco de dados geográfico de Belo Horizonte, contendo, além de dados sobre logradouros, bairros, endereços, pontos de referência, divisões administrativas e imagens de $40 \mathrm{~cm}$ de resolução da cidade.

No primeiro experimento de reconhecimento de endereços em páginas da Web, $90 \%$ dos objetos foram localizados exatamente, $8 \%$ foram associados a um número aproximado ou a um ponto de referência e somente $2 \%$ não 
foram localizados devido ao endereço estar incompleto ou pertencer a cidades da região metropolitana de Belo Horizonte. No segundo experimento para avaliar os padrões de extração automática de endereçõs de páginas da Web, $57 \%$ das páginas continham endereços formatados de acordo com algum tipo de padrão. Ao codificar usando o $\mathrm{CEP}, 90 \%$ dos objetos foram localizados exatamente.

\subsubsection{Abordagem baseada em ontologia, gazetteers e WordNet para o processo de desambiguação (Volz et al. , 2007)}

No trabalho de Volz et al. (2007) é apresentada uma abordagem baseada em ontologia para desambiguar as entidades geográficas dos textos. A ontologia define as bases conceituais e é usada para fazer um ranking das características geográficas baseadas em regras de desambiguação que leva em conta a informação estrutural contida na ontologia. A ontologia usada pelos autores incorpora dados extraídos dos gazetteers Geonames e GNIS, assim como também inclui as palavras comuns e conhecimento linguístico obtido da WordNet. A ontologia é usada como gazetteer para mapear as referências para vários candidatos a entidades geográficas ambíguas. A abordagem para desambiguar os dados, lida com três tipos de ambiguidade:

1. Ambiguidade multirreferente, que acontece quando duas localizações geográficas diferentes compartilham o mesmo nome;

2. Ambiguidade de variação de nome, que acontece quando uma mesma localização geográfica tem dois ou mais nomes diferentes;

3. Ambiguidade geo e não-geo, na qual o nome de localização pode também representar alguma outra palavra, como uma pessoa, um substantivo, entre outros. Por exemplo, "Metro" representado como uma cidade na Indonésia, ou "Metro" como um sistema de transporte.

\section{Método}

A abordagem usada para desambiguar estabelece um ranking entre todos os candidatos reconhecidos no texto. São usadas também heurísticas que permitem dar escores às entidades, as quais dão preferência a certos tipos de conceitos na ontologia que outros. Por exemplo, nomes geográficos de cidades predominam sobre nomes geográficos de florestas ou rios. O processo de desambiguação proposta pelos autores envolve três passos: 
1. Procurar candidatos de identificadores geográficos no texto utilizando a ontologia como gazetteer. Neste, o texto é transformado em uma representação de bag-of-words. Depois, são usadas algumas técnicas de Processamento de Língua Natural (PLN) para determinar se os candidatos são pessoas, organizações ou entidades geográficas. Finalmente, a ontologia é usada como gazetter para obter as referências dos candidatos.

2. Redução de candidatos usando a informação textual (desambiguação textual). Neste, é usado o vetor de termos construído no passo anterior e uma janela deslizante de dois termos consecutivos é aplicada. Se algum termo dentro da janela refere-se a alguma característica geográfica ou região administrativa a ambiguidade fica resolvida. Por exemplo, o texto "Paris, França" dá a informação que a entidade Paris refere-se à capital da França.

3. Ranking dos candidatos usando a informação ontológica (desambiguação baseada em ontologia). Neste, os conjuntos de candidatos ambíguos são rankeados utilizando pesos obtidos com a WordNet. Se o peso de um candidato é negativo, o candidato é descartado. Os pesos variam dependendo das características das entidades, tais como população, capitais, ou entidades que repetem-se muito no texto.

\section{Resultados}

Para a avaliação dos resultados os autores construíram dois corpus baseados no corpus Reuters2 1578.

- Corpus 1, que conta com 250 documentos anotados à mão com todas as referências geográficas.

- Corpus 2, que conta com 100 documentos anotados à mão com um país de referência que identifica o foco do documento.

No primeiro experimento não foram usados os pesos da WordNet e obtevese uma precisão de $40 \%$ e uma cobertura de $86 \%$. No segundo experimento, foram usados todos os termos WordNet para atribuir pesos. Nesse experimento obteve-se $70 \%$ para precisão e $87 \%$ para cobertura. Finalmente, no terceiro experimento experimentou-se a sensitividade e precisão dos pesos das entidades populadas e o WordSenses da WordNet. Nessas configurações obitveram-se $68 \%$ de precisão e $87 \%$ de cobertura. 


\subsubsection{Densidade Conceitual da WordNet (Buscaldi e Rosso, 2008)}

No trabalho de Buscaldi e Rosso (2008) é apresentado um método de desambiguação baseado na densidade conceitual (DC) da WordNet. A DC é uma medida de correlação entre o sentido de uma determinada palavra e o contexto. Essa medida é computada considerando as sub-hierarquias da WordNet.

\section{Método}

O algoritmo de desambiguação consiste em:

- Selecionar a próxima palavra ambígua $w \operatorname{com}|\mathbf{w}|$ sentidos;

- Selecionar o contexto, por exemplo, uma sequência de palavras de $w$;

- Construir $|\mathrm{w}|$ sub-hierarquias, uma para cada sentido de w;

- Para cada sentido $s$ de uma palavra $w$, calcular a DC;

- Atribuir a $w$ o sentido que maximize a DC.

As sub-hierarquias construídas consideram relações de homonímia já que as hierarquias permitem discernir diferentes localizações (que tem o mesmo nome) em uma forma mais efetiva.

\section{Resultados}

Os autores usaram o corpus "GeoSemCor" e obtiveram 94.7\% de precisão e $74.2 \%$ de cobertura, considerando o documento como contexto. Os autores detectaram algumas situações críticas na qual o DC não pode ser computado. Isso acontece quando um nome de lugar, por exemplo "New York" é usado para referir-se à cidade e ao estado. Como os dois sentidos pertecem a uma mesma sub-hierarquia não é permitido a atribuição de um único sentido para "New York".

\subsubsection{Extração de conhecimento geográfico (Campelo e Bap- tista, 2009)}

No trabalho de Campelo e Baptista (2009) é apresentado um protótipo chamado GeoSEn que permite detectar as referências geográficas em documentos

\footnotetext{
${ }^{7}$ http://users.dsic.upv.es/ dbuscaldi/resources/geosemcor2.0.tar.gz
} 
Web baseados em um conjunto de heurísticas. O GeoSEn foi desenvolvido como uma extensão do "Framework Apache Nucth" ${ }^{8}$ com capacidade para manipular e extrair informação geográfica. Para isso, foram implementados os seguintes plugins:

1. Parser, que é responsável por detectar os termos geográficos;

2. Filtro indexador, que adiciona ao índice a informação no escopo geográfico;

3. Filtro de consultas, toma em consideração a informação do escopo geográfico;

4. Filtro de URL, que oferece diferentes maneiras de detectar referências geográficas e relações espaciais com as URLs associadas.

\section{Método}

O processo de detecção de referências geográficas está baseado em um conjunto de heurísticas. Cada referência detectada é associada a um fator de confiança. Esse valor está composto por um peso associado a cada heurística. As referências com fator de confiança menor que um valor de threshold são eliminadas. Foi também considerado uma hierarquia da forma "Cidade, estado, região e país”. Cada localização contida em um documento é associada a um valor que é usado para a geração de um ranking de relevância.

A taxa de confiança é atribuída para os termos geográficos detectados. A taxa é definida como:

- Taxa de Confiança, que representa a probabilidade dessa referência ser um lugar válido e está entre 0 e 1 . Se mais de um nome de lugar é detectado, por exemplo, Londres na Inglaterra e Londres no Canadá, o valor de confiança é computado para cada lugar e aquele com o maior valor é selecionado como o desambiguado. O valor de confiança é calculado usando os valores das entidades conhecidas como fator de confiança;

- Fator de confiança, que é uma medida associada a cada característica analisada. O uso desta medida pode variar de acordo com o local, nos quais o termo aparece no texto, por exemplo, título, corpo e URL;

- Modificador de Confiança, que é usado quando uma referência está relacionada muitas vezes com outra característica do mesmo tipo;

$8_{\text {http: / / lucene.apache.org/nutch }}$ 
- Termos Especiais que são termos que podem incrementar a confiança que a entidade selecionada refere-se a uma entidade geográfica. Por exemplo, "cidade de Londres";

- Extração de confiança da busca textual, que é um processo que associa um nome de lugar com uma probabilidade do termo se referir a uma localização;

- Referências cruzadas, que são as referências geográficas encontradas no texto que podem ter relação com as outras referências e assim ajudar no processo de desambiguação. Por exemplo, no texto encontra-se a entidade ambígua "Atalaia" que refere-se a duas cidades do Brasil, uma no Nordeste e outra no Sul. Nesse mesmo texto encontra-se também a entidade "Alagoas", porém existe uma maior probabilidade que a entidade "Atalaia" do Nordeste seja a entidade desambiguada ao estar relacionada indiretamente com a entidade "Alagoas", localizada também no Nordeste.

O valor de confiança é computado somando cada fator de confiança associado a uma referência, de acordo com sua importância.

\section{Resultados}

Para avaliar os resultados o sistema GeoSEn foi executado usando uma coleção de 50 documentos previamente selecionados. Os resultados mostraram:

- $71 \%$ das referências válidas foram corretamente detectadas;

- 92\% das referências inválidas foram corretamente ignoradas;

- Entre as referências que foram corretamente detectadas e não havia ambiguidade, $84 \%$ foram processadas corretamente pelo desambiguador.

- Entre os $23 \%$ das referências ignoradas incorretamente, $65 \%$ têm os nomes de lugar detectados por outras referências no mesmo documento.

Os resultados mostraram que o mecanismo proposto tem uma boa eficácia, principalmente quando se observa a eliminação das referências inválidas e a resolução dos problemas de ambiguidade. 


\subsubsection{Relações arborescentes entre topônimos calculando a Den- sidade Geográfica (DG) da WordNet (Bensalem e Kholladi, 2010)}

No trabalho de Bensalem e Kholladi (2010) é apresentada uma nova heurística para o processo de desambiguação de topônimos a qual está baseada na quantificação da proximidade arborescente entre topônimos. Essa quantificação foi feita usando uma medida proposta pelos autores e nomeada como Densidade Geográfica (DG). A heurística proposta está baseada no contexto e em como o trabalho de Buscaldi e Rosso (2008) usa a hierarquia obtida da WordNet como fonte primária para o processo de desambiguação. Neste tipo de heurística pressupõe-se a existência de uma certa proximidade geográfica entre os topônimos referidos ao mesmo contexto. Em uma forma hierárquica podem se distinguir dois tipos de relações arborescentes:

- Relações hierárquicas;

- Relações não hierárquicas.

As relações hierárquicas existem entre componentes do mesmo ramo na árvore, por exemplo, as relações entre país e cidade. As relações não hierárquicas existem entre os nós dos diferentes ramos mas que tem um pai em comum, por exemplo, a cidade de "Sevilla" e a cidade de "Cordoba" tem como pai comum o estado de "Andalusia" na Espanha. Existem dois tipos de relações hierárquicas:

- Meronímia, que são as relações "parte-de”;

- Homonímia, que são as relações "faz-parte".

A heurística dos autores está baseada na suposição que os topônimos que aparecem juntos no mesmo documento estão geograficamente relacionados com relações arborescentes.

\section{Método}

O processo de desambiguação consiste em:

1. Extrair todos os topônimos de um documento D,

2. Eliminação dos topônimos repetidos, 
3. Determinar uma lista de candidatos para cada topônimo, esses candidatos devem estar representados na forma hierárquica,

4. Calcular a densidade geográfica (DG) de cada candidato,

5. Atribuir a cada candidato a máxima densidade geográfica.

O valor da DG aumenta quando:

- O candidato apresenta relações de homonímia com outros candidatos,

- As relações de homonímia são também relações de homonímia de outros candidatos,

- As relações de homonímia herdadas pertencem parcial ou totalmente ao contexto.

\section{Resultados}

Para avaliar seu método os autores usaram o corpus "GeoSemCor". Esse corpus contém 123 documentos, que por sua vez, têm 1210 topônimos, 498 topônimos ambíguos e 9.84 topônimos por documento aproximadamente. O trabalho foi comparado com o métodos proposto por Buscaldi e Rosso (2008). O novo método dos autores obteve $88.2 \%$ de precisão versus $94.7 \%$ obtida no trabalho de Buscaldi e Rosso (2008), e 87.4\% de cobertura versus $74.2 \%$.

\subsubsection{Desambiguação de Topônimos usando eventos (Roberts et al. , 2010)}

Roberts et al. (2010) apresentam um método que leva em consideração que uma estrutura de eventos contribui com o entendimento da correta localização das entidades.

\section{Método}

- Foi construída uma ontologia que considera todas as entidades geo-políticas (GPE) do planeta, mas foram omitidos alguns continentes e regiões arbitrárias;

- A ontologia GPE baseada em três níveis considerando a Terra como raiz, depois são considerados os países, estados e localidades;

- Para popular a ontologia foi usado o gazetteer Geonames ${ }^{9}$. A ontologia $9_{\text {http }}$ //geonames.org/ 
considera coordenadas geográficas, dados de população e nomes alternativos incluindo acrônimos, nicknames e pronuncias em linguagens diferentes do inglês.;

- Foi construída também uma ontologia de eventos que considera a evidência que duas entidades participaram no mesmo evento como um forte indicador de relação entre os participantes.

- Para a construção da ontologia de eventos foram considerados três tipos de entidades que podem participar dos eventos: pessoas, organizações e localizações GPE;

- Utiliza-se a ontologia populada com o gazetteer e depois são usados os links da Wikipédia para enlaçar pessoas e organizações as localizações GPE que estão relacionadas. Por exemplo, na frase "O político Ward Armstrong não apareceu para a reunião”, as entidades estarão enlaçados com Roanoke (lugar de nascimento), Estados Unidos, Collinsville (lugar onde ele morou), e Caroll County (o distrito que ele representa). Guando as pessoas e organizações são mapeadas da Wikipédia é assumido que não é necessário fazer uma desambiguação.

Para detectar a correta localização geográfica de uma entidade mencionada no texto usam-se três etapas:

1. Encontrar os topônimos de lugar,

2. Extrair todos os candidatos para o topônimo das entradas do gazetteer,

3. Desambiguar as entradas do gazetteer para determinar a localização correta e normalizada do topônimo.

\section{Resultados}

Para comparar o desempenho do sistema baseado em eventos com a ontologia geográfica os autores testaram quatro hipóteses:

- H1:“Desambiguação plana”, que não usa informação da ontologia geográfica;

- H2:"Probabilidade de transição de ontologia”, a qual determina um ranking para determinar os caminhos mais prováveis por meio da ontologia para desambiguar os candidatos. Constrói-se também uma árvore de atribuição para cada candidato, que é um subgrafo da ontologia; 
- H3: “Transição de ontologia e probabilidade dos nós”, o qual melhora as árvores de atribuição gerados em (2). Por exemplo, em (2) a entidade New York pode-se referir ao estado ou a cidade. Nesta hipótese o estado de New York sempre sera escolhido sobre a cidade de New York por que o nó filho tem uma menor probabilidade de ser a entidade correta. Nesta hipótese combinam-se as probabilidades do eixo e do nó para não ter casos como o mencionado no exemplo anterior;

- H4:“Ontologia de Eventos e Probabilidade de Nós”, usa o método proposto pelo autor, no qual cada evento no documento representado pela árvore de atribuição A é extraído e colocado em sua própria árvore de atribuição.

Nesse trabalho foi utilizado também o corpus SpatialML que contem 428 documentos manualmente marcados e foram reconhecidos 6,337 anotações de lugar. Para detectar as entidades do tipo pessoa e organização foi usado o "BIOS named entity tagger ${ }^{10 " . ~ P a r a ~ d e t e c t a r ~ o s ~ e v e n t o s ~ f o i ~ u s a d o ~ o ~ s i s t e m a ~}$ descrito por (Bejan, 2007). Para avaliar o processo de desambiguação são consideradas duas métricas:

- Precisão, que mede o número de topônimos corretamente resolvidos,

- Escore Ontológico, que assume que as respostas erradas que tem pelo menos uma parte da resposta correta são melhores que aqueles que não reconhecem nenhuma parte da resposta correta. Por exemplo, se a resposta correta fosse "Henry County, Virginia, USA", a respostas incorreta mas consideradas como parcialmente corretas seria "Henry, Georgia, USA".

A hipótese $\mathrm{H} 4$ apresentou os melhores valores de precisão com $93.57 \%$ sobre $92.35 \%$ para $\mathrm{H} 3,87.85 \%$ para $\mathrm{H} 2$ e $92 \%$ para H1. Para a métrica de escore ontológico a hipótese $\mathrm{H} 4$ também apresentou os melhores resultados de precisão de $94.83 \%$ sobre $94.72 \%$ para $\mathrm{H} 3,92.08 \%$ para $\mathrm{H} 2$ e $93.27 \%$ para $\mathrm{H} 1$.

\subsubsection{Gazetteer Ontológico para Recuperação de Informação Geográfica (Ribeiro Machado, 2011)}

No trabalho de Ribeiro Machado (2011) é apresentado um método que permite gerar um gazetteer que inclui elementos como relacionamentos espaciais, conceitos e termos relacionados formando assim uma ontologia geográfica. O

\footnotetext{
10http://www. surdeanu.name/mihai/bios/
} 
gazetteer ontológico é denominada como "OntoGazetteer", e fornece suporte semântico para resolver vários problemas comuns na Recuperação de Informação Geográfica. Inicialmente é estabelecida uma correspondência direta entre as estruturas de uma ontologia e os elementos necessários para um gazetter como apresentado na Tabela 3.1.

Tabela 3.1: Correspondência entre ontologia e elementos do gazetteer (Ribeiro Machado, 2011)

\begin{tabular}{|c|c|c|c|}
\hline $\begin{array}{l}\text { Relacionamento } \\
\text { ontológico }\end{array}$ & Definição & $\begin{array}{l}\text { Equivalente no gazet- } \\
\text { teer }\end{array}$ & Exemplo \\
\hline Sinonímia & $\begin{array}{l}\text { Um termo } X \text { tem } \\
\text { quase o mesmo sig- } \\
\text { nificado que o termo } \\
Y\end{array}$ & $\begin{array}{ll}\text { Nomes } & \text { alternativos, } \\
\text { apelidos, nomes his- } \\
\text { tóricos, abreviações, } \\
\text { variações de grafia }\end{array}$ & $\begin{array}{l}\text { Belo Horizonte: BH, Belô, } \\
\text { B. Horizonte, Cidade de } \\
\text { Minas }\end{array}$ \\
\hline Homonímia & $\begin{array}{l}\text { O termo } X \text { tem a } \\
\text { mesma grafia que o } \\
\text { termo Y, porém tem } \\
\text { significado diferente }\end{array}$ & $\begin{array}{l}\text { Nomes ambíguos: lu- } \\
\text { gares com nomes coin- } \\
\text { cidentes, lugares com } \\
\text { nomes de outra coisa }\end{array}$ & $\begin{array}{l}\text { São Paulo (município) e } \\
\text { São Paulo (time de fute- } \\
\text { bol); município de Viçosa } \\
\text { (MG) e Viçosa (AL); Vitória } \\
\text { (ES) e o substantivo vitó- } \\
\text { ria }\end{array}$ \\
\hline Hiperonímia & $\begin{array}{l}\text { Um termo X tem sig- } \\
\text { nificado mais amplo } \\
\text { do que o termo Y }\end{array}$ & $\begin{array}{l}\text { Lugar em nivel supe- } \\
\text { rior em uma hierarquia } \\
\text { espacial }\end{array}$ & $\begin{array}{l}\text { Minas Gerais em relação a } \\
\text { Belo Horizonte }\end{array}$ \\
\hline Hiponímia & $\begin{array}{l}\text { Um termo X tem sig- } \\
\text { nificado mais res- } \\
\text { trito do que o termo } \\
\mathrm{Y}\end{array}$ & $\begin{array}{l}\text { Lugar em nível inferior } \\
\text { em uma hierarquia es- } \\
\text { pacial }\end{array}$ & $\begin{array}{l}\text { Bacia do Rio Tietê em rela- } \\
\text { ção a bacia do Rio Paraná }\end{array}$ \\
\hline Associação & $\begin{array}{l}\text { O termo X está as- } \\
\text { sociado a um termo } \\
\text { Y, isto é, existe um } \\
\text { relacionamento se- } \\
\text { mântico entre eles }\end{array}$ & $\begin{array}{l}\text { Relacionamento se- } \\
\text { mântico entre lugares }\end{array}$ & $\begin{array}{l}\text { Municípios ao longo da } \\
\text { BR-040; Municípios pro- } \\
\text { dutores de soja; rios da } \\
\text { Amazônia; cidades histó- } \\
\text { ricas }\end{array}$ \\
\hline
\end{tabular}

O "OntoGazetteer" permite modelar diversas representações geográficas para os lugares como área ou Polígono, Ponto e Linha. Todos os nomes de lugares estão armazenados na classe Lugar. A classe Lugar_alternativo mantém nomes alternativos, abreviaturas, siglas, entre outras variações para os nomes de lugar. Cada lugar pertence a um tipo de lugar representado pela classe Tipo_Lugar. Os diversos relacionamentos entre dois lugares são armazenados na classe Relacionamento_Geo. É considerado também a possibilidade que dois lugares possam ter vários relacionamentos entre eles, diferenciado pelo tipo, e representado pela classe Tipo_Relacionamento_Geo. A desambiguação de nomes é apoiada pela classe Nome_Ambiguo, que mantém nomes ambíguos já conhecidos. A classe Lugar mantém um atributo para a URL que é a entrada da entidade na Wikipédia. Finalmente, cada lugar pode 
ter uma ou mais representações geográficas pelas classes Ponto, Linha ou Polígono.

A construção do banco de dados buscou abranger dados do Brasil como um todo até o nivel de bairros. Diversas fontes de dados geográficos foram usadas, como o Instituto Brasileiro de Geografia e Estatística (IBGE), o gazetteer da Alexandria Digital Library (ADL), dados do projeto GeoMinas, da prefeitura de Belo Horizonte, da Wikipédia, do gazetteer do Locus, Centro de Análises de Sistemas Navais (CASNAV), entre outras prefeituras.

\section{Método}

Após a coleta de notícias, é realizado um pré-processamento dos documentos, no qual foram retiradas as stopwords exceto "de”, "da(s)”, "do(s)”, que são muito comuns para nomes de entidades brasileiras. Ainda na etapa de préprocessamento os termos candidatos a nomes de lugares são extraídos dos documentos usando expressões regulares para identificar nomes próprios, compostos ou não. O reconhecimento e identificação do tipo dos nomes de lugares encontrados nos documentos foi apoiada pelo "OntoGazetteer", realizando um casamento entre os termos candidatos, os nomes de lugares e os nomes de lugares alternativos presentes no gazetteer. O processo de desambiguação consta de uma série de passos detalhados a seguir:

1. Identificação de nomes ambíguos e não ambíguos;

2. Identificação de indicadores de localidade, ou seja, nomes de tipo de lugar no texto que geralmente antecedem o nome de lugar, por exemplo, "bairro" eldorado;

3. Uso de informações sobre os relacionamentos entre lugares do "OntoGazetter", na qual todas as relações entre os nomes de lugar candidatos são recuperados, armazenados e usados para a construção de um grafo de relacionamento entre os lugares, sendo que os lugares são os nós e os relacionamentos são os vértices. Os relacionamentos entre os nomes ajudam na desambiguação da seguinte forma: um relacionamento fraco entre um nome de lugar com os outros elementos encontrados no mesmo texto podem indicar um termo ambíguo e ser desconsiderado;

4. O "OntoGazetter" mantém informação sobre as hierarquias espacias e lugares adjacentes para inferir a coocorrência de lugares relacionados e desconsiderar outros nomes de lugares candidatos; 
5. O contexto de um documento pode se referir a algum nível superior da hierarquia espacial, por exemplo, um texto que menciona várias cidades em um mesmo estado, tem como contexto real o próprio estado;

6. A desambiguação de nomes também pode ser feita com o usa das listas de nomes de lugares ambíguos, nomes alternativos e termos relacionados. Essas listas são usadas como apoio para as heurísticas que estabelecem qual dos nomes de lugares ambíguos é o mais provável para um determinado texto.

Depois de efetuar o processo de desambiguação um determinado nome de lugar será escolhido como o correto se for aquele com o maior número de relações com os outros lugares.

\section{Resultados}

Após executar os processo de reconhecimento e desambiguação de nomes de lugares na coleção de notícias coletadas, a avaliação do processo foi realizada por meio de uma verificação manual da taxa de sucesso. A coleção inicialmente contava com 160 notícias das quais 152 tiveram nomes de lugares identificados e 128 tinham nomes de lugar ambíguos. Os resultados mostraram que 346 nomes de lugares foram analisados, e $82 \%$ foram avaliados como desambiguados corretamente.

\subsubsection{Desambiguação de topônimos por uma ontologia em es- panhol (López et al. , 2012)}

O método proposto por López et al. (2012) usa uma ontologia de domínio para os países que falam espanhol. A metodologia proposta está baseada na proximidade geográfica entre os topônimos no mesmo contexto, usando relações hierárquicas providas pela ontologia e um peso associado que é complementado pela distância Haversine. A ontologia construída pelos autores considera as seguintes classes principais: Divisão_territorial dos níveis 1 até 4, Continente, País e Abreviação.

\section{Método}

O processo de desambiguação proposto pelos autores considera os seguintes passos: 
1. Carga do contexto e pré-processamento;

2. Busca por nomes na estrutura da ontologia para determinação da ambiguidade;

3. Busca por relações hierárquicas e não hierárquicas;

4. Aplicação de um peso ontológico hierárquico;

5. Cálculo de um peso adicional, conhecido como a distância Haversine.

Uma vez que todos os topônimos foram encontrados, é realizada uma busca para cada elemento na ontologia. Se foi encontrada mais de uma referência, então estabelece-se a hipótese que a entidade é ambígua no contexto. Quando os topônimos ambíguos foram identificados,buscam-se relações do tipo: "tem-parte", "é-parte-de" e relações entre irmãs usando a SPARQL. Após, comparam-se as relações hierárquicas e não hierárquicas dos topônimos considerando a proximidade geográfica no mesmo contexto. Finalmente, os topônimos aumentam seu peso baseados na distância Haversine, esta fórmula ajuda a calcular a distância do círculo formado entre dois pontos no globo baseados na longitude e latitude.

\section{Resultados}

A ontologia foi a base dos experimentos dos autores já que a ontologia tem a vantagem de ter uma estrutura que pode ser consultada considerando a semântica e não só palavras-chave. Os autores apresentaram estatísticas da coleção de documentos. Na qual existem 2352 topônimos, 672 topônimos ambíguos e 200 contextos analisados.

\subsection{Síntese de trabalhos relacionados}

O problema da ambiguidade é um problema base pesquisado geralmente nas áreas de Processamento da Língua Natural, Mineração de Textos e outras áreas que tenham que fazer uma análise profunda dos textos. Neste trabalho são tratadas as ambiguidades geográficas, isto é aquelas palavras cujos nomes representam locais geográficos. Na literatura existem muitos trabalhos que abordam o problema da ambiguidade de topônimos e tentam resolver de diferentes formas e métodos. As formas mais comuns para resolver ambiguidade usam elementos externos tais como Gazetteers, Sistemas de Informação 
Geográficos, Wikipédia, Ontologias geográficas, entre outras. Nesta seção os trabalhos foram divididos entre aqueles que fazem uso de ontologias geográficas e aqueles que usam gazetteers ou a Wikipédia como elemento externo de informação.

Na Tabela 3.2, é apresentada uma síntese dos trabalhos baseados na resolução de topônimos fazendo uso de gazetteers ou elementos como a Wikipédia e na Tabela 3.3 apresenta-se uma síntese dos trabalhos que usam ontologias geográficas como base.

\begin{tabular}{|c|c|c|}
\hline Referência & Abordagem & Descrição \\
\hline $\begin{array}{l}\text { (Smith e Crane, } \\
\text { 2001) }\end{array}$ & $\begin{array}{l}\text { Baseado em } \\
\text { mapas }\end{array}$ & $\begin{array}{l}\text { - Atualização dos centroides das entidades; } \\
\text { - Cada entidade tem um escore baseado na distância } \\
\text { espacial de um topônimo ambíguo a um topônimo } \\
\text { selecionado; } \\
\text { - Interpretações de país tem maior peso que cidades; } \\
\text { - CoRPUS: Corpus históricos de Grécia, Roma antiga, } \\
\text { Londres e documentos do Congresso de Califórnia e } \\
\text { Centro-Oeste americano. }\end{array}$ \\
\hline (Yi et al., 2006) & Gazetteers & $\begin{array}{l}\text { - Uso de gazetteer e thesauro para atribuir } \\
\text { probabilidade inicial; } \\
\text { - Considera informações como contexto, população, } \\
\text { palavras-chave geográficas para aumentar a } \\
\text { probabilidade; } \\
\text { - CoRPUS: TdBaseline, como o corpus base que } \\
\text { não usa resolução de topônimos; TdGeoDexp e; } \\
\text { TdGeoQexp. }\end{array}$ \\
\hline $\begin{array}{l}\text { (Overell et al., } \\
2006 \text { ) }\end{array}$ & Wikipédia & $\begin{array}{l}\text { - Utiliza-se um Modelo de Coocorrência (MC) das } \\
\text { palavras; } \\
\text { - Para gerar o MC foram usadas heurísticas para } \\
\text { anotar as localizações geográficas que ocorrem na } \\
\text { Wikipédia; } \\
\text { - Consideraram-se os enlaces que acredita-se sejam } \\
\text { entidades geográficas, enlaces que não são entidades } \\
\text { geográficas e um mapeamento de artigos da } \\
\text { Wikipédia; } \\
\text { - CORPUS: Foi obtido do GeoCLEF 2006, mas não é } \\
\text { especificado o nome. }\end{array}$ \\
\hline
\end{tabular}


Tabela 3.2 - Continua da página anterior

\begin{tabular}{|c|c|c|}
\hline Referência & Abordagem & Descrição \\
\hline (Leidner, 2008) & Gazetteer & $\begin{array}{l}\text { - Mapeiam-se os topônimos não ambíguos; } \\
\text { - Constrói-se um polígono entre os topônimos não } \\
\text { ambíguos; } \\
\text { - Mapeiam-se um dos topônimos ambíguos por vez; } \\
\text { - Seleciona-se como desambiguado aquele topônimo } \\
\text { que pertença ao polígono ou seja o ponto mais perto; } \\
\text { - CORPUS: Reuters-21578. }\end{array}$ \\
\hline $\begin{array}{l}\text { (Xingguang } \\
\text { et al., 2010) }\end{array}$ & Gazetteer & $\begin{array}{l}\text { - Calcula-se a relação semântica entre duas entidades } \\
\text { geográficas; } \\
\text { - Utiliza-se a teoria Dempster-Shafer para combinar as } \\
\text { várias ocorrências de evidencias de topônimos; } \\
\text { - CORPUS: Não reportado. }\end{array}$ \\
\hline $\begin{array}{l}\text { (Zubizarreta } \\
\text { et al., 2008) }\end{array}$ & Heurísticas & $\begin{array}{l}\text { - Extraem-se os candidatos e organiza-se na forma de } \\
\text { grafo } k \text {-partido; } \\
\text { - Cada aresta representa a distância no texto; } \\
\text { - Verifica-se cada aresta para eliminar relações não } \\
\text { existentes; } \\
\text { - Utilizam-se heurísticas de filtro multi caminho, } \\
\text { desambiguação democrática, atribuição de escores e } \\
\text { filtro de população; } \\
\text { - CoRPUS: Open Directory Project (ODP), e os autores } \\
\text { criaram os corpus Espanha(ES), Espanha (ES+EN), } \\
\text { Reino Unido(EN) e Estados Unidos (EN). }\end{array}$ \\
\hline $\begin{array}{l}\text { (Buscaldi e } \\
\text { Magnini, 2010) }\end{array}$ & Gazetteer & $\begin{array}{l}\text { - Os topônimos menos frequentes representam mais } \\
\text { ambiguidade; Os topônimos tendem a estar } 400 \mathrm{~km} \\
\text { de distância da fonte do documento; } \\
\text { - Desenvolveu-se um método que usa as características } \\
\text { geográficas, informação sobre a correlação dos } \\
\text { topônimos ambíguos e a frequência; } \\
\text { - Considera-se como a chave para resolver as } \\
\text { ambiguidades a distância entre as palavras no texto; } \\
\text { - CORPUS: SpatialML. }\end{array}$ \\
\hline
\end{tabular}

Continuação na página seguinte 
Tabela 3.2 - Continua da página anterior

\begin{tabular}{|c|c|c|}
\hline Referência & Abordagem & Descrição \\
\hline $\begin{array}{l}\text { (De Alencar } \\
\text { et al., 2010) }\end{array}$ & $\begin{array}{l}\text { Dirigido a da- } \\
\text { dos / Wikipé- } \\
\text { dia }\end{array}$ & $\begin{array}{l}\text { - Recolhe-se a informação sobre referências de } \\
\text { localização da Wikipédia, formando um grafo de } \\
\text { links; } \\
\text { - Para cada link ou hiperlink que é apontado por uma } \\
\text { entidade de interesse, armazena-se o título como um } \\
\text { termo relacionado; } \\
\text { - Obtém-se as características dos termos relacionados } \\
\text { com cada entidade; } \\
\text { - Os termos que estão relacionados com menos } \\
\text { entidades tem um peso maior, o qual serve para fazer } \\
\text { um ranking; } \\
\text { - CoRPUs: Não reportado. }\end{array}$ \\
\hline
\end{tabular}

Tabela 3.2: Síntese dos trabalhos baseados na resolução de topônimos fazendo uso de gazetteers, a Wikipédia ou na WordNet

\begin{tabular}{|c|c|c|}
\hline Referência & Abordagem & Descrição \\
\hline $\begin{array}{ll}\text { (De } & \text { Vascon- } \\
\text { celos } & \text { Borges, } \\
2006) & \end{array}$ & Ontologia & $\begin{array}{l}\text { - Uso de evidências geográficas como endereço, } \\
\text { telefone e código postal; } \\
\text { - Extração e reconhecimento de evidências geográficas } \\
\text { em páginas Web; } \\
\text { - Consideram-se quatro heurísticas para evitar falsos } \\
\text { positivos e ambiguidades no reconhecimento de um } \\
\text { endereço; } \\
\text { - CORPUS: Páginas Web brasileiras da coleção WBR05. }\end{array}$ \\
\hline $\begin{array}{l}\text { (Volz et al., } \\
2007)\end{array}$ & $\begin{array}{l}\text { Gazetteers e } \\
\text { WordNet }\end{array}$ & $\begin{array}{l}\text { - Procura de candidatos usando a ontologia como } \\
\text { gazetteer; } \\
\text { - Redução de candidatos usando a desambiguação } \\
\text { textual; } \\
\text { - Ranking dos candidatos usando os pesos obtidos da } \\
\text { WordNet; } \\
\text { - CORPUS: Reuters-21578. }\end{array}$ \\
\hline $\begin{array}{l}\text { (Buscaldi e } \\
\text { Rosso, 2008) }\end{array}$ & WordNet & $\begin{array}{l}\text { - Seleciona-se a palavra ambígua e identificam-se } \\
\text { todos os sentidos; } \\
\text { - Seleciona-se o contexto; } \\
\text { - Constrói-se uma sub-hierarquia para cada sentido e } \\
\text { calcula-se a Densidade Conceitual (DC); } \\
\text { - Atribui-se à palavra o sentido que maximize a DC; } \\
\text { - coRPus: GeoSemCor. }\end{array}$ \\
\hline
\end{tabular}


Tabela 3.3 - Continua da página anterior

\begin{tabular}{|c|c|c|}
\hline Referência & Abordagem & Descrição \\
\hline $\begin{array}{l}\text { (Campelo e } \\
\text { Baptista, 2009) }\end{array}$ & $\begin{array}{l}\text { Ontologia e } \\
\text { Heurísticas }\end{array}$ & $\begin{array}{l}\text { - Cada referência detectada é associada a um Fator de } \\
\text { Confiança (FC); } \\
\text { - As referências cujo (FC) seja menor que um threshold } \\
\text { são eliminadas; } \\
\text { - Considera-se a hierarquia da forma cidade, estado, } \\
\text { região e país; } \\
\text { - Cada localização contida em um documento é } \\
\text { associada a um valor que serve para construir um } \\
\text { ranking; } \\
\text { - CORPUS: Não reportado. }\end{array}$ \\
\hline $\begin{array}{l}\text { (Bensalem e } \\
\text { Kholladi, 2010) }\end{array}$ & WordNet & $\begin{array}{l}\text { - Determina-se uma lista de candidatos para cada } \\
\text { topônimo e calcula-se a Densidade Geográfica; } \\
\text { - Atribui-se a cada candidato a máxima densidade } \\
\text { geográfica considerando um conjunto de heurísticas; } \\
\text { - CORPUS: GeoSemCor. }\end{array}$ \\
\hline $\begin{array}{l}\text { (Roberts et al., } \\
\text { 2010) }\end{array}$ & $\begin{array}{l}\text { Ontologia, } \\
\text { Gazetteer } \\
\text { Wikipédia }\end{array}$ & $\begin{array}{l}\text { - Constrói-se uma ontologia hierárquica das entidades } \\
\text { geo-políticas (GPE), e consideram-se os niveis de } \\
\text { Terra, país, estado e localidade; } \\
\text { - Constrói-se uma ontologia de eventos; } \\
\text { - Utilizam-se os links da Wikipédia para ligar a } \\
\text { ontologia de eventos com a ontologia GPE; } \\
\text { - CORPUS: SpatialML. }\end{array}$ \\
\hline $\begin{array}{l}\text { (Ribeiro Ma- } \\
\text { chado, 2011) }\end{array}$ & $\begin{array}{l}\text { Gazetteer e } \\
\text { Ontologia }\end{array}$ & $\begin{array}{l}\text { - Identificam-se os nomes ambíguos e não ambíguos; } \\
\text { - Identificam-se indicadores de localidade, por } \\
\text { exemplo, bairro ou cidade; } \\
\text { - Utiliza-se informações sobre os relacionamentos de } \\
\text { todas as entidades e constrói-se um grafo; } \\
\text { - Seleciona-se a entidade com maior número de } \\
\text { relações com outros lugares; } \\
\text { - CORPUS: Não reportado. }\end{array}$ \\
\hline $\begin{array}{l}\text { (López et al., } \\
2012 \text { ) }\end{array}$ & Ontologia & $\begin{array}{l}\text { - Reconhecimento do contexto e pré-processamento } \\
\text { dos documentos; } \\
\text { - Pesquisa-se as relações hierárquicas e não } \\
\text { hierárquicas dos topônimos reconhecidos; } \\
\text { - Para cada topônimo, aplica-se um peso de acordo } \\
\text { com seu nivel ontológico; } \\
\text { - Calcula-se um peso adicional usando a distância } \\
\text { Haversine; } \\
\text { - CORPUS: Não reportado. }\end{array}$ \\
\hline
\end{tabular}


Tabela 3.3 - Continua da página anterior

\begin{tabular}{l|l|l}
\hline Referência & Abordagem & Descrição \\
\hline
\end{tabular}

Tabela 3.3: Síntese dos trabalhos baseados na resolução de topônimos fazendo uso de ontologias geográficas

\subsection{Considerações Finais}

Neste capítulo foram apresentados os trabalhos relacionados com a área de estudo. Observou-se que os problemas de ambiguidade podem ser separados em três tipos: (i) baseados em mapas, (ii) baseados em conhecimento e (iii) supervisionados. O foco deste trabalho foi explorar a desambiguação baseada em conhecimento. Dentro da abordagem baseada em conhecimento dividimos os trabalhos em duas abordagens: (i) abordagem baseado em gazetteers ou Wikipédia e (ii) abordagem de resolução por ontologia geográfica. Finalmente foi apresentada uma síntese de todos os trabalhos e os resultados obtidos. Esses trabalhos servem como base para nossa pesquisa já que um de nossos objetivos é comparar o processo de desambiguação usando uma ontologia geográfica a um processo usando um sistema de informação geográfica. 


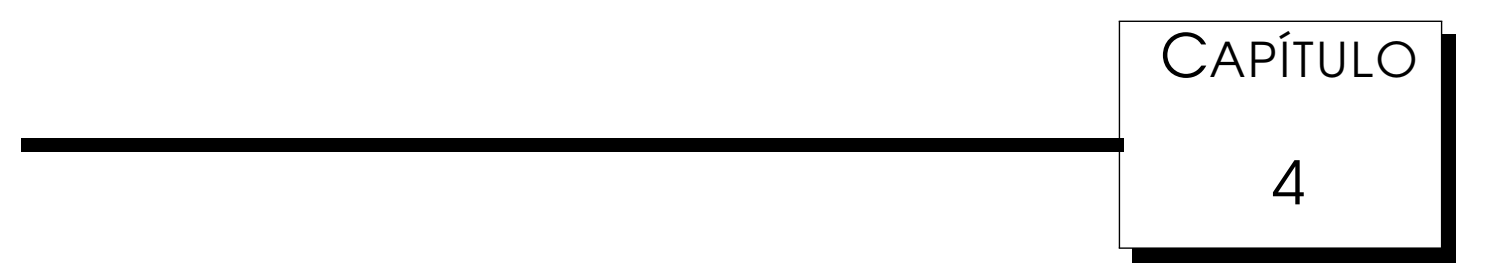

\section{Metodologia para a Descoberta da Cobertura Espacial dos Documentos: SpatialCIM}

\subsection{Considerações Iniciais}

A língua é o veículo por meio do qual o ser humano expressa ideias, modelos de processos cognitivos e precisa compreender um léxico que funcione como um universo onde um conceito possa ser representado dentro dele (Gomes, 2009). Porém, algumas vezes, um discurso pode não representar, de maneira clara, os conceitos que foram pensados. Nesse momento percebe-se que um entendimento de um discurso consiste não somente do conhecimento simples das palavras que o compõe, mas também do contexto sobre o qual elas ocorrem. De forma geral, as técnicas para detecção e tratamento de ambiguidades costumam partir do mesmo princípio para solucionar o problema: obter informações dentro do contexto na qual localiza-se a ambiguidade. A diferença entre as técnicas de desambiguação está na forma como essas informações de contexto serão buscadas (Gomes, 2009).

Para resolver ambiguidade espacial dos textos é necessário uma série de passos preparatórios para a desambiguação, como reconhecer as entidades e obter os dados específicos de cada uma delas. Neste projeto de mestrado foi proposta a metodologia SpatialCIM (Spatial Coverage Identification Methodo- 
logy) que estabelece uma série de passos e recursos a serem utilizados para desambiguar as entidades geográficas associadas os documentos.

Na Seção 4.2 é apresentada a visão geral da metodologia SpatialCIM, na qual explicam-se cada um dos componentes e as formas de obter os dados. Na Seção 4.2.3 é detalhado o processo de Desambiguação por Pontos, e na Seção 4.2.3 o processo de Desambiguação Textual e Estrutural. Finalmente, na Seção 4.3 detalha-se os recursos usados e desenvolvidos para poder aplicar os métodos de desambiguação propostos.

\subsection{A Metodologia SpatialCIM}

Neste trabalho foi proposta a metodologia SpatialCIM que é formada por uma série de passos que permitem identificar e localizar geograficamente um conjunto de documentos considerando a estrutura hierárquica do Brasil. A estrutura considerada é da forma "Macro-Região, Região, Estado, Meso-Região, Micro-Região, Município, Usina e País”. Neste projeto considera-se que o conjunto de documentos que serve como entrada da metodologia encontra-se na língua portuguesa e são do âmbito agrícola, mais especificamente do tópico da cana-de-açúcar. Na Figura 4.1 é ilustrada a metodologia SpatialciM que é composta por três etapas: (i) Pré-processamento, (ii) Expansão dos dados e (iii) Desambiguação.

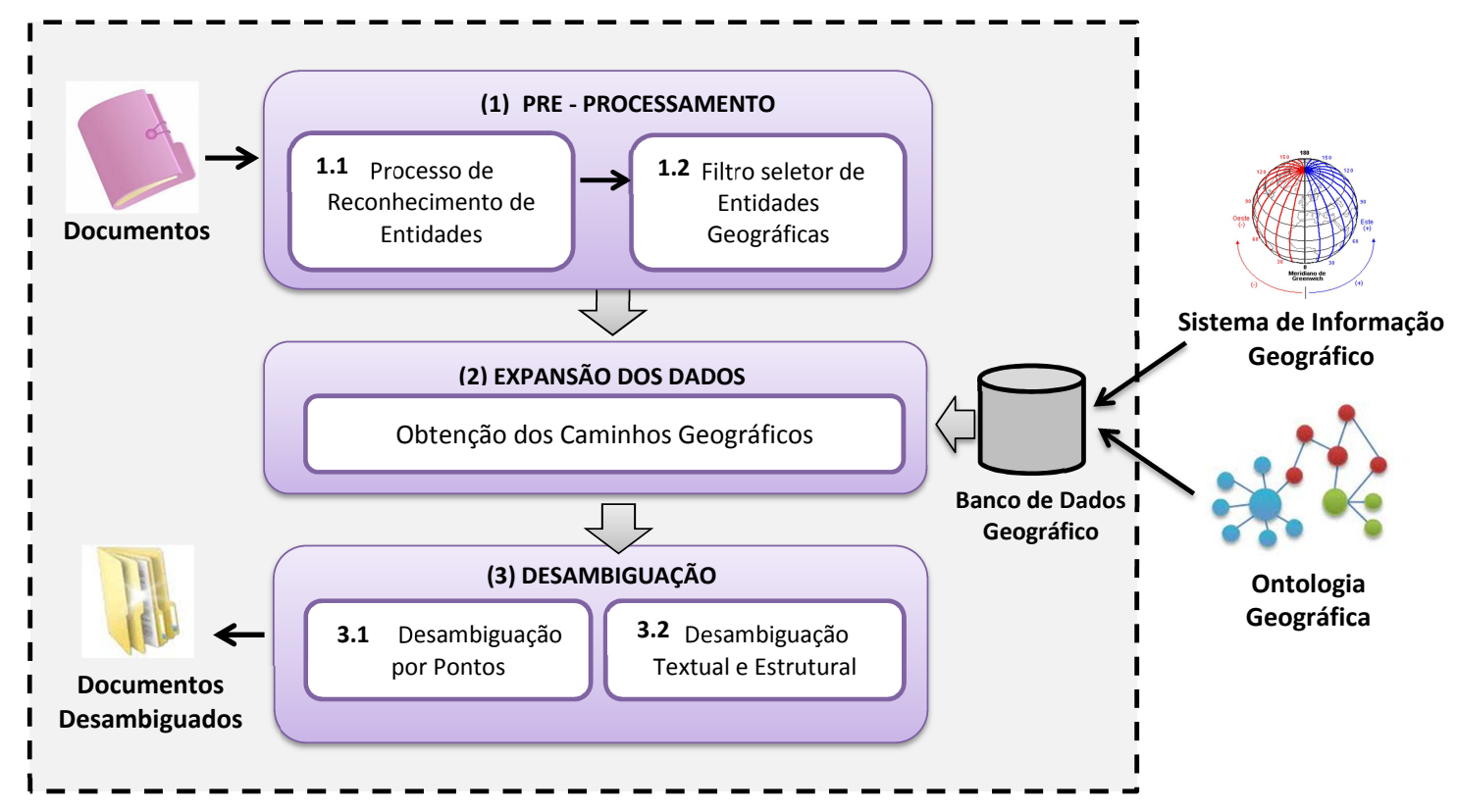

Figura 4.1: Visão geral da metodologia SpatialCIM 
Como observado na Figura 4.1, os dados de entrada são um conjunto de documentos, os quais ao final do processo são convertidos a uma representação que contêm seus respetivos caminhos geográficos desambiguados. Na primeira etapa da metodologia os documentos são pré-processados de forma que seja realizado um reconhecimento das entidades geográficas. O processo de reconhecimento de entidades geográficas pode ser auxiliado por ferramentas linguísticas que analisem o contexto de cada palavra para assim determinar se a palavra representa uma entidade geográfica. Uma vez que as entidades foram reconhecidas procede-se com a expansão dos caminhos geográficos de cada entidade, ou seja, identificar a estrutura hierárquica à qual pertence a entidade. De forma que se a entidade "São Paulo" foi reconhecida no préprocessamento, na expansão de caminhos obterá-se a Macro-Região, Região, Meso-Região, Micro-Região e Município à qual está associado. Para realizar a expansão dos caminhos geográficos a metodologia SpatialCIM permite fazê-lo de duas formas: (1)Sistema de Informação geográfico e (2)Ontologia geográfica. Como será detalhado nas seções seguintes, a seleção de uma dessas formas de expansão de dados determinará o processo de desambiguação a ser utilizado. Uma vez que os caminhos geográficos foram obtidos usando alguma abordagem para preencher o banco de dados analisam-se as entidades ambíguas e soluciona-se usando uma abordagem para desambiguar entidades. Por exemplo, para a entidade "São Paulo" obtêm-se dois caminhos ambíguos, um deles reconhece um caminho até o nível de Estado e o outro até o nível de Município. É tarefa dos processos de desambiguação determinar qual desses dois caminhos representa a verdadeira localização para esse documento.

Nas seguintes seções serão exploradas em detalhe cada etapa que compõe a metodologia SpatialCIM.

\subsubsection{Pré-Processamento}

Na etapa de pré-processamento o objetivo é analisar os documentos e conseguir extrair as entidades geográficas mencionadas. Esta etapa pode ser subdividida em (i) Processo de reconhecimento de entidades, que visa reconhecer todos os tipos de entidades presentes nos documentos, e (ii) Filtro seletor de entidades geográficas, que selecionará unicamente as entidades de carácter geográfico. 


\section{Reconhecimento de Entidades Mencionadas}

Esta etapa visa reconhecer as entidades presentes nos documentos para depois classificar-las em diferentes tipos. Esse reconhecimento de entidades pode ser realizado utilizando uma ferramenta linguística que analisa o contexto de cada palavra, ou fazendo uso de uma ferramenta baseada em regras que analisa as palavras para determinar se são ou não entidades geográficas. Devido ao fato dos documentos estarem escritos em português, a ferramenta linguística selecionada para efetuar o Reconhecimento de Entidades Mencionadas (REM) foi escolhido o Rembrandt (Cardoso, 2008). Por outro lado, a ferramenta baseada em regras, é o Vocabulário Controlado AGRI-BR, o qual foi desenvolvido neste projeto.

A ferramenta Rembrandt, como explicado no Capítulo 2, é uma ferramenta linguística que permite o Reconhecimento de Entidades Mencionadas em português (Cardoso, 2008). O Rembrandt permite o reconhecimento de diversas entidades, como números, organizações, pessoas e tempo.

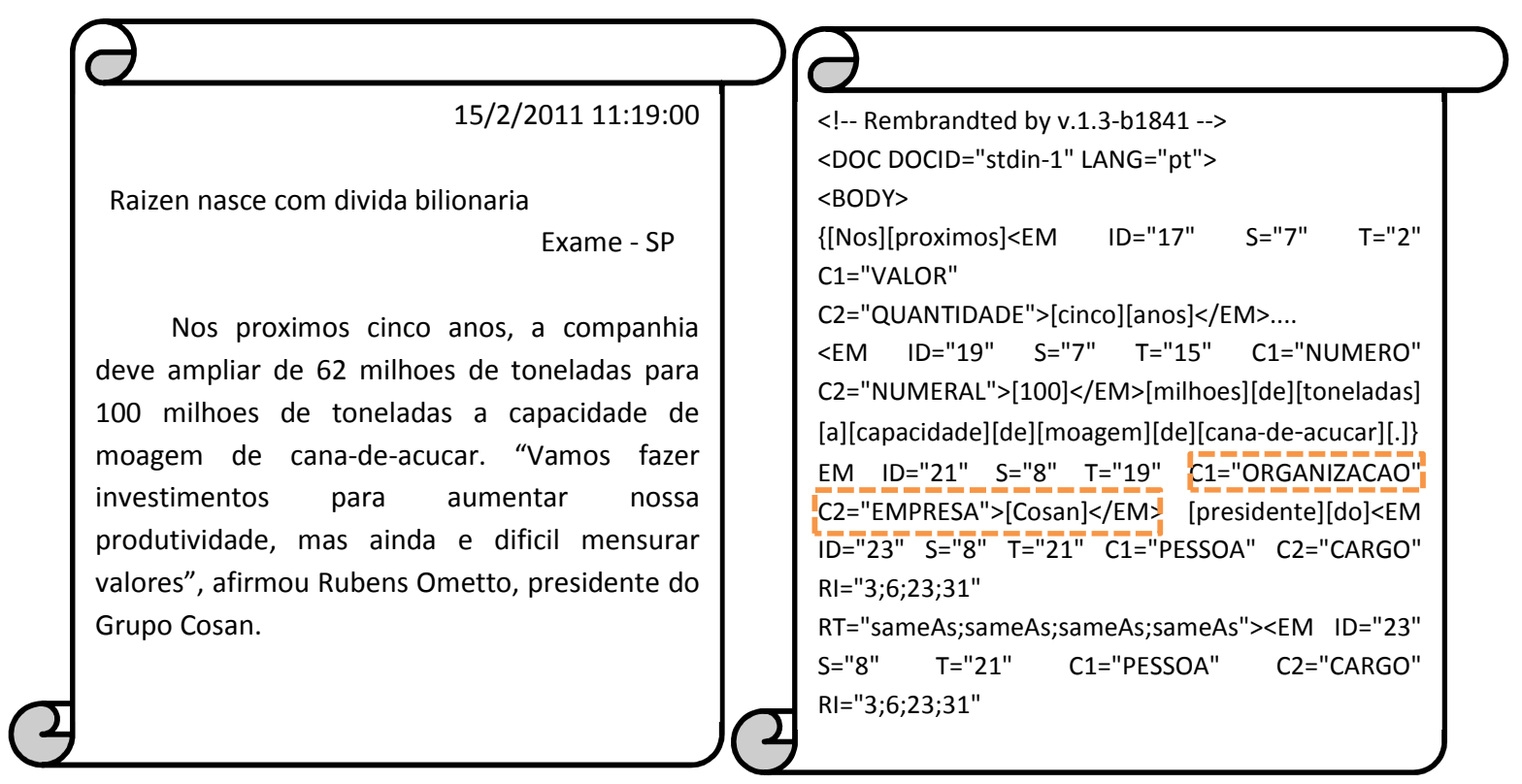

(b) Documento Original

(a) Resultado do Rembrandt

Figura 4.2: Exemplo de um documento pré-processado pela ferramenta Rembrandt

Na Figura 4.2 é mostrado um documento que foi pré-processado pela ferramenta Rembrandt. Como observado, o Rembrandt analisa oração por oração e coloca uma marcação dentro do próprio documento do tipo e sub-tipo de entidade que foi reconhecida. Observa-se também que esta ferramenta é capaz 
de identificar, nesse texto, a usina "Cosan" que foi marcada como tipo organização. Para que esta ferramenta reconheça o contexto das palavras, faz uso de informações linguísticas. Sendo assim, para que tais informações sejam reconhecidas, não é possível realizar uma limpeza dos documentos (como remoção de acentos e stopwords) antes do processamento. Assim, o processo de reconhecimento de entidades de alguns documentos pode levar mais tempo que outros.

Por outro lado, o vocabulário controlado AGRI-BR é uma técnica mais simples de reconhecimento de entidades. O funcionamento é baseado no casamento de palavras dos documentos com uma lista de entidades geográficas e termos agrícolas contidas no AGRI-BR. Dado que o AGRI-BR não faz uso de informações linguísticas, como análise de orações ou contexto, é possível fazer uma limpeza prévia dos documentos fazendo a remoção das stopwords.

Uma vantagem de utilizar como reconhecedor de entidades a ferramenta Rembrandt é que ao analisar o contexto do documento a probabilidade de reconhecer entidades que representem ambiguidades do tipo geo/não-geo é menor. Por exemplo, no Brasil existe um município denominado "Flores", quando utiliza-se o Rembrandt para reconhecer a entidade, é provável que, de acordo com o contexto, "Flores" não seja anotada como entidade geográfica. Por outro lado, quando utiliza o AGRI-BR, a palavra é reconhecida como uma entidade geográfica pelo fato de "Flores" estar presente na lista que faz parte do vocabulário.

Depois de ter reconhecido as entidades mencionadas dentro dos documentos é necessário aplicar um filtro para extrair as entidades geográficas.

\section{Filtro de Entidades Geográficas}

O Filtro de Entidades Geográficas é aplicado unicamente quando os documentos foram processados pelo Rembrandt devido à variedade de entidades reconhecidas. Para extrair as entidades geográficas foram analisadas as marcações feitas pelo Rembrandt, ilustradas na Figura 4.2(b). Os tipos de entidades que possuem dados geográficos e que foram identificados e extraídos pela ferramenta são:

- Entidades: Local, Humano, Físico, Virtual, Divisão;

- Empresas - Usinas: Organização, Empresa, Pessoa, Individual.

Como observado, na lista de entidades filtradas consideram-se as entidades marcadas como "Pessoa" e "Individual". Esta decisão foi necessária pelo fato 


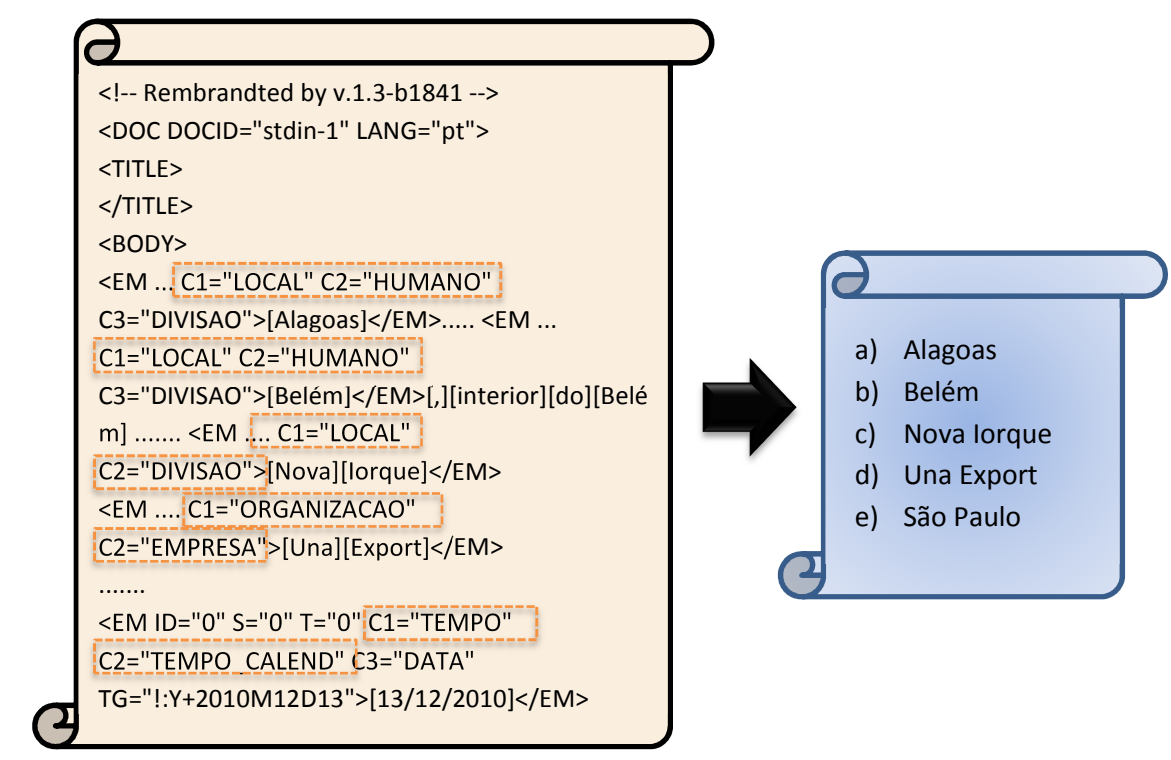

Figura 4.3: Exemplo de Reconhecimento e filtro de entidades geográficas para um documento

que algumas usinas brasileiras têm nomes próprios. Por exemplo, usina São Martinho, Santa Helena, Santa Maria e São Antônio. Em função do contexto dos documentos ser estritamente agrícola, considerou-se que se uma entidade for reconhecida como pessoa, esta tem uma probabilidade grande de estar se referindo a uma usina.

Na Figura 4.3 é ilustrado um exemplo de um documento pré-processado pelo Rembrandt. No lado esquerdo da figura observa-se um extrato das entidades reconhecidas. Já no lado direito, observa-se a lista das entidades geográficas extraídas baseadas no documento analisado.

\subsubsection{Expansão dos Dados}

Após a seleção das entidades geográficas é necessário obter as possíveis localidades em que a entidade pertence. Neste trabalho, as localidades associadas com as entidades serão chamadas de caminhos geográficos. Para isso, é utilizado um banco de dados geográfico, mostrado na Figura 4.1. Esse banco de dados pode ser preenchido de duas formas diferentes e o tipo de preenchimento determinará a maneira como a desambiguação será aplicada na seguinte etapa, que pode ser: (1) Sistema de Informação Geográfico (SIG) ou (2) Ontologia Geográfica.

Escolheu-se essas duas formas de preenchimento para poder analisar os métodos de desambiguação que serão aplicadas com cada estratégia. A princi- 
pal diferença entre essas maneiras de desambiguar os textos é que o SIG usa como base para a desambiguação as coordenadas geográficas enquanto que a ontologia geográfica usa como base a estrutura hierárquica das entidades. Os processos de extração dos dados da hierarquia da entidade são similares em ambos casos mudando unicamente a linguagem da consulta. Para fazer consultas dentro do SIG usam-se as consultas clássicas do SQL e para a ontologia o SPARQL.

Na Tabela 4.1 é mostrada a expansão dos caminhos geográficos realizadas para as entidades geográficas reconhecidas na Figura 4.3. Observa-se que as entidades (b) Belém, (c) Nova Iorque e (e) São Paulo têm vários caminhos associados, porém são consideradas como entidades ambíguas.

Tabela 4.1: Exemplo dos caminhos geográficos extraídos para as entidades reconhecidas de um documento

\begin{tabular}{|c|c|c|c|c|c|c|c|c|}
\hline & $\begin{array}{l}\text { MACRO } \\
\text { REGIÃOO }\end{array}$ & REGIÃO & ESTADO & MESO REGIÃO & MICRO REGIÃO & MUNICÍPIO & USINA & PAÍS \\
\hline A1 & Nordeste & Nordeste & Alagoas & - & - & - & - & - \\
\hline B1 & Nordeste & Norte & Pará & $\begin{array}{l}\text { Metropolitana de } \\
\text { Belém }\end{array}$ & Belém & Belém & - & - \\
\hline B2 & Amazônia & Norte & Pará & $\begin{array}{l}\text { Metropolitana de } \\
\text { Belém }\end{array}$ & Belém & - & - & - \\
\hline B3 & Amazônia & Nordeste & Paraíba & Agreste Paraibano & Guarabira & Belém & - & - \\
\hline B4 & Nordeste & Nordeste & Alagoas & Agreste Alagoano & Palmeira dos Índios & Belém & - & - \\
\hline C1 & Nordeste & Nordeste & Maranhão & Leste Maranhense & $\begin{array}{l}\text { Chapadas do alto } \\
\text { Itapecuru }\end{array}$ & $\begin{array}{l}\text { Nova } \\
\text { lorque }\end{array}$ & - & - \\
\hline C2 & - & - & - & - & - & - & - & $\begin{array}{l}\text { Nova } \\
\text { lorque }\end{array}$ \\
\hline D1 & Nordeste & Nordeste & Pernambuco & $\begin{array}{l}\text { Mata } \\
\text { Pernambucana }\end{array}$ & $\begin{array}{l}\text { Mata Meridional } \\
\text { Pernambucana }\end{array}$ & Marial & $\begin{array}{l}\text { Una } \\
\text { Export }\end{array}$ & - \\
\hline E1 & Centro-Sul & Sudeste & São Paulo & $\begin{array}{l}\text { Metropolitana de } \\
\text { São Paulo }\end{array}$ & São Paulo & São Paulo & - & - \\
\hline E2 & Centro-Sul & Sudeste & São Paulo & $\begin{array}{l}\text { Metropolitana de } \\
\text { São Paulo }\end{array}$ & São Paulo & - & & - \\
\hline E3 & Centro-Sul & Sudeste & São Paulo & - & - & - & - & - \\
\hline
\end{tabular}

Na Tabela 4.1 pode-se apreciar diferentes tipos de ambiguidades com as quais os desambiguadores têm que lidar e tentar resolver.

- Ambiguidade de nomes: que é o tipo de ambiguidade mais comum que acontece. Por exemplo a entidade "Belém"é associada a diferentes caminhos geográficos com diferentes níveis de hierarquia, como "B1", "B2", "B3" e "B4";

- Ambiguidade hierárquica: que está representada na figura pela entidade "São Paulo", na qual tem-se os mesmos caminhos geográficos ("E1", "E2" e "E3"), mudando unicamente o nível da hierarquia reconhecido; 
- Ambiguidade local-internacional: que está representada pela entidade "Nova Iorque", que pode pertencer tanto a um município do Brasil ou a uma entidade internacional. Um fato representativo deste tipo de ambiguidade é a forma de descrever a entidade no texto. Por exemplo, se no texto a entidade tivesse aparecido como "New York" não teria sido reconhecida como ambígua.

\subsubsection{Desambiguação}

Uma vez que os caminhos geográficos foram obtidos usando alguma estratégia de extração de dados, é necessário aplicar um processo de desambiguação nas entidades que foram previamente detectadas como ambíguas. Na metodologia SpatialCIM são consideradas duas formas de efetuar a desambiguação: (i) Desambiguação por Pontos e (ii) Desambiguação Textual e Estrutural.

\section{Desambiguação por Pontos}

O processo de Desambiguação por Pontos é baseado no método proposto por Leidner (2008). Esse método usa como base as entidades não ambíguas reconhecidas e com base nelas desambiguam-se as outras entidades. No trabalho de Leidner (2008) são utilizadas como base as coordenadas de cada entidade obtidas de um gazetteer e a estrutura hierárquica da entidade não é considerada. Neste trabalho são utilizadas também as coordenadas geográficas de cada entidade e são obtidas de um gazetteer Brasileiro. Diferente do trabalho de Leidner (2008), neste trabalho é considerada a estrutura hierárquica das entidades. Assim, por exemplo, as coordenadas geográficas associadas à entidade "São Paulo" do tipo estado são diferentes às associadas à entidade "São Paulo" do tipo município. Para efetuar a desambiguação é necessário em primeiro lugar, obter as coordenadas geográficas de todas as entidades que têm caminhos geográficos associados. Um exemplo desta etapa pode ser observado na Figura 4.4, na qual obteve-se para cada caminho geográfico uma representação em coordenadas.

Para o processo de desambiguação das entidades apresentadas na Tabela 4.1, identificou-se que as entidades não ambíguas são (A1) Alagoas e (D1) Una Export. O primeiro passo, como ilustrado na Figura 4.5(a), é mapear no espaço o conjunto de entidades não ambíguas e construir um polígono entre elas. Após ter formado o polígono inicial, trabalha-se com cada conjunto de 


\begin{tabular}{|l|l|l|}
\hline & Latitude & Longitude \\
\hline A1 & -36.62 & -9.51 \\
\hline B1 & -48.45 & -1.24 \\
\hline B2 & $-48,49$ & -1.36 \\
\hline B3 & -35.49 & -6.70 \\
\hline B4 & -36.49 & -9.54 \\
\hline C1 & -44.04 & -6.74 \\
\hline
\end{tabular}

\begin{tabular}{|l|l|l|}
\hline & Latitude & Longitude \\
\hline C2 & -112.56 & 45.65 \\
\hline D1 & -35.76 & -8.83 \\
\hline E1 & -46.64 & -23.65 \\
\hline E2 & -46.59 & -23.68 \\
\hline E3 & -48.72 & -23.68 \\
\hline
\end{tabular}

Figura 4.4: Extração das coordenadas geográficas para as entidades reconhecidas

entidades ambíguas uma a uma. Na Figura 4.5(b) o processamento para a entidade "Belém" é mostrado. Esta entidade é representada na Tabela 4.1 pela letra "B". Como observado, a entidade ambígua "B4" pertence ao polígono formado inicialmente pelas entidades não-ambíguas. Dessa forma, a entidade "B4" é reconhecida como a entidade desambiguada da entidade "B". Após esse processo, um novo polígono é formado considerando agora as entidades "A1", "D1" e "B4". Na Figura 4.5(c) ilustra-se a construção do polígono para o conjunto de entidades ambíguas "C1" e "C2". Observa-se que nesse caso nenhuma das entidades pertence ao polígono formado no passo anterior. Nesse caso, a entidade mais próxima de qualquer entidade que forma o polígono será considerada como a entidade desambiguada. No exemplo, a entidade "C1" é a entidade desambiguada. Com essa nova entidade, um novo polígono é formado e repete-se a operação até não encontrar mais entidades ambíguas, conforme ilustrado na Figura 4.5(d).

Assim, este método de desambiguação é baseado nas coordenadas de cada entidade. No entanto, é importante ter um conjunto de entidades não-ambíguas desde o início para apoiar a formação dos polígonos. No caso em que não tenha sido detectada nenhuma entidade não-ambígua no início utilizam-se as seguintes heurísticas:

- Selecionar de forma aleatória uma entidade considerando seu nível de detalhe hierárquico. Neste projeto é desejável que os documentos sejam classificados até o nível de Usina. Por isso, para selecionar a entidade, considera-se a seguinte ordem: Usina, Macro-região, Região e Estado;

- Se existem duas entidades ambíguas que tenham o mesmo nível hierárquico, por exemplo, duas entidades que chegam até o nível estado, seleciona-se aleatoriamente uma entre elas;

- Se existem duas entidades ambíguas e uma delas é do âmbito local e a 


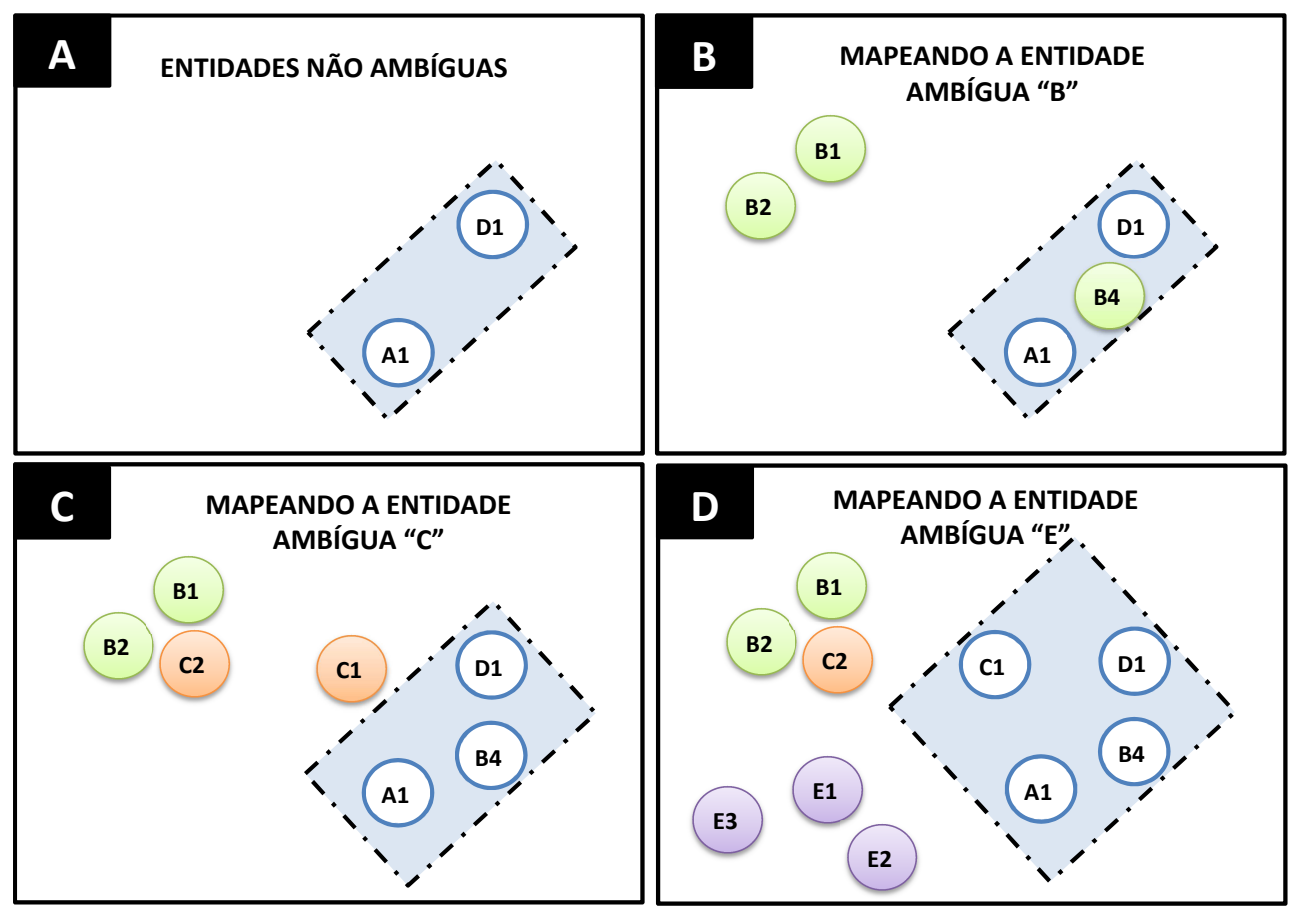

Figura 4.5: Exemplo da construção de polígonos para o processo de Desambiguação por Pontos

outra internacional, da-se preferência à entidade local.

\section{Desambiguação Textual e Estrutural}

A Desambiguação Textual e Estrutural proposta neste trabalho, utiliza a ideia de atribuir pesos às entidades considerando diferentes heurísticas como proposto no trabalho de Campelo e Baptista (2009). Assim, neste trabalho foram consideradas diferentes heurísticas para atribuir pesos. Foram consideradas três tipos de pesos associados às entidades: (i) peso $\alpha$, que atribui-se as entidades que têm dicas de localização no texto; (ii) peso $\beta$, que atribui-se as entidades que compartem partes da hierarquia dos caminhos não-ambíguos; e (iii) pesos de penalização, que são atribuídos às entidades com a finalidade de escolher o caminho geográfico mais geral. É também proposta a utilização de um valor $\delta$ como limiar de corte, o que permitirá eliminar entidades que podem ter sido reconhecidas de forma errada.

A desambiguação Textual e Estrutural não mapeia as entidades no espaço e portanto não faz uso das coordenadas geográficas. Nesta abordagem de desambiguação faz-se primeiro uma desambiguação usando o documento fonte e depois utiliza-se a hierarquia das entidades para determinar a entidade desambiguada. 
Desambiguação Textual Nos textos, é muitas vezes comum encontrar palavras ou termos associados que dão indicação de uma aproximação ou especificação de um lugar geográfico. Segundo Campelo e Baptista (2009), uma característica dos documentos que pode ser analisada é a ocorrência de Termos Especiais (ST - Special Terms). ST é que é definido como um termo cuja ocorrência em um texto pode ser decorrente da presença de referências geográficas no mesmo texto. Por exemplo, "cidade de quirinópolis", “estado de Goiás” e "grupo Cosan'.

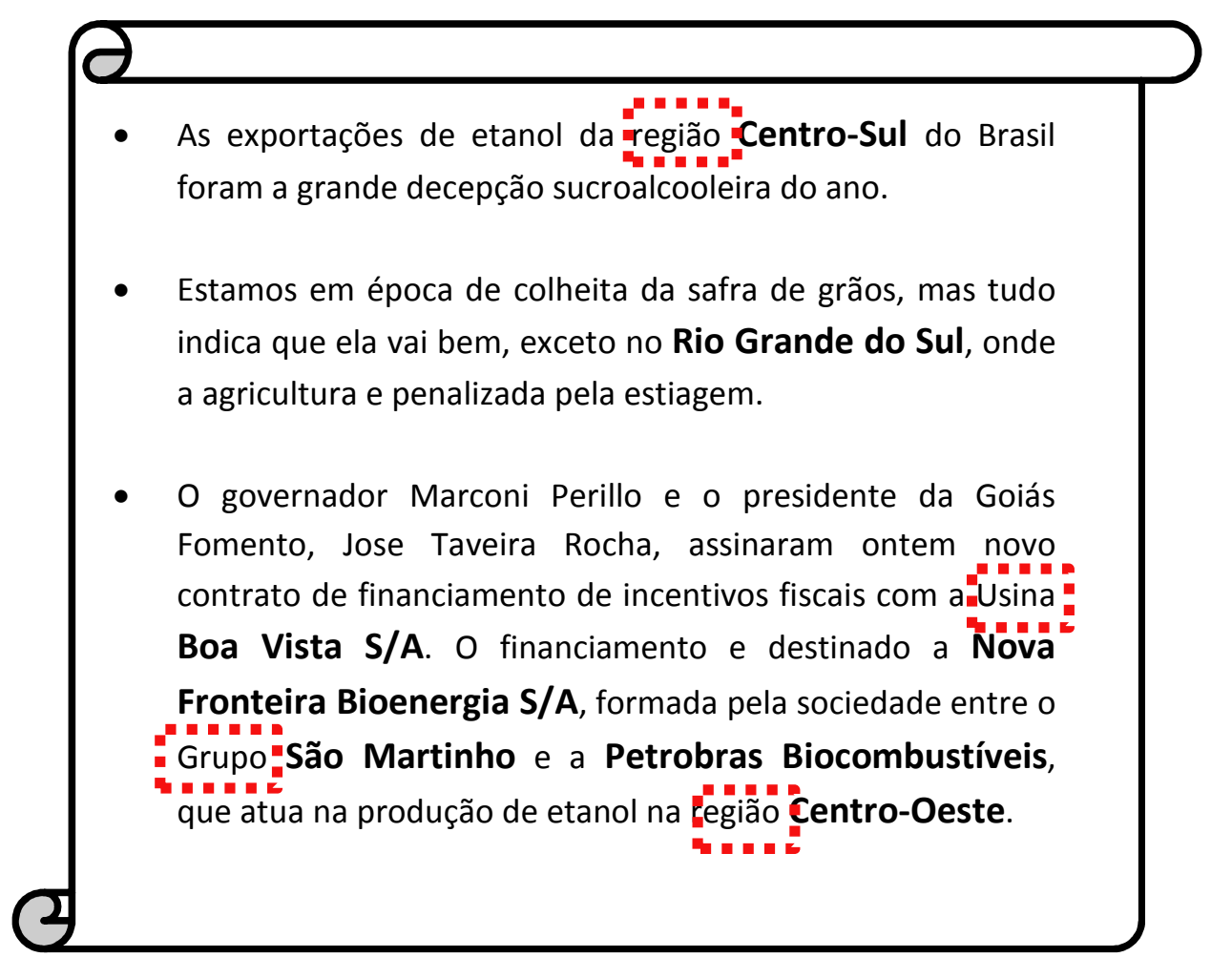

Figura 4.6: Exemplo de Termos Especiais nos documentos

Na Figura 4.6 são mostrados extratos de três documentos diferentes. No primeiro extrato foi identificada a entidade "Centro-sul" e como podese observar o termo especial "região" está associado. O mesmo acontece com o terceiro extrato, na qual identificam-se os termos "usina", "grupo" e "região". Por outro lado, no segundo extrato, não foi reconhecido nenhum termo especial associado com a entidade.

Os Termos Especiais aparentam fornecer uma melhor localização da entidade dentro do contexto do documento. Por isso, nesta abordagem de desambiguação, utiliza-se uma janela de tamanho 2. Essa janela serve para olhar se existem termos especiais antes ou depois da entidade geo- 
gráfica. Escolheu-se uma janela de tamanho 2 já que usualmente os termos especiais estão o mais perto da palavra, por exemplo, "grupo Cosan", " estado de Alagoas". O processo de desambiguação textual é realizado nas seguintes etapas:

1. Analisa cada documento com a finalidade de encontrar o lugar no qual está referenciada a entidade geográfica (linhas ou orações);

2. Uma vez encontrada a entidade, procura-se 2 palavras para frente e 2 para trás com a finalidade de encontrar algum termo especial;

3. Para todos os termos especiais encontrados atribui-se um valor $\alpha$ que será denominado como "Peso Dica Texto". Esse valor serve para dar um maior peso a aquelas partes da hierarquia que foram referenciadas no texto. Por exemplo, assume-se que foi reconhecida a entidade "São Paulo" e têm associados dois caminhos geográficos. Um dos caminhos chega até o nível Estado e o outro até Município. Supondo que o termo especial "estado" foi encontrado, o caminho que chega até o nível estado tem mais probabilidade de ser o caminho correto. Assim, atribui-se o valor $\alpha$ para que, nesse contexto, "estado de São Paulo" tenha um maior peso que "município de São Paulo".

Desambiguação Estrutural Uma vez obtidos os termos especiais que encontram-se no texto, procede-se com a desambiguação estrutural das entidades. Na Figura 4.7 é mostrado um extrato dos caminhos apresentados na Tabela 4.1. Pode-se observar que a desambiguação estrutural aplicada para a entidade ambígua "Belém" considera a entidade nãoambígua "Alagoas".

A desambiguação estrutural pode ser dividida nos seguintes passos:

1. Identificar o conjunto de entidades não ambíguas;

2. Para cada parte da hierarquia das entidades não ambíguas atribuise um valor $\beta$ que é denominado como "Peso Entidade não Ambígua". Esse valor $\beta$ representa um peso para cada nível da hierarquia das entidades não-ambíguas e serve para que as entidades ambíguas que compartem parte dos níveis não-ambíguos tenham um maior peso. Por exemplo, na Figura 4.7 para a entidade não-ambígua "Alagoas" atribui-se um valor $\beta$ para cada nível da hierarquia que faz parte seu caminho. Se observa-se as entidades ambíguas "B1", "B2", "B3" e 

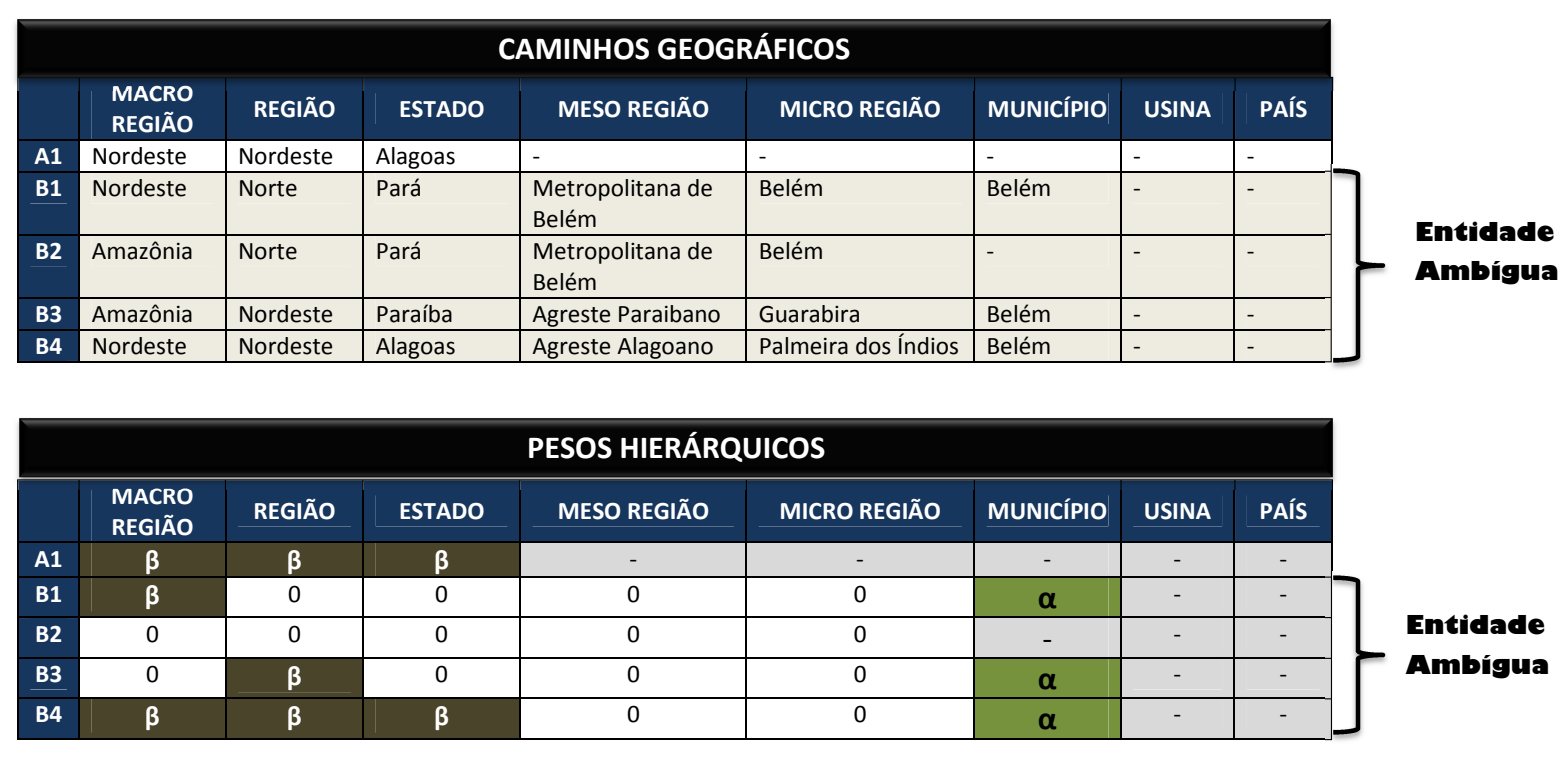

Figura 4.7: Exemplo de Desambiguação estrutural das entidades

"B4" nota-se que a entidade "B4" comparte os mesmos niveis que a entidade não-ambígua "Alagoas". Assim, atribui-se um valor $\beta$ para esses niveis. Nota-se também que a entidade "B1" comparte a mesma Macro-Região que a entidade de "Alagoas", porém, atribui-se um valor $\beta$ para a Macro-Região de "B1";

3. Analisa-se cada grupo de entidades ambíguas e associa-se um peso para cada parte da hierarquia da entidade tomando como base as entidades não ambíguas. Por exemplo, na Figura 4.7 a entidade não ambígua tem como estado "Alagoas”, então todas entidades ambíguas que tenham dentro da sua hierarquia o estado "Alagoas" obtém o valor $\beta$;

4. Para todas as partes da hierarquia que tenham sido reconhecidas com termos espaciais associa-se um valor $\alpha$, denominado "Peso Dica Texto". Por exemplo, assumindo que no texto encontrou-se o termo "município de Belém", todos os caminhos geográficos de "Belém" que cheguem até o nível de município terão associadas um valor $\alpha$, como mostrado na Figura 4.7;

5. Os níveis da hierarquia que não tenham um valor $\alpha$ ou $\beta$ associado terão um valor zero;

6. Aplica-se, então, uma desambiguação heurística para cada conjunto de entidades. O objetivo dessa desambiguação é dar maior importância a entidades mais gerais. Assim, para a entidade "São Paulo" 
apresentada na Tabela 4.1 (entidade "E1", "E2" e "E3"), o melhor caminho geográfico é o apresentado pela entidade "E3". Essa desambiguação consiste em colocar valores de penalização à hierarquia; os valores considerados neste projeto são: (1)Município: -9 ; (2)Micro-Região: -8; (3)Meso-Região: -7 e (4)Usina: +10. O nível de usina tem um valor positivo porque no escopo deste projeto esperase classificar os documentos considerando como parte importante as usinas reconhecidas. Esses valores de penalização foram escolhidos considerando que a desambiguação heurística tem um menor peso comparada com a desambiguação baseada no texto e na estrutura hierárquica das entidades. A finalidade desses valores é permitir variar um pouco a soma total para que caminhos genéricos tenham maiores valores e ao mesmo tempo não afete os valores $\alpha$ e $\beta$ atribuídos;

7. Finalmente, todos os valores são somados e obtém-se um valor total para cada entidade. Escolhe-se aquela entidade que tem o maior valor e depois compara-se com um valor de descarte $\delta$. Se a entidade tiver um valor menor igual que $\delta$ é então descartada já que poderia se tratar de uma entidade que foi mal reconhecida.

Ao finalizar o processo de Desambiguação Textual e Estrutural, existe a possibilidade de ter eliminado várias entidades que podem ter sido bem ou mal reconhecidas nos processo de REM. Existe também a possibilidade de zerar todas as entidades reconhecidas se os valores das variáveis $\alpha, \beta$ e $\delta$ forem muito altos. Por isso, é importante ajustar os valores de $\alpha, \beta$ e $\delta$ até obter uma configuração apropriada para o problema, permitindo a eliminação de entidades que estejam abaixo de um limiar de eliminação determinado no início.

A metodologia SpatialcIM provê de uma série de etapas que permitem estruturar os processos de Resolução de Topônimos. Entre as etapas proposta, está a etapa de desambiguação que visa determinar a correta localização espacial dos documentos. Neste trabalho foram exploradas duas formas diferentes de resolver a ambiguidade nos documentos: (1) Desambiguação por Pontos e (2) Desambiguação Textual e Estrutural. A (1) Desambiguação por Pontos usa como fonte de conhecimento externo um gazetteer que proporciona informação sobre as coordenadas geográficas associadas a cada entidade. O processo de desambiguação usa as coordenadas geográficas de cada entidade para formar polígonos. O polígono serve para determinar entre um conjunto de enti- 
dades ambíguas, aquela que está mais perto da realidade do documento, ou seja, aquela entidade que têm maior relação com as outras entidades e porém será considerada como a entidade desambiguada. A (2) Desambiguação Textual e Estrutural usa como fonte de conhecimento externo uma ontologia geográfica. A ontologia dá informação sobre a estrutura das entidades reconhecidas. Neste tipo de desambiguação é utilizada a informação extraída do documento fonte, assim como da estrutura obtida da ontologia. A Desambiguação Textual e Estrutural está baseada em 3 parâmetros base, os quais dão pesos para as entidades reconhecidas. Esta abordagem de desambiguação permite a eliminação de entidades que podem ter sido reconhecidas incorretamente.

\subsection{Materiais e Métodos}

Para a implementação dos métodos de desambiguação propostos foi necessário ter acesso a um gazetteer que proporcionasse as coordenadas geográficas e a estrutura hierárquica de cada entidade, assim como também a uma ontologia geográfica que considerasse a estrutura hierarquia do Brasil. Assim, neste projeto foram desenvolvidas e adaptados um gazeteer e uma ontologia que considera a estrutura geo-política do Brasil, assim como também as cidades e países mais importantes.

Nas seguintes seções é detalhada a implementação e adaptação que foi realizada para gerar o gazetteer, a ontologia geográfica e o vocabulário controlado AGRI-BR.

\subsubsection{O Gazetteer Brasileiro}

Para o gazetteer, inicialmente tentou-se adaptar à ferramenta de Desambiguação por Pontos o gazetteer GeoNames ${ }^{1}$ para obter as coordenadas geográficas de cada entidade brasileira. Infelizmente o GeoNames não leva em consideração toda a divisão geo-política do Brasil, desconsiderando as entidades do tipo Macro-Região, Meso-Região, entre outras.

Na Figura 4.8 é ilustrado um exemplo dos dados obtidos com o gazetteer GeoNames. Como observado, a entidade procurada foi "Belém" e os resultados obtidos estão relacionados com os diferentes estados da entidade "Belém", mas a Meso-Região e a Micro-Região não foram reconhecidas. Esse padrão repete-

\footnotetext{
${ }^{1}$ http: //www.geonames.org/
} 
se para várias entidades brasileiras.

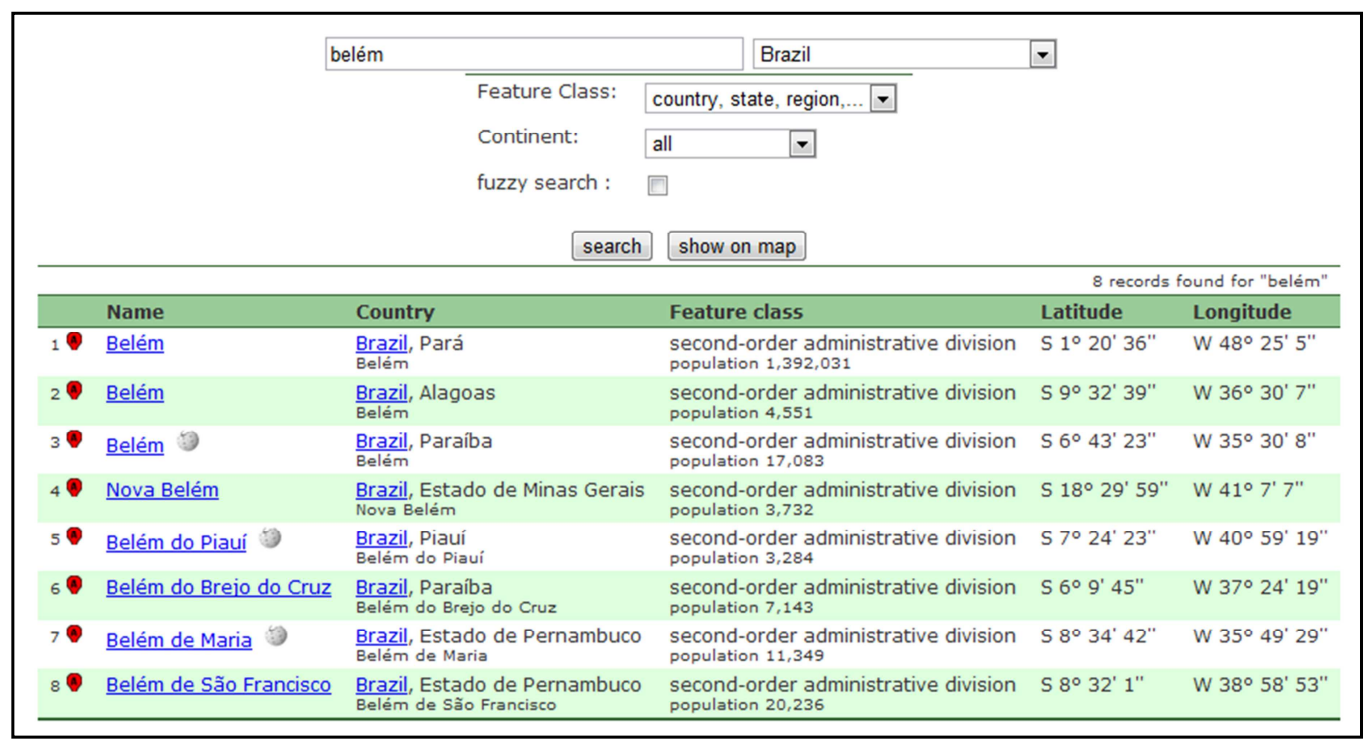

Figura 4.8: Exemplo dos dados obtidos com o gazetteer GeoNames

Assim, optou-se por construir um gazetteer brasileiro, que além de considerar a divisão geo-política do Brasil pudesse considerar também as usinas e os principais Países e cidades do mundo. Para a implementação do gazetter brasileiro foi obtida uma lista da IBGE ${ }^{2}$ que contêm todos os Estados, Regiões, Meso-regiões, Macro-regiões, Micro-regiões e Municípios brasileiros. Foram obtidos também arquivos ".shape" relacionados a essa lista, os quais permitem fazer gráficos espaciais da estrutura dos os Estados, Regiões e Municípios. Para poder obter as coordenadas geográficas de cada entidade e gerar as coordenadas de elementos que não eram considerados nos arquivos “.shape”, como Meso-Região, Micro-Região e Macro-Região, utilizou-se a ferramenta Quantum-GIS ${ }^{3}$.

Na Figura 4.9(a) é mostrado o mapa das Meso-Regiões da região CentroOeste obtido com a ferramenta Quantum-GIS. Na Figura 4.9(b) são ilustradas as coordenadas geográficas obtidas para cada uma das Meso-Regiões. Observa-se também que as coordenadas obtidas são os centroides de cada Meso-Região. Para o caso das usinas, a única informação disponível é o município no qual ela está instalada. Assim, cada usina registrada no banco de dados tem as coordenadas do município associado.

O gazetteer brasileiro implementado neste projeto foi carregado em um banco de dados em SQL e PostgreSql. É importante mencionar que este gazet-

\footnotetext{
${ }^{2}$ http://www.ibge.gov.br/home/

$3_{\text {http: }} / /$ www. qgis.org/
} 

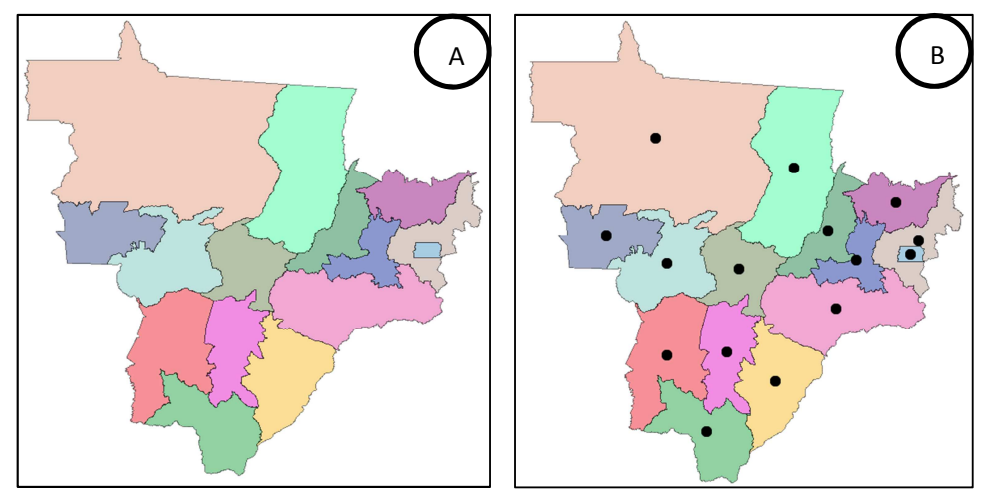

Figura 4.9: Exemplo das coordenadas e mapeamento das Meso-Regiões da Região centro-oeste

teer não contém informações como população de cada entidade, capitais, rios, montanhas, entre outras coisas que os gazetteers mundiais consideram. Essa é certamente uma desvantagem deste gazetteer já que não provê vários dados que poderiam ajudar no processo de desambiguação. Mas espera-se melhorar e implementar os elementos faltantes neste gazetteer em um trabalho futuro.

\subsubsection{Ontologia Geográfica do Brasil}

Para desenvolver a Desambiguação Textual e Estrutural é necessário ter uma ontologia que, como o gazetteer geográfico, contenha informações sobre a divisão geo-política do Brasil e inclua os relacionamentos até o nível de usina. Na literatura encontrou-se o trabalho de Venâncio et al. (2003) que usa uma ontologia geográfica do Brasil. Na Figura 4.10 são ilustradas as classes usadas para implementar a ontologia e a Figura 4.11 ilustra a relação entre os conceitos e as instâncias na ontologia.

Como observado na Figura 4.11, a ontologia original provida pelos autores não considera a classe usina, assim como também é considerado unicamente o Brasil como País dentro da ontologia. Para que a ontologia for o mais semelhante com o gazetteer geográfico foi incorporada a classe usina como uma especialização da classe município. Foram considerados também outros países e suas principais cidades dentro da classe País. A ontologia foi modificada e gerada com ajuda da ferramenta Protegé ${ }^{4}$ e gerou-se uma ontologia em formato “.owl”. Vale ressaltar que não foram consideradas coordenadas geográficas nesta ontologia, pois o tipo de Desambiguação Textual e Estrutural não precisa de tais coordenadas.

\footnotetext{
$4_{\text {http: }: / / p r o t e g e . s t a n f o r d . e d u /}$
} 


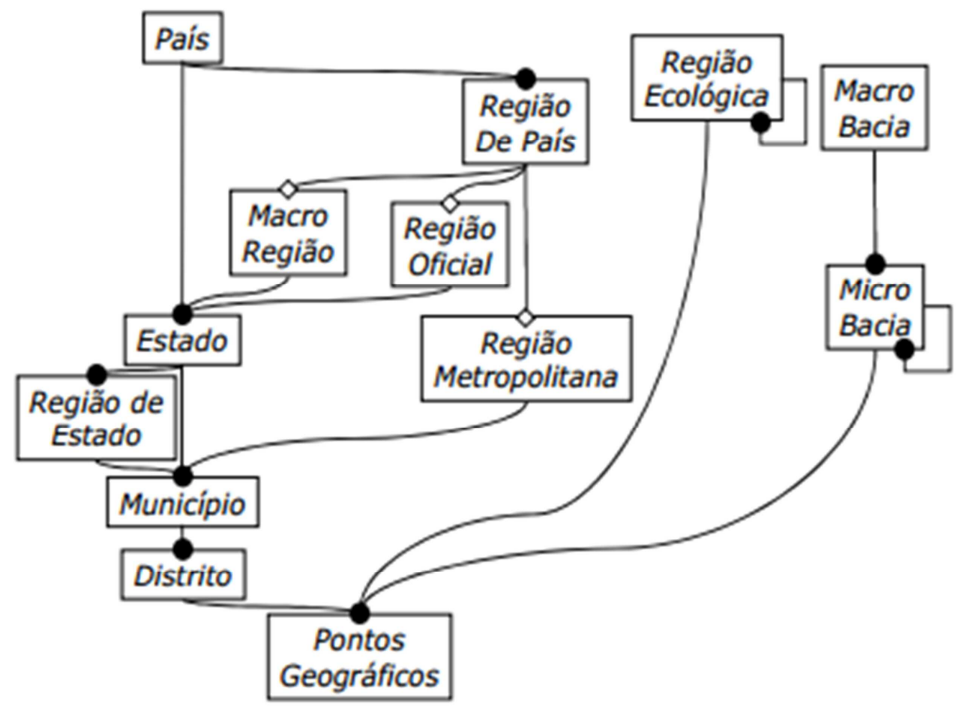

Figura 4.10: A dimensão Território da ontologia agrícola (Venâncio et al., 2003)
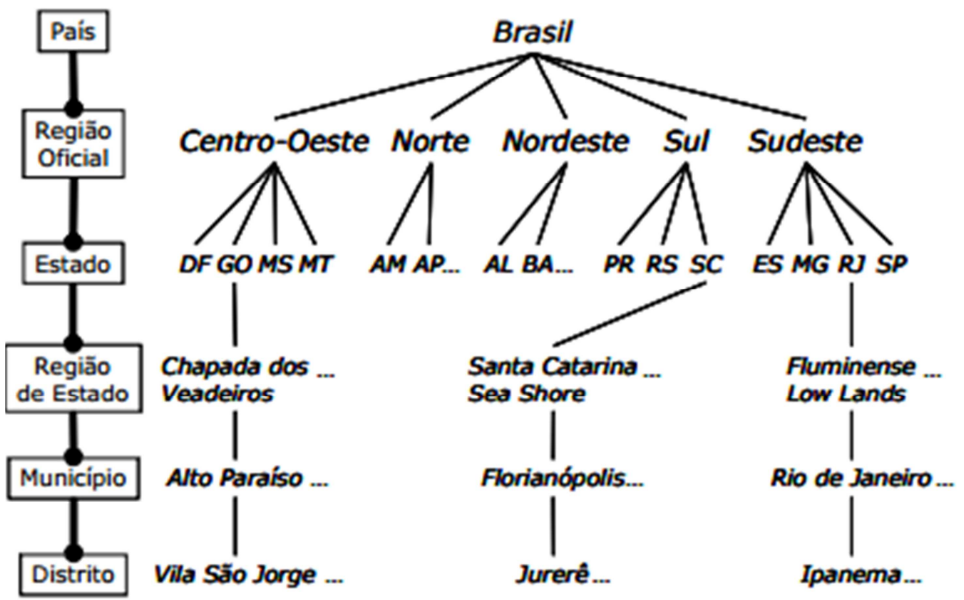

Figura 4.11: Relação entre conceitos e instâncias (Venâncio et al., 2003)

\subsubsection{Vocabulário Controlado AGRI-BR}

O vocabulário controlado AGRI-BR foi constituído usando como base um Banco de Dados Brasileiro (BDB) obtido do Instituto Brasileiro de Geografia e Estatística ( $\left(\mathrm{BGE}^{5}\right)$, o qual têm uma lista de todas as entidades geográficas brasileiras. Foi considerada também a bag-of-words (BOW) obtida do conjunto de documentos que serão desambiguados. A bag-of-words gerada para os documentos é considerada como um elemento dinâmico. Devido ao fato que se outro conjunto de documentos fosse utilizado, uma nova BOW sería gerada para esse conjunto de documentos.Para formar o vocabulário comparou-se

$5_{\text {http }}$ / / www . ibge.gov .br/ 
o BDB com a BOW e obteve-se a interseção de palavras como mostrado na Figura 4.12. Esse conjunto de palavras faz parte do Vocabulário Controlado Agrícola Brasileiro AGRI-BR.

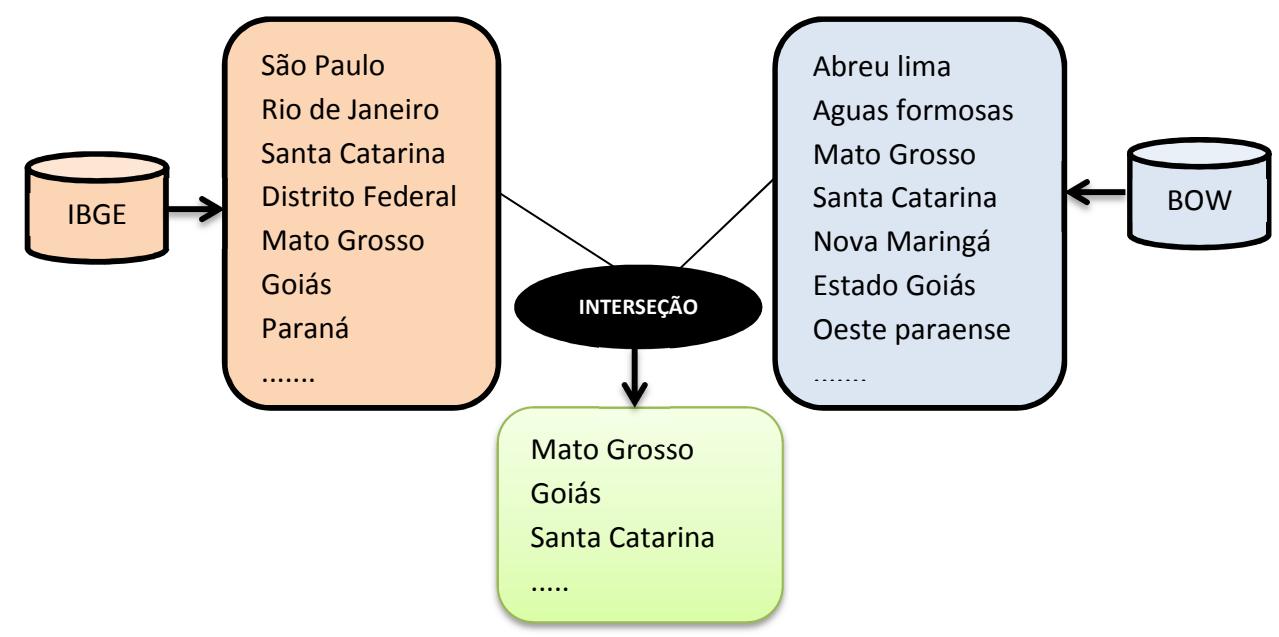

Figura 4.12: Processo de criação do Vocabulário Controlado AGRI-BR

\subsubsection{Ferramentas Desenvolvidas}

Além da implementação do gazetteer brasileiro, a adaptação da ontologia geográfica do Brasil e a criação do vocabulário controlado AGRI-BR também foram desenvolvidas 3 ferramentas. Estas ferramentas foram desenvolvidas durante o projeto de mestrado para viabilizar a utilização da metodologia SpatialCIM.

BraGeoPs: Marcação de caminhos geográficos pelo Especialista

Esta ferramenta foi desenvolvida como parte do projeto de mestrado com o objetivo de auxiliar o especialista na marcação dos documentos seguindo a estrutura hierárquica do Brasil. A ferramenta foi desenvolvida utilizando CSharp e SQL. Essa ferramenta foi desenvolvida de maneira que ambos os processos manual e automático, tivessem a capacidade de fazer a marcação dos caminhos no mesmo formato, para assim facilitar uma comparação posterior. Na Figura 4.13 é ilustrada a tela principal da ferramenta.

Nesta ferramenta os dados são carregados de forma automática utilizando o banco de dados, evitando desta forma possíveis erros de digitação. Outra funcionalidade da ferramenta que facilita o uso pelo especialista é a lista de documentos presente à esquerda da tela. Nessa lista são apresentados todos 


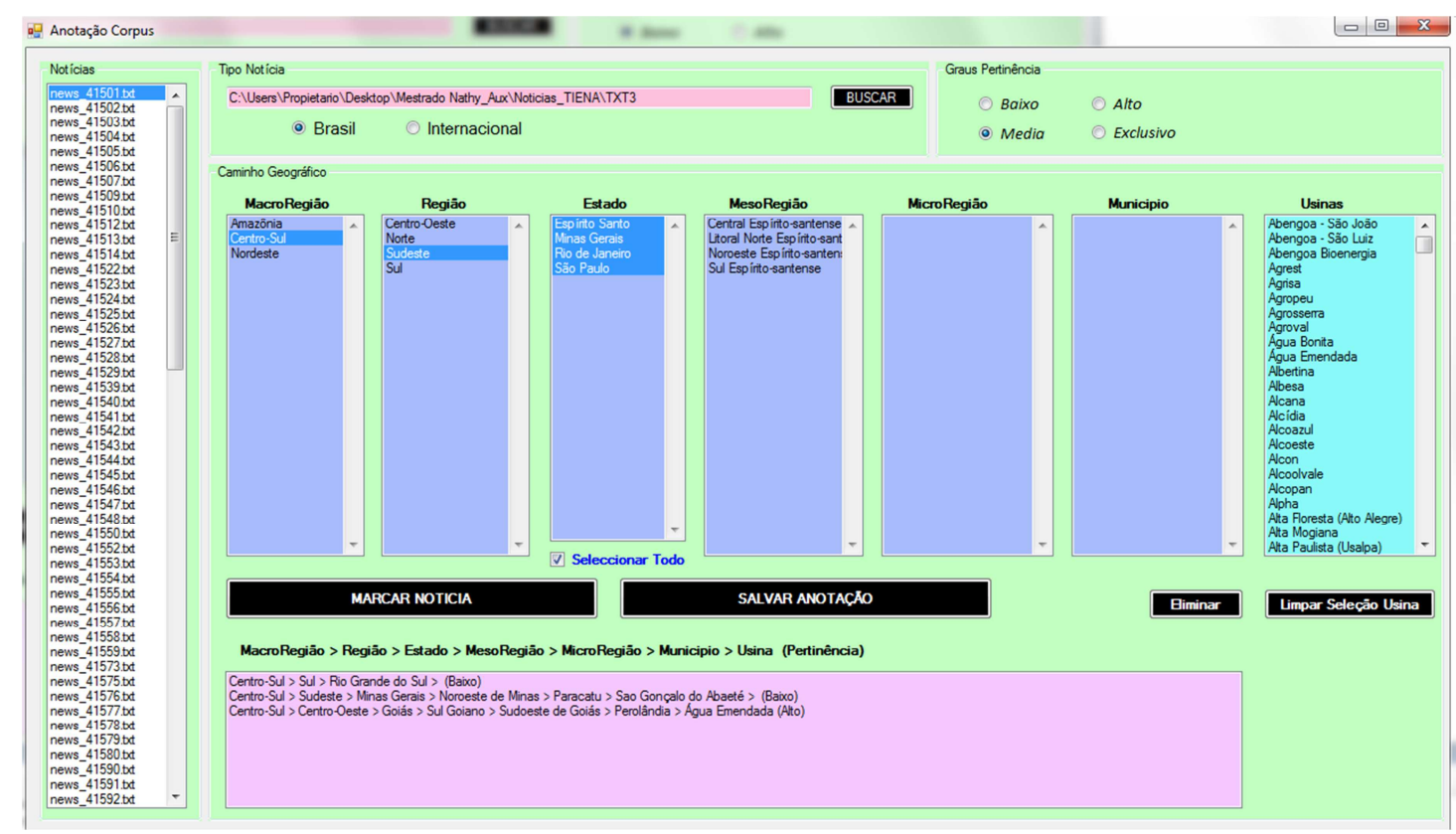

Figura 4.13: Tela principal do programa de Marcação de Corpus Geográfico

os documentos a serem marcados e, a medida que o documento é anotado, o mesmo desaparece da lista. Além disso, a ferramenta permite armazenar os dados em dois formatos: (1) formato escrito, o qual descreve em forma de linguagem natural os caminhos que foram marcados para cada documento, e (2) formato para métodos de Aprendizado de Máquina, o qual deixa os dados preparados para serem utilizados como parte do treinamento do classificador. Para obter o formato para Aprendizado de Máquina, consideram-se como classes todas as entidades geográficas do Brasil. Após, quando o especialista faz uma anotação de um caminho geográfico gera-se um documento no qual coloca-se 1 para cada classe marcada e 0 para as que não foram marcadas.

A ferramenta, como observado na Figura 4.13, permite ao especialista registrar o grau de pertinência de cada caminho geográfico. Considerando que cada documento pode ter entre $1-n$ caminhos geográficos marcados. Os graus de pertinência permitidos são: baixo, meio, alto e exclusivo. A marcação usando os graus de pertinência irá servir posteriormente para determinar a importância de cada caminho geográfico dentro de um documento. Alguns caminhos geográficos marcados podem ser mais representativos que outros, e, portanto esses caminhos devem ter um peso maior na hora de classificá-los ou mostrá-los em ordem de importância. 
DePP: Desambiguação por Pontos

Esta ferramenta permite a classificação de um conjunto de documentos utilizando a Desambiguação por Pontos, explorada neste trabalho de mestrado. Inicialmente a ferramenta foi desenvolvida em CSharp e SQL.

A ferramenta foi desenvolvida por linha de comando e permite fazer o filtro de entidades dos documentos processados com a ferramenta Rembrandt ou o vocabulário AGRI-BR. É importante ressaltar que a ferramenta não faz o pré-processamento que faz o Rembrandt. Ou seja, a entrada da ferramenta deve ser um conjunto de documentos previamente pré-processados pelo Rembrandt.

DeTE: Desambiguação Textual e Estrutural

A ferramenta DeTE permite fazer a classificação de um conjunto de documentos utilizando a Desambiguação Textual e Estrutural proposta neste projeto de mestrado. Esta ferramenta utiliza como base para as consultas e desambiguação uma ontologia geográfica do Brasil que está em formato ".owl”. As consultas para extrair os caminhos geográficos da ontologia foram feitas utilizando a linguagem SPARQL.

Da mesma forma que a ferramenta DePP não se inclui dentro da ferramenta o pré-processamento embutido do Rembrandt. Esta ferramenta que foi desenvolvida também por linha de comando, permite ao usuário mudar os valores dos parâmetros de corte, peso de entidades ambíguas e peso de dicas no texto desde o início.

Como resultado final das ferramentas DePP e DeTE, cria-se uma nova pasta que contém um arquivo por cada documento que foi processado, e cada documento contém uma lista dos caminhos hierárquicos reconhecidos. Estas ferramentas foram parte importante para viabilizar as avaliações que serão mostradas no Capítulo 5.

\subsection{Considerações Finais}

Neste capítulo foi apresentada a metodologia proposta para a realização da descoberta da cobertura espacial dos documentos. A metodologia SpatialCIM proposta está baseada em três etapas fundamentais: (1) reconhecimento das entidades geográficas associadas a cada documento; (2) obtenção dos caminhos geográficos de cada entidade, e (3) desambiguação das entidades. 
Adicionalmente foram detalhados os dois processos de desambiguação propostos: (1) Desambiguação por Pontos, que usa como base as coordenadas geográficas para construir um polígono entre todas as entidades, e (2) Desambiguação Textual e Estrutural, que utiliza como base o próprio documento fonte e uma análise profunda da hierarquia para obter resultados.

Foram explorados também os recursos e as ferramentas implementadas para viabilizar a utilização da metodologia SpatialCIM. Como recursos foram implementados ou adaptados o gazetteer brasileiro, a ontologia geográfica do Brasil e o vocabulário controlado denominado AGRI-BR. Esses recursos foram desenvolvidos para permitir o correto funcionamento das ferramentas desenvolvidas. Entre as ferramentas desenvolvidas encontra-se o BraGeoPs, que permite a marcação dos caminhos geográficos por parte de um especialista e viabiliza a criação de uma marcação apta para ser usada por métodos de Aprendizado de Máquina. As ferramentas DePP e DeTE, que foram também desenvolvidas neste trabalho, permitem a realização da Desambiguação por Pontos e a Desambiguação Textual e Estrutural respetivamente.

Para poder comparar os resultados dos dois tipos de desambiguação propostos, assim como também a influência das ferramentas de Reconhecimento de entidades mencionadas foram realizados uma série de experimentos que visam determinar o comportamento desta abordagem e que será apresentado no seguinte capítulo. 


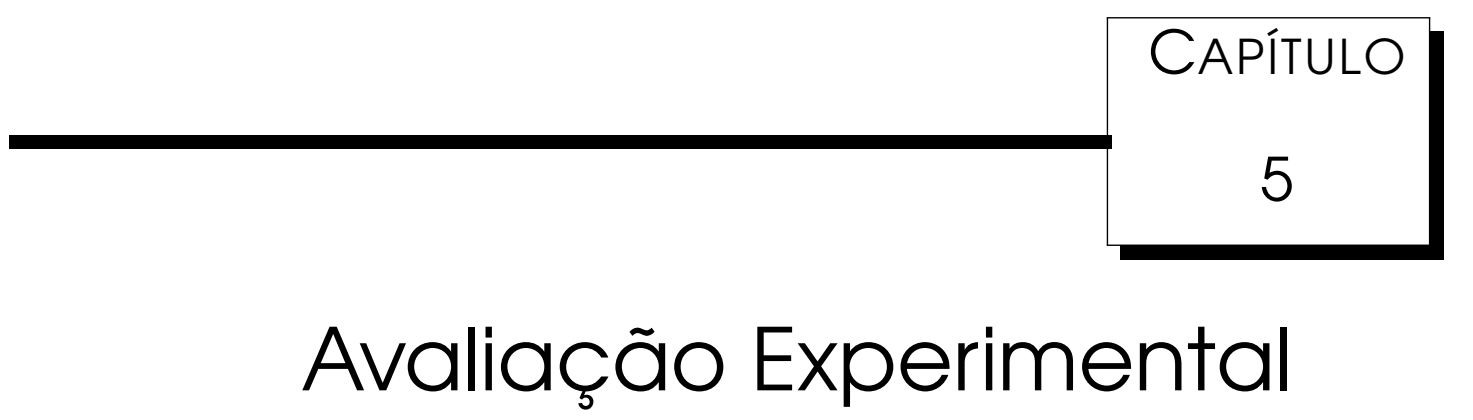

\subsection{Considerações Iniciais}

Para avaliar os métodos de desambiguação da metodologia SpatialCIM, detalhados no Capítulo 4 foram realizados quatro experimentos. Os dois primeiros experimentos consistem em avaliar o desempenho da abordagem de Desambiguação por Pontos e a Desambiguação Textual e Estrutural, detalhadas na Seção 4.2.3, avaliando os resultados a nível global e considerando também cada nível da hierarquia. O terceiro experimento busca comparar a técnica de classificação hierárquica multi-rótulo de Aprendizado de Máquina com os processos de desambiguação da metodologia SpatialCIM para assim mostrar alguns desafios de se utilizar a abordagem de Aprendizado de Máquina neste tipo de problema. Finalmente, o quarto experimento consiste em determinar qual dos dois métodos de desambiguação tem um melhor desempenho no problema abordado.

Nas seguintes seções são detalhados os processos de avaliação, os experimentos realizados, a coleção de documentos textual utilizada, e os resultados obtidos.

\subsection{Visão Geral da Avaliação}

O objetivo principal dos experimentos é avaliar o desempenho de cada uma das abordagens de desambiguação propostas para assim determinar aquela 
que soluciona de uma forma mais eficiente o problema de determinação da cobertura espacial dos documentos. Um objetivo importante deste projeto de mestrado é determinar se a desambiguação dos caminhos geográficos ajuda no processo de determinar a correta localização dos documentos. Para isso, é necessário avaliar se os caminhos geográficos não-desambiguados tem um melhor desempenho que os caminhos geográficos desambiguados ou viceversa. É importante também, considerando o escopo deste projeto, avaliar a influência das ferramentas de Reconhecimento de Entidades Mencionadas nos caminhos geográficos obtidos.

As seguintes ferramentas foram usadas para a realização dos experimentos:

1. DePP: ferramenta desenvolvida neste projeto de mestrado para executar a Desambiguação por Pontos, descrita na seção 4.3.4 e usada como parte do processo de desambiguação da metodologia SpatialCIM;

2. DeTE: ferramenta desenvolvia neste projeto de mestrado para executar a Desambiguação Textual e Estrutural, descrita na seção 4.3.4 e usada como parte do processo de desambiguação da metodologia SpatialCIM;

3. Pretext (Soares et al., 2008): usada para realizar o pré-processamento dos documentos;

4. Mulan (Tsoumakas et al., 2011): biblioteca para classificação hierárquica multi-rótulo usada para os experimentos com Aprendizado de Máquina;

5. Rembrandt (Cardoso, 2008): ferramenta linguística que permite o reconhecimento de entidades mencionadas em português, utilizada como parte do pré-processamento da metodologia SpatialCIM.

Para a avaliação dos resultados, dividiu-se os experimentos em dois grupos: (1) métricas de avaliação, e (2) métricas de comparação. As primeiras métricas tem por objetivo avaliar o desempenho de cada abordagem de desambiguação proposta, analisando o $F$-Score da abordagem e o $F$-score por cada nível hierárquico para assim determinar em que nível ocorrem mais erros de classificação. As métricas comparativas permitirão avaliar que processo de desambiguação tem uma melhor desempenho. Dentro dessas métricas comparativas foi considerado o teste estatístico Paired t-teste. O Paired t-teste é um teste paramétrico que é usado para comparar duas amostras de exemplos sobre o mesmo assunto ou que estão relacionadas com o tempo (Wohlin 


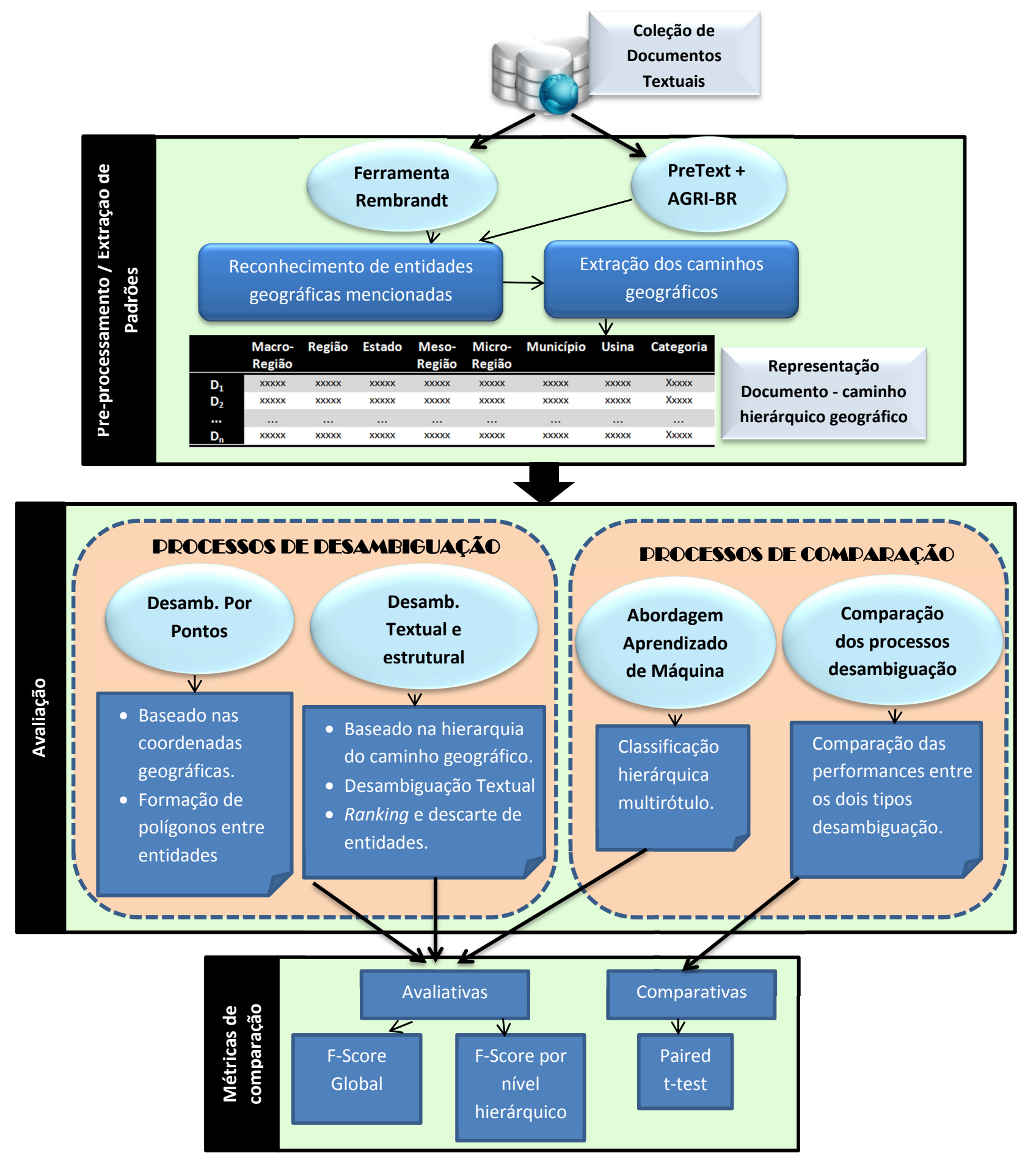

Figura 5.1: Visão Geral da Avaliação 
et al., 2000). Esse teste foi escolhido para fazer uma comparação entre duas amostras processadas com os dois tipos diferentes de desambiguadores, com o objetivo de determinar se os processos de desambiguação são estatisticamente significantes. Na Figura 5.1 são ilustrados os passos utilizados nos experimentos.

Para a realização destes experimentos utilizou-se um banco de documentos provido pela Embrapa Informação Agricultural ${ }^{1}$, que contém 698 notícias agrícolas da cana-de-açúcar em português. Esse conjunto de documentos foi previamente marcado por um especialista da Embrapa, o qual serviu para validar os resultados obtidos pelos desambiguadores.

O processo começa passando o conjunto de documentos pelas ferramentas (1) Rembrandt e (2) vocabulário controlado AGRI-BR. Para os documentos que usaram o Rembrandt para reconhecer as entidades mencionadas não foi realizado um pré-processamento dos documentos como limpeza de stopwords ou stemização. Isso, devido ao fato que o Rembrandt precisa analisar cada frase para assim determinar e classificar as entidades segundo o contexto e o sentido da palavra. Para os documentos que foram pré-processados usando o vocabulário controlado AGRI-BR foi feita uma limpeza e redução de termos usando a ferramenta PreText.

Na seção 5.2.1 será apresentada um descrição da coleção de documentos utilizados para a avaliação. Após, na seção 5.2.2 é apresentada uma análise dos documentos considerando a quantidade de entidades reconhecidas para determinar se o tamanho dos documentos influência nas abordagens de desambiguação.

\subsubsection{Coleções de Documentos Textuais utilizadas nos experimen- tos}

Os experimentos foram realizados utilizando a coleção textual provida pela Embrapa Informática Agropecuária. Esse conjunto de documentos é formado por 698 notícias que foram extraídas do Jornal da Cana ${ }^{2}$ usando a ferramenta NewsCap (Magalhaes e Moura, 2010).

Cada documento consta de 800 palavras aproximadamente, e têm entre $1 \mathrm{e}$ 10 entidades geográficas associadas. Para o conjunto de documentos, o especialista reconheceu um total de 1597 entidades geográficas. Nesse conjunto de documentos marcadas pelo especialista detectou-se: (i) 414 documentos com

\footnotetext{
${ }^{1}$ http: / / cnptia.embrapa.br/

2 http: / / jornalcana.com.br/
} 


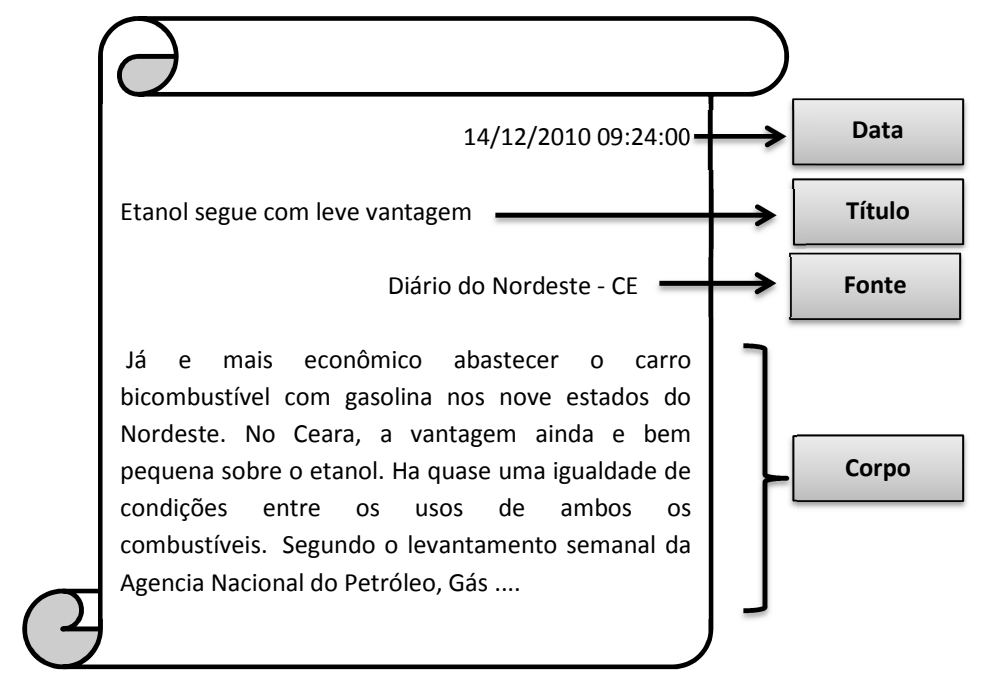

Figura 5.2: Documento da coleção de notícias da cana-de-açúcar

um único caminho associado; (ii) 121 documentos tem dois caminhos associados; (iii) 51 documentos tem três caminhos associados; (iv) 21 documentos tem quatro caminhos associados; (v) 16 documentos tem cinco caminhos associados; e (vi) 75 documentos tem mais de cinco caminhos associados. Esses valores representam uma maior quantidade de documentos marcados com poucas entidades. Entre as marcações consideram-se os caminhos geográficos de cada entidade considerando a divisão geo-política do Brasil. O conjunto de documentos foi pré-processado usando (1) ferramenta Rembrandt, e (2) vocabulário controlado AGRI-BR, com o objetivo de avaliar o desempenho de cada uma das ferramentas no processo de desambiguação.

Na Figura 5.2 é ilustrada a estrutura dos documentos que foram analisados. Nos documentos encontram-se informação como data, título, fonte e corpo do documento. Para este projeto de mestrado foram utilizadas o título, a fonte e o corpo do documentos, devido ao fato que esses três campos têm maior probabilidade de ter mais entidades geográficas associadas.

Uma importante preocupação para fazer os experimentos foi a quantidade de caminhos geográficos reconhecidos para cada documento e a penalização aplicada para cada um. Como penalização entende-se o número de entidades incorretas reconhecidas, afetando dessa forma os valores de precisão e cobertura. Sendo que os documentos pequenos com poucas entidades tem uma maior possibilidade de ter uma quantidade maior de entidades certas que os documentos com muitas entidades marcadas. A seguir é apresentado um estudo realizado com duas amostras da coleção de documentos com o objetivo de verificar se a quantidade de entidades reconhecidas influencia nos 
resultados dos desambiguadores.

\subsubsection{Estabilidade no Tamanho dos Documentos}

Após de fazer uma análise dos documentos marcados pelo especialista, determinou-se que existem dois grupos de documentos que podem ser diferenciados pelo número de entidades reconhecidas: (1) documentos com poucas entidades marcadas, que geralmente tem entre 1 e 5 caminhos reconhecidos, e (2) documentos com um grande número de entidades marcadas, que tem entre 5 e 10 caminhos reconhecidos aproximadamente.

Para realizar este experimento foi tomado como amostra um conjunto de 40 documentos. Esses documentos foram escolhidos observando o número de entidades marcadas pelo especialista e que estão entre 1 e 5. Para cada documento calculou-se a cobertura, precisão e $F$-score com o intuito de observar o comportamento dos documentos que passam pelo processo nãodesambiguado e desambiguado utilizando o Rembrandt e o AGRI-BR. O resultado desse primeiro teste, ilustrado na Figura 5.3, mostra que o processo "Rembrandt - processo desambiguado" apresenta melhores resultados que os outros métodos.Para realizar o teste ilustrado na Figura 5.3 utilizou-se como base o F-score dos diferentes processos considerando dez thresholds. O objetivo é observar o comportamento de cada processo para cada threshold, é dizer, observar o comportamento dos processos quando estabelece-se um limiar. Assim, quando estabelece-se um limite de 10\% como máximo, pode-se observar que os processos que usam o AGRI-BR apresentam melhores resultados. Se utiliza-se um limiar de $50 \%$ observa-se que os processos deambiguados que utilizaram o Rembrandt e o AGRI-BR apresentam melhores taxas de F-score. Finalmente, se coloca-se como limiar $100 \%$ pode-se observar que os dois processos que utilizam o Rembrandt aprensentam os melhores resultados. Essa mudança de comportamentos entre os processos demonstra que a maior exigencia os processos que se apresentam como melhores são aqueles que utilizaram o Rembrandt e foram desambiguados. Dessa forma observouse o comportamento dos processos considerando uma exigencia de $F$-score de $10 \%$ até $100 \%$.

A segunda parte do experimento considerou outra amostra de 40 documentos. Nesse experimento, considerou-se os documentos que o especialista marcou mais de 7 entidades. Assim como no experimento anterior, as métricas de cobertura, precisão e $F$-Score foram calculadas. Na Figura 5.4 é ilustrado o comportamento dos diferentes processos. Nessa figura foram utili- 


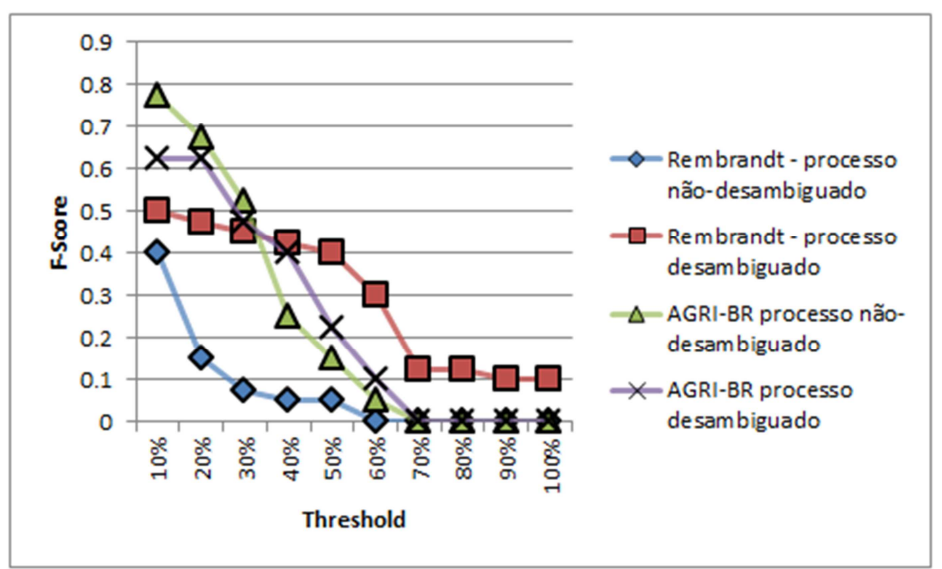

Figura 5.3: Comportamento dos processos não-desambiguado e desambiguado para documentos com poucas entidades reconhecidas e préprocessados com o Rembrandt e o AGRI-BR

zados também dez limiares que consideram o $F$-score como base para observar os comportamentos dos diferentes processos.

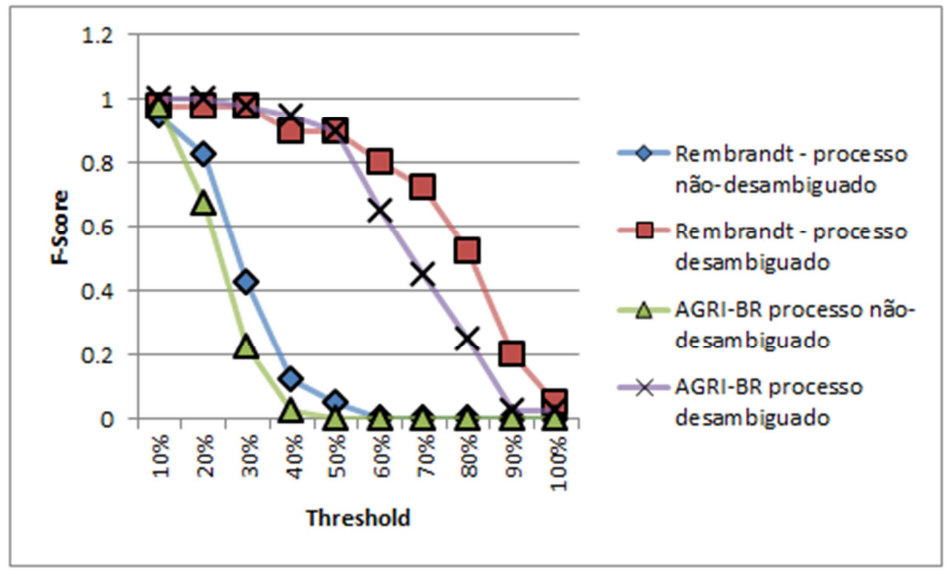

Figura 5.4: Comportamento dos processos não-desambiguado e desambiguado para os documentos com várias entidades reconhecidas e préprocessados com o Rembrandt e o AGRI-BR

Como pode-se observar nas Figuras 5.3 e 5.4 o processo "Rembrandt - processo desambiguado" apresenta os melhores resultados comparados com os outros métodos. Observa-se também que a ordem em que aparecem os quatro processos são similares à ordem apresentada com o primeiro experimento. Dessa forma, pode-se apreciar que o tamanho de entidades reconhecidas em cada documento não afeta de forma significativa o desempenho dos processos de desambiguação. 


\subsubsection{Avaliação das Abordagens de Desambiguação}

Para avaliar o desenvolvimento das abordagens com o conjunto de documentos, foram utilizadas as ferramentas: (1) Rembrandt, e (2) Vocabulário Controlado AGRI-BR como parte do pré-processamento dos documentos. Foi avaliada também a influência da desambiguação nos documentos usando as medidas de precisão, cobertura e $F$-score. Os experimentos foram divididos em:

- Avaliação Global, que tem o objetivo de avaliar a desambiguação como um todo sem considerar os erros de cada parte da hierarquia;

- Avaliação Hierárquica, que tem o objetivo é avaliar o erro em cada nível da hierarquia e dessa forma observar em que parte se produz a maior quantidade de erros.

Nas Seções 5.3 e 5.4 são apresentados os resultados da avaliação das duas abordagens de desambiguação propostas neste projeto. A Tabela 5.1 mostra uma descrição das abreviações que serão utilizadas neste capítulo para descrever os experimentos realizados.

Tabela 5.1: Descrição de Legenda das Tabelas de Avaliação Global e Hierárquica para a Desambiguação por Pontos e Desambiguação Textual e Estrutural

\begin{tabular}{l|l}
\hline Abreviação & Descrição \\
\hline $\mathbf{E}$ & Número de Entidades reconhecidas pelo Especialista \\
\hline $\mathbf{R}$ & $\begin{array}{l}\text { Número de Entidades reconhecidas pelo processo não- } \\
\text { desambiguado }\end{array}$ \\
\hline VP - ATP & $\begin{array}{l}\text { Número de Entidades certas reconhecidas pelo processo } \\
\text { não-desambiguado }\end{array}$ \\
\hline FP - ATN & $\begin{array}{l}\text { Número de Entidades incorretas reconhecidas pelo pro- } \\
\text { cesso não-desambiguado }\end{array}$ \\
\hline D & $\begin{array}{l}\text { Número de Entidades reconhecidas pelo processo desam- } \\
\text { biguado }\end{array}$ \\
\hline VP - DTP & $\begin{array}{l}\text { Entidades Certas reconhecidas pelo processo desambi- } \\
\text { guado }\end{array}$ \\
\hline FP - DTN & $\begin{array}{l}\text { Entidades Incorretas reconhecidas pelo processo desambi- } \\
\text { guado }\end{array}$ \\
\hline IRD & Número de Entidades que concordam na interseção \\
\hline VP - ITP & $\begin{array}{l}\text { Número de Entidades que concordam certo (Corretamente } \\
\text { reconhecidas por ambos processos) }\end{array}$ \\
\hline
\end{tabular}

Nas seguintes seções são apresentados os experimentos realizados para avaliar os métodos de desambiguação propostos. É apresentada também uma 
comparação dessas abordagens com uma abordagem de Aprendizado de Máquina.

\subsection{Avaliação da Abordagem de Desambiguação por Pontos}

Para obter os resultados com essa abordagem foi usado o conjunto dos 698 documentos processados com a ferramenta DePP. Os resultados dos processos não-desambiguado e o processo desambiguado foram comparados com os resultados marcados pelo Especialista. Na Tabela 5.2 é ilustrado um exemplo dos valores obtidos para os 15 primeiros documentos da coleção pré-processados com a ferramenta Rembrandt. Como observado, utilizamse vários critérios para definir a semelhança dos caminhos encontrados com os caminhos marcados pelo especialista. Uma das partes mais importantes encontra-se na última coluna já que esta analisa a interseção entre as entidades corretamente reconhecidas e a quantidade de entidades que foram reconhecidas em comum pelos dois processos.

Na Tabela 5.3 é ilustrado um exemplo dos 15 primeiros documentos da coleção pré-processados com o vocabulário controlado AGRI-BR. Comparando a Tabela 5.2 e 5.3 observa-se que em ambos casos o processo não-desambiguado reconhece uma maior quantidade de entidades comparadas com o processo desambiguado. Por exemplo, para o documento "41503" observa-se que o especialista marcou 8 entidades, o processo não-desambiguado usando o Rembrandt, ilustrado na Tabela 5.2, reconheceu 17 entidades e o AGRI-BR, ilustrado na Tabela 5.3, reconheceu 28. Observa-se também que ambas formas de pré-processamento obtiveram as 8 entidades corretas. No entanto, o AGRI-BR teve um erro maior ao reconhecer as entidades. No processo desambiguado, o número de entidades reconhecidas diminui, sendo que o Rembrandt reconheceu 12 entidades versus 18 do AGRI-BR. Porém, pode-se observar que o processo de desambiguação reduz o número de entidades reconhecidas. No entanto, os dados pré-processados com o Rembrandt tem como resultado uma menor quantidade de entidades reconhecidas.

Outro exemplo pode ser observado na Tabela 5.2 no documento "41509", para o qual o especialista reconheceu 10 entidades. O processo não-desambiguado usando o Rembrandt reconheceu 13 entidades e acertou 4. Por outro lado, o processo desambiguado reconheceu 7 entidades e acertou 3 . Na Tabela 5.3, para o mesmo documento, observa-se que o processo não-desam- 
Tabela 5.2: Comparação entre entidades corretas e incorretas dos processos não-desambiguado e desambiguado usando o Rembrandt para os 15 primeiros documentos da coleção para a abordagem de Desambiguação por Pontos

\begin{tabular}{c|c|ccc|cccccc}
\hline \multicolumn{10}{c|}{ Avaliação com Ferramenta Rembrandt } \\
\hline & Espec. & \multicolumn{1}{c|}{ Não-desambiguado } & \multicolumn{2}{c}{ Desambiguado } & $\begin{array}{c}\text { Não-Des. } \\
\text { vs Des. }\end{array}$ \\
\hline & E & R & VP-ATP & FP-ATN & D & VP-DTP & FP-DTP & IRD & VP-ITP \\
\hline 41501 & 2 & 10 & 1 & 9 & 9 & 1 & 8 & 9 & 1 \\
\hline 41502 & 1 & 3 & 0 & 3 & 1 & 0 & 1 & 1 & 0 \\
\hline 41503 & 8 & 17 & 8 & 9 & 12 & 8 & 4 & 12 & 8 \\
\hline 41504 & 2 & 6 & 1 & 5 & 2 & 0 & 2 & 2 & 0 \\
\hline 41505 & 2 & 5 & 2 & 3 & 3 & 2 & 1 & 3 & 2 \\
\hline 41506 & 2 & 5 & 2 & 3 & 3 & 2 & 1 & 3 & 2 \\
\hline 41507 & 1 & 1 & 1 & 0 & 1 & 1 & 0 & 1 & 1 \\
\hline 41509 & 10 & 13 & 4 & 9 & 7 & 3 & 4 & 7 & 3 \\
\hline 41510 & 2 & 3 & 2 & 1 & 3 & 2 & 1 & 3 & 2 \\
\hline 41512 & 1 & 2 & 1 & 1 & 2 & 1 & 1 & 2 & 1 \\
\hline 41513 & 2 & 2 & 1 & 1 & 1 & 1 & 0 & 1 & 1 \\
\hline 41514 & 1 & 1 & 0 & 1 & 1 & 0 & 1 & 1 & 0 \\
\hline 41522 & 2 & 7 & 1 & 6 & 4 & 0 & 4 & 4 & 0 \\
\hline 41523 & 1 & 5 & 0 & 5 & 3 & 0 & 3 & 3 & 0 \\
\hline 41716 & 10 & 16 & 10 & 6 & 12 & 7 & 5 & 12 & 7 \\
\hline
\end{tabular}

biguado usando o AGRI-BR reconheceu 22 entidades e acertou 8 e o processo desambiguado reconheceu 12 e acertou 6 entidades. Assim, nesse exemplo, nos dados processados com o Rembrandt e com o AGRI-BR o processo nãodesambiguado teve uma maior taxa de acerto. No entanto, a quantidade de entidades reconhecidas pelo processo não-desambiguado é maior que o processo desambiguado.

Uma vez que os dados de acerto e erro de entidades para cada um dos processos e com cada uma das ferramentas de pré-processamento foram obtidos, podem ser analisados usando medidas estatísticas. O objetivo principal da avaliação é demostrar que o processo de desambiguação melhora os processos de não-desambiguação. Outro objetivo é determinar qual método de pré-processamento dos documentos gera melhores resultados para a abordagem de Desambiguação por Pontos. 
Tabela 5.3: Comparação entre entidades corretas e incorretas dos processos não-desambiguado e desambiguado usando o Vocabulário Controlado AGRIBR para os 15 primeiros documentos da coleção para a abordagem de Desambiguação por Pontos

\begin{tabular}{c|c|ccc|ccc|ccc}
\hline \multicolumn{8}{|c|}{ Avaliação com o Vocabulário Controlado AGRI-BR } \\
\hline & Espec. & \multicolumn{2}{c|}{ Não-desambiguado } & \multicolumn{2}{c}{ Desambiguado } & \multicolumn{2}{c}{$\begin{array}{c}\text { Não-Des. } \\
\text { vs Des. }\end{array}$} \\
\hline & E & R & VP-ATP & FP-ATN & D & VP-DTP & FD-DTP & IRD & VP-ITP \\
\hline 41501 & 2 & 19 & 2 & 17 & 15 & 2 & 13 & 15 & 2 \\
\hline 41502 & 1 & 5 & 0 & 5 & 3 & 0 & 3 & 3 & 0 \\
\hline 41503 & 8 & 28 & 8 & 20 & 18 & 7 & 11 & 18 & 7 \\
\hline 41504 & 2 & 7 & 1 & 6 & 3 & 0 & 3 & 3 & 0 \\
\hline 41505 & 2 & 11 & 2 & 9 & 7 & 1 & 6 & 7 & 1 \\
\hline 41506 & 2 & 7 & 2 & 5 & 6 & 2 & 4 & 6 & 2 \\
\hline 41507 & 1 & 2 & 1 & 1 & 2 & 1 & 1 & 2 & 1 \\
\hline 41509 & 10 & 22 & 8 & 14 & 12 & 6 & 6 & 12 & 6 \\
\hline 41510 & 2 & 15 & 4 & 11 & 7 & 3 & 4 & 7 & 3 \\
\hline 41512 & 1 & 8 & 1 & 7 & 6 & 1 & 5 & 6 & 1 \\
\hline 41513 & 2 & 3 & 1 & 2 & 3 & 1 & 2 & 3 & 1 \\
\hline 41514 & 1 & 2 & 0 & 2 & 2 & 0 & 2 & 2 & 0 \\
\hline 41522 & 2 & 15 & 2 & 13 & 8 & 1 & 7 & 8 & 1 \\
\hline 41523 & 1 & 1 & 0 & 1 & 1 & 0 & 1 & 1 & 0 \\
\hline 41716 & 10 & 19 & 9 & 10 & 12 & 14 & 7 & 14 & 7 \\
\hline
\end{tabular}

Na seguintes seções serão descritos os resultados obtidos das avaliações globais e hierárquicos.

\subsubsection{Avaliação Global}

Na Tabela 5.4 é apresentado um resumo das medidas de precisão, cobertura e $F$-score para o conjunto dos 698 documentos comparando os processos não-desambiguado e desambiguado com a utilização da ferramenta Rembrandt e o AGRI-BR. Os resultados mostram um melhor desempenho dos documentos que foram pré-processados utilizando a ferramenta Rembrandt e passaram pelo processo desambiguação. Para os documentos préprocessados com o AGRI-BR, observou-se melhores resultados no processo desambiguado. O Rembrandt usando a Desambiguação por Pontos obteve um 
F-Score de 0.4862 e o AGRI-BR obteve 0.3836, demonstrando uma melhor performance dos documentos desambiguados e pré-processados com ajuda do Rembrandt.

Tabela 5.4: Avaliação da Precisão, Cobertura e F-Score dos processos nãodesambiguado e desambiguado para a Desambiguação por Pontos

\begin{tabular}{|c|cc|cc}
\hline \hline & \multicolumn{2}{c}{\begin{tabular}{c} 
Rembrandt \\
\multicolumn{2}{c|}{ AGRI-BR } \\
Não-Desamb. Desamb.
\end{tabular} Não-Desamb. Desamb. } \\
\hline Precisão & 0.3147 & $\mathbf{0 . 4 1 9 6}$ & 0.2131 & $\mathbf{0 . 2 5 9 0}$ \\
\hline Cobertura & $\mathbf{0 . 6 7 0 2}$ & 0.5780 & $\mathbf{0 . 9 0 4 7}$ & 0.7391 \\
\hline F-Score & 0.4283 & $\mathbf{0 . 4 8 6 2}$ & 0.3450 & $\mathbf{0 . 3 8 3 6}$ \\
\hline
\end{tabular}

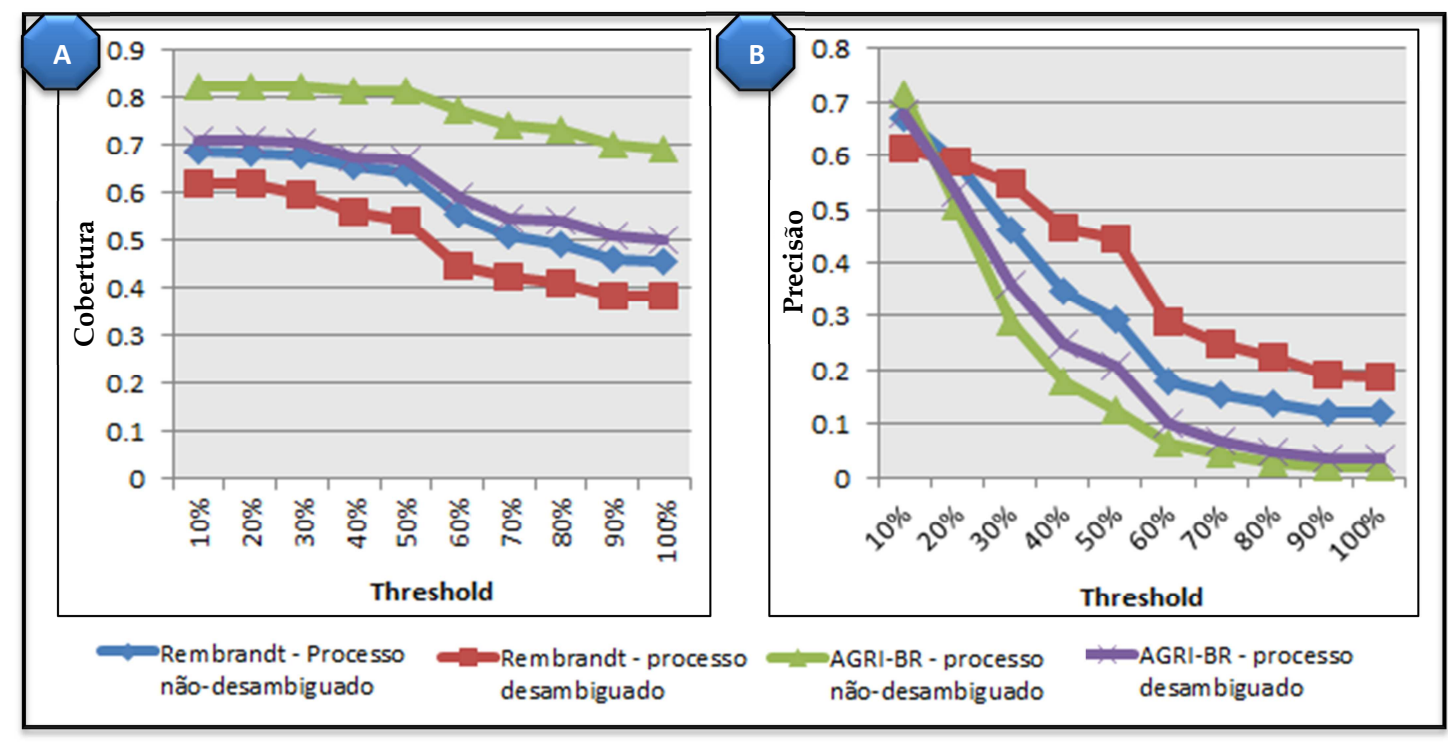

Figura 5.5: Precisão e Cobertura para os processos não-desambiguados e desambiguados usando o Rembrandt e o AGRI-BR na Desambiguação por Pontos

Na Figura 5.5 é ilustrado o comportamento do processo não-desambiguado e o processo desambiguado usando os dois tipos de pré-processamento definidos. Na Figura 5.5(a) é ilustrado o comportamento comparando a cobertura de todos os processos, e a Figura 5.5(b) ilustra o comportamento utilizando a precisão. Utilizou-se 10 thresholds para avaliar os 4 processos. Cada threshold representa um valor máximo a ser alcanzado. Assim, um threshold de $10 \%$ mostrara o comportamento dos processos quando se quer um valor de cobertura, precisão ou F-score de 0.1. Um threshold de $100 \%$ mostrara o 
comportamento dos processos quando se quer um valor de 1. Assim, avaliando o comportamento dos processos para cada threshold espera-se observar o comportamento do processo quando a exigencia é maior. Como observado na Figura 5.5(a), o processo que tem uma maior cobertura e recupera uma maior quantidade de entidades é o "AGRI-BR não-desambiguado". No entanto, esse mesmo processo na Figura 5.5(b) representa aquele que tem a menor taxa de precisão. Observa-se também que os processos não-desambiguados representam aqueles com maior cobertura e menor precisão. Por outro lado, os processos de desambiguação mostram uma cobertura e uma precisão média.

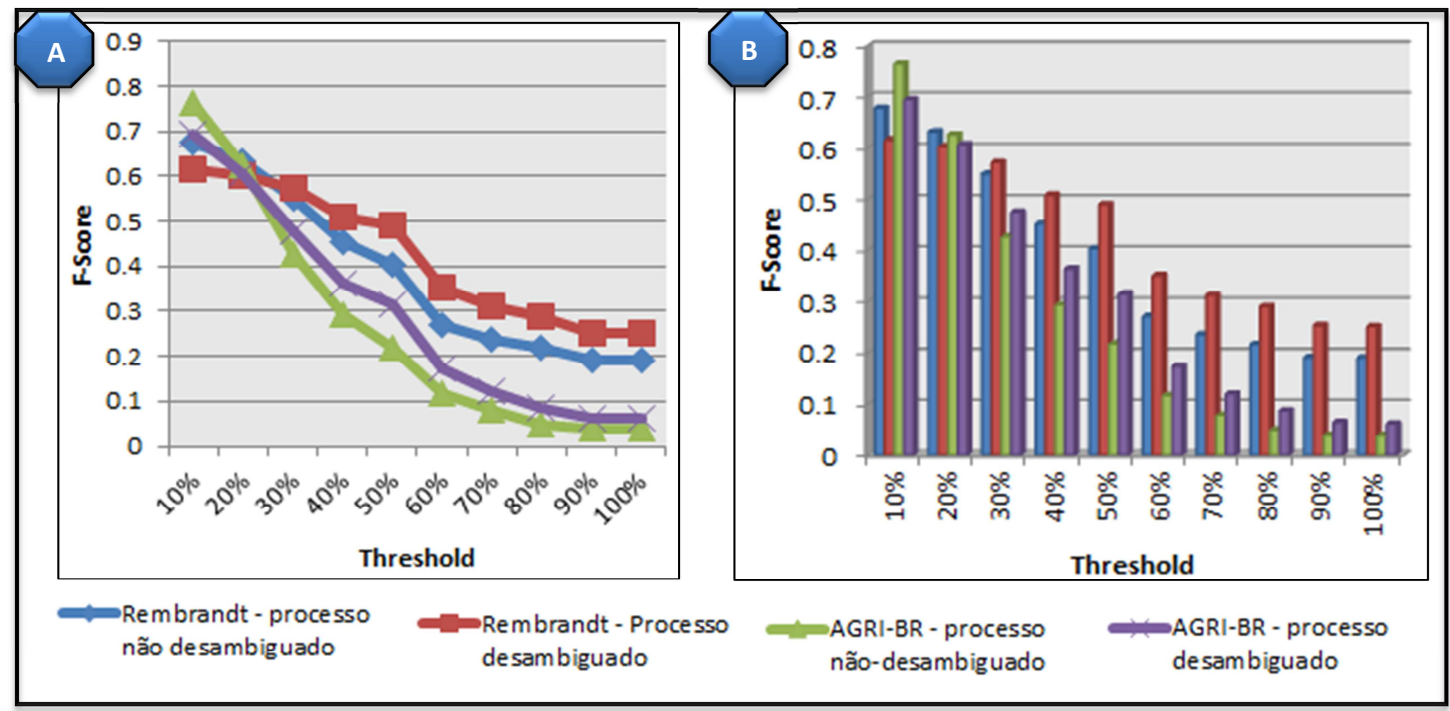

Figura 5.6: F-Score para os processos não-desambiguados e desambiguados usando o Rembrandt e o AGRI-BR na Desambiguação por Pontos

Na Figura 5.6 é ilustrado o comportamento dos processos de desambiguação e não-desambiguação usando o pré-processamento do Rembrandt e o AGRI-BR utilizando a medida $F$-Score. A primeira coluna do gráfico representa o "Rembrandt - processo não-desambiguado", seguido pelo " Rembrandt - processo desambiguado", "AGRI-BR processo não-desambiguado”, e finalmente "AGRI-BR processo desambiguado". Com essa comparação pretende-se determinar qual processo apresenta-se mais estável considerando a precisão e cobertura. Ou seja, procura-se identificar o processo que mantem uma precisão e cobertura equilibradas. Na Figura 5.6(a) pode-se observar que nos thresholds de $10 \%$ e $20 \%$ o processo "AGRI-BR não-desambiguado" apresenta um pico. Nos thresholds seguintes os processos começam a se estabilizar e observa-se que o processo que tem um maior $F$-Score é o "Rembrandt com o processo desambiguado, seguido pelo Rembrandt com o processo não-desam- 
biguado e por último os processos que usaram o AGRI-BR. Na Figura 5.6(b) observa-se também que a medida que o F-Score do Rembrandt desambiguado aumenta os demais F-Scores diminuem consideravelmente, especialmente dos processados com o AGRI-BR.

O fato do F-Score aumentar para o Rembrandt e diminuir para o AGRI-BR deve-se à diferença entre a quantidade de entidades reconhecidas e a quantidade de entidades corretamente reconhecidas por cada processo. Nesse caso, observa-se que os processos que foram pré-processados com o Rembrandt tendem a ter menor quantidade de entidades reconhecidas e maior quantidade de entidades corretamente reconhecidas.

Como observado na Tabela 5.4, os valores de precisão, cobertura e $F$-score obtidos são relativamente baixos comparados com os valores na literatura. Uma importante variação da abordagem aqui proposta com algumas da literatura é o fato de utilizar uma desambiguação considerando a hierarquia das entidades, o que poderia estar influenciando nos resultados finais. Assim, a próxima seção apresenta uma avaliação considerando cada parte da hierarquia.

\subsubsection{Avaliação por partes da Hierarquia}

Acredita-se que o problema da baixa precisão e cobertura se deve à influência da estrutura hierárquica no processo de desambiguação. Nas Tabelas 5.5 e 5.6 mostram-se os valores de acerto e erro para os processos não-desambiguados e desambiguados usando o Rembrandt. O objetivo desta avaliação analisar em que parte da hierarquia está acontecendo a maior quantidade de erros, o que poderia estar influenciando os resultados globais apresentados anteriormente.

Como observado na Tabela 5.5, referente aos dados pré-processados com o Rembrandt, a maior parte dos erros, considerando o processo não-desambiguado, acontecem na classificação de Usinas, gerando um erro de $80.67 \%$. Outra parte da hierarquia que está gerando grande parte dos erros é no nível de Município com $72.85 \%$ de erro. Para o processo desambiguado, apresentado na Tabela 5.6, a maior parte dos erros encontra-se também no nível de Usina, sendo o erro de 79.41\%. Já o segundo nível que apresenta grande percentagem de erro é o País, gerando um erro de 63.32\%. Por outro lado, os níveis que tem menor quantidade de erros para ambos processos encontram-se nos níveis mais superiores da hierarquia e são MacroRegião, Estado e Região.

Na Tabela 5.7, referente aos dados pré-processados com o AGRI-BR, pode- 
Tabela 5.5: Avaliação hierárquica da coleção de documentos usando Rembrandt para o processo não-desambiguado para a Desambiguação por Pontos

\begin{tabular}{|c|c|c|c|c|c|}
\hline \multicolumn{6}{|c|}{$\begin{array}{c}\text { Resumo Avaliação Hierárquica (Rembrandt) do conjunto de documentos } \\
\text { não-desambiguados }\end{array}$} \\
\hline & \multirow{2}{*}{$\begin{array}{l}\text { Entidades } \\
\text { Especialista }\end{array}$} & \multicolumn{4}{|c|}{ Processo não-desambiguado } \\
\hline & & Nro Entidades & $\begin{array}{l}\text { Total Ent. } \\
\text { Corretas }\end{array}$ & Erro & \% Erro \\
\hline Macro-Região & 1219 & 792 & 784 & 435 & 35.68 \\
\hline Região & 1152 & 948 & 659 & 493 & 42.80 \\
\hline Estado & 1146 & 1367 & 543 & 603 & 52.62 \\
\hline Meso-Região & 835 & 1489 & 351 & 484 & 57.96 \\
\hline Micro-Região & 823 & 1501 & 330 & 493 & 59.90 \\
\hline Municipio & 792 & 1513 & 215 & 577 & 72.85 \\
\hline Usina & 476 & 582 & 92 & 384 & 80.67 \\
\hline País & 379 & 639 & 136 & 243 & 64.12 \\
\hline
\end{tabular}

Tabela 5.6: Avaliação hierárquica da coleção de documentos usando Rembrandt para o processo desambiguado para a Desambiguação por Pontos

\begin{tabular}{|c|c|c|c|c|c|}
\hline \multicolumn{6}{|c|}{$\begin{array}{c}\text { Resumo Avaliação Hierárquica (Rembrandt) do conjunto de documentos } \\
\text { desambiguados }\end{array}$} \\
\hline & \multirow{2}{*}{$\begin{array}{l}\text { Entidades } \\
\text { Especialista }\end{array}$} & \multicolumn{4}{|c|}{ Processo Desambiguado } \\
\hline & & Nro Entidades & $\begin{array}{l}\text { Total Ent. } \\
\text { Corretas }\end{array}$ & Erro & \% Erro \\
\hline Macro-Região & 1219 & 677 & 794 & 425 & 34.86 \\
\hline Região & 1152 & 778 & 681 & 471 & 40.89 \\
\hline Estado & 1146 & 1367 & 570 & 576 & 50.26 \\
\hline Meso-Região & 835 & 973 & 370 & 465 & 55.69 \\
\hline Micro-Região & 823 & 946 & 375 & 448 & 54.43 \\
\hline Municipio & 792 & 977 & 302 & 490 & 61.87 \\
\hline Usina & 476 & 538 & 98 & 378 & 79.41 \\
\hline País & 379 & 529 & 139 & 240 & 63.32 \\
\hline
\end{tabular}

se verificar que a maior parte dos erros, considerando o processo não-desambiguado, acontecem na classificação de Usinas, gerando um erro de $92.02 \%$. Outra parte da hierarquia que está gerando grande parte dos erros é no nível de Município com 91.04\%. Para o processo desambiguado, cujos resultados são apresentados na Tabela 5.8, a maior parte dos erros encontra-se também no nível de Usina, gerando um erro de 87.39\%. Já o segundo nível que apresenta grande percentagem de erro é o nível País, gerando um erro de $79.04 \%$. 
Tabela 5.7: Avaliação hierárquica da coleção de documentos usando o AGRIBR para o processo não-desambiguado para a Desambiguação por Pontos

\begin{tabular}{|c|c|c|c|c|c|}
\hline \multicolumn{6}{|c|}{$\begin{array}{l}\text { Resumo Avaliação Hierárquica (AGRI-BR) do conjunto de documentos } \\
\text { não-desambiguados }\end{array}$} \\
\hline & \multirow{2}{*}{$\begin{array}{l}\text { Entidades } \\
\text { Especialista }\end{array}$} & \multicolumn{4}{|c|}{ Processo não-desambiguado } \\
\hline & & Nro Entidades & $\begin{array}{l}\text { Total Ent. } \\
\text { Corretas }\end{array}$ & Erro & $\%$ Erro \\
\hline Macro-Região & 1219 & 1440 & 706 & 513 & 42.08 \\
\hline Região & 1152 & 1768 & 598 & 554 & 48.09 \\
\hline Estado & 1146 & 3190 & 445 & 701 & 61.17 \\
\hline Meso-Região & 835 & 3915 & 251 & 584 & 69.94 \\
\hline Micro-Região & 823 & 4054 & 213 & 610 & 74.12 \\
\hline Municipio & 792 & 3889 & 71 & 721 & $91 . \overline{04}$ \\
\hline Usina & 476 & 1066 & 38 & 438 & 92.02 \\
\hline País & 379 & 614 & 124 & 255 & 67.28 \\
\hline
\end{tabular}

Tabela 5.8: Avaliação hierárquica da coleção de documentos usando o AGRIBR para o processo não-desambiguado para a Desambiguação por Pontos

\begin{tabular}{|c|c|c|c|c|c|}
\hline \multicolumn{6}{|c|}{$\begin{array}{c}\text { Resumo Avaliação Hierárquica (AGRI-BR) do conjunto de documentos } \\
\text { desambiguados }\end{array}$} \\
\hline & \multirow{2}{*}{$\begin{array}{l}\text { Entidades } \\
\text { Especialista }\end{array}$} & \multicolumn{4}{|c|}{ Processo Desambiguado } \\
\hline & & Nro Entidades & $\begin{array}{c}\text { Total Ent. } \\
\text { Corretas }\end{array}$ & Erro & \% Erro \\
\hline Macro-Região & 1219 & 1318 & 717 & 502 & 41.18 \\
\hline Região & 1152 & 1524 & 629 & 523 & 45.40 \\
\hline Estado & 1146 & 3190 & 495 & 651 & 56.81 \\
\hline Meso-Região & 835 & 2917 & 285 & 550 & 65.87 \\
\hline Micro-Região & 823 & 2985 & 269 & 554 & 67.31 \\
\hline Municipio & 792 & 3035 & 166 & 626 & 79.04 \\
\hline Usina & 476 & 962 & 60 & 416 & 87.39 \\
\hline País & 379 & 527 & 141 & 238 & 62.80 \\
\hline
\end{tabular}

Por outro lado, os níveis que tem menor quantidade de erros para ambos processos encontram-se nos níveis superiores da hierarquia e são MacroRegião, Estado e Região, assim como nos documentos pré-processados com o Rembrandt.

Na Figura 5.7 é ilustrada a percentagem de erro obtida em cada nivel da hierarquia. Como observado na Figura 5.7(a) o processo que gera maior quantidade de erros de classificação é o "AGRI-BR não-desambiguado", seguido pelo "AGRI-BR desambiguado". O processo que gera uma menor quantidade 


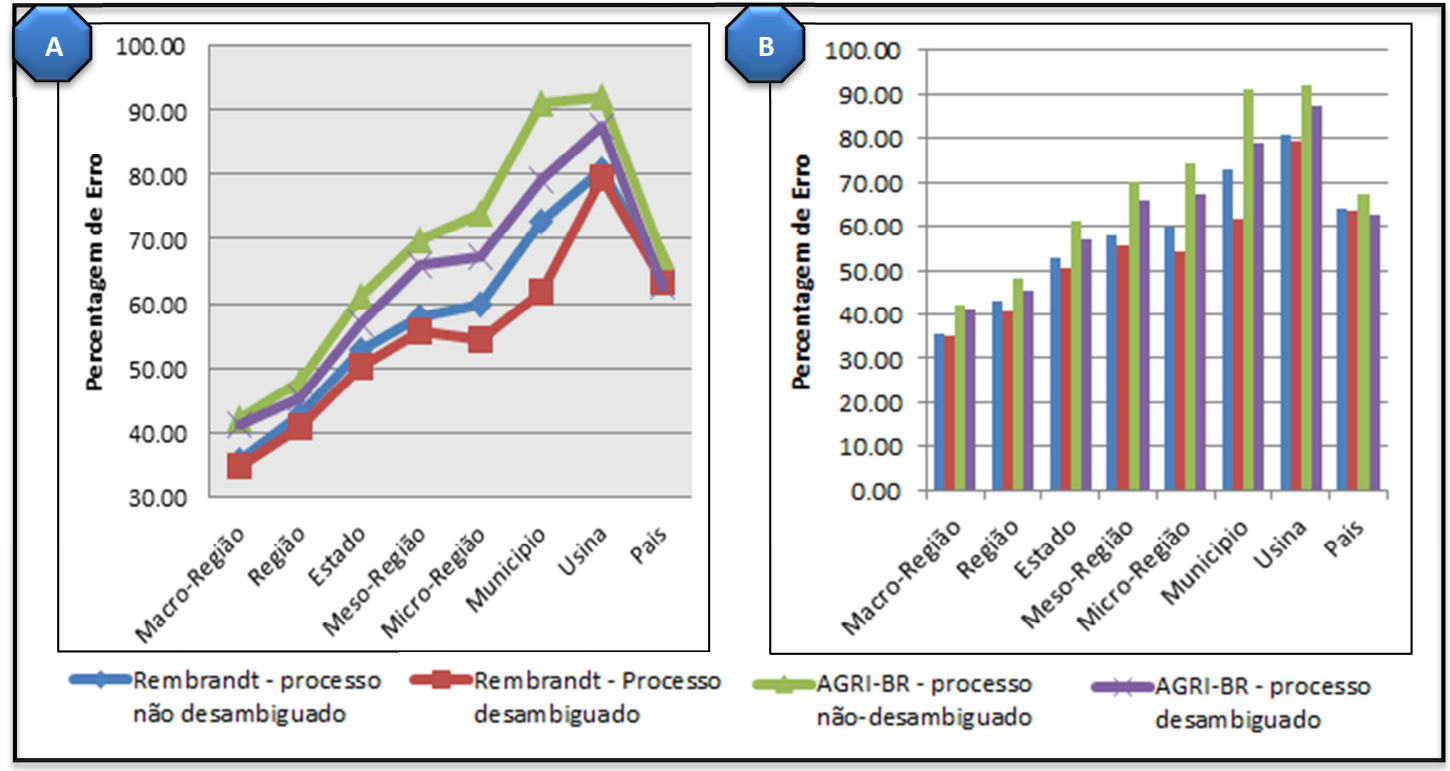

Figura 5.7: Avaliação Hierárquica entre os documentos pré-processados com o Rembrandt e o AGRI-BR para os processos não-desambiguado e desambiguado

de erro é o "Rembrandt desambiguado". Na Figura 5.7(b) pode-se observar em que níveis da hierarquia estão acontecendo a maior quantidade de erros. Sendo que, da mesma maneira, os dados processados pelo AGRI-BR geram maiores erros em todos os niveis da hierarquia.

Os erros de classificação na hierarquia podem ser atribuídos aos seguintes fatos:

- No Brasil existem diversas variações de nomes para nomear as cidades, meso-regiões, micro-regiões, etc. Alguns desses nomes são peculiares tais como o município "Óleo", "Flores" ou "Floresta”. Esses nomes podem ser facilmente confundidos com entidades que não sejam do tipo geográfico, podendo gerar assim um erro no reconhecimento de entidades mencionadas;

- Se uma entidade foi mal reconhecida no início, esta será desambiguada. Para formar o polígono de desambiguação estar-se-ia considerando o erro dessa entidade, o qual pode levar a mal classificar outras entidades;

- O gazetteer brasileiro, construído como parte deste projeto, ainda não considera dados que poderiam ajudar a solucionar alguns problemas de ambiguidades, como populações de cada entidade, capitais e cidades mais importantes; 
- Nos níveis mais profundos da hierarquia precisa-se de maior nível de conhecimento, já que geralmente esses últimos níveis são aqueles que representam mais ambiguidade.

- Na avaliação hierárquica observou-se que o maior número de erros acontece nos níveis de Usina e Município. Esses erros podem ter sido ocasionados por que se uma entidade foi mal reconhecida no inicio e foi desambiguada os resultados dos polígonos serão errados, e porém geram uma maior quantidade de erro especialmente com os níveis mais baixos da hierarquia.

A abordagem de Desambiguação Textual e Estrutural tem como objetivo solucionar alguns dos problemas apresentados com a abordagem de Desambiguação por Pontos, com a intenção de melhorar os processos de desambiguação e classificação para os documentos. Na próxima seção são mostrados os experimentos e resultados obtidos com a abordagem de Desambiguação Textual e Estrutural.

\subsection{Avaliação da Abordagem de Desambiguação Tex- tual e Estrutural}

Nesta abordagem, foram usados 698 documentos processados com a ferramenta DeTE. Os resultados dos processos não-desambiguado e o processo desambiguado foram comparados com os resultados marcados pelo Especialista, assim como na Desambiguação por Pontos. Na Tabela 5.9, é ilustrado um exemplo dos valores obtidos para os 15 primeiros documentos da coleção pré-processados com a ferramenta Rembrandt. Ao comparar os resultados obtidos com a Desambiguação por Pontos, apresentados na Tabela 5.2, observa-se que em termos gerais o número de entidades reconhecidas e reconhecidas corretamente são similares. No entanto, existem alguns casos em que a Desambiguação Textual e Estrutural reconhece uma menor quantidade de entidades, para o processo desambiguado, e em alguns casos reconhece corretamente mais entidades que o processo de Desambiguação por Pontos. Por exemplo, no documento " 41716 " no processo desambiguado da Desambiguação por Pontos utilizando o Rembrandt, reconheceu 12 entidades e acertou 7 entidades. Para o mesmo documento na Desambiguação Textual e Estrutural utilizando o Rembrandt, foram reconhecidas 11 entidades e 8 foram reconhecidas corretamente. Como pode ser observado, há alguns casos em 
que a abordagem de Desambiguação Textual e Estrutural descarta algumas entidades. Esse processo de descarte pode ser vantajoso porque tem menos entidades a serem analisadas, mas pode ser ao mesmo tempo perigoso se considera-se que entidades corretamente reconhecidas poderiam ser eliminadas.

Tabela 5.9: Comparação entre entidades corretas e incorretas dos processos não-desambiguado e desambiguado usando o Rembrandt para os 15 primeiros documentos da coleção para a abordagem de Desambiguação Textual e Estrutural

\begin{tabular}{|c|c|c|c|c|c|c|c|c|c|}
\hline \multicolumn{10}{|c|}{ Avaliação com Ferramenta Rembrandt } \\
\hline & \multirow{2}{*}{$\frac{\text { Espec. }}{\mathrm{E}}$} & \multicolumn{3}{|c|}{ Não-desambiguado } & \multicolumn{3}{|c|}{ Desambiguado } & \multicolumn{2}{|c|}{$\begin{array}{c}\text { Não-Des. } \\
\text { vs Des. }\end{array}$} \\
\hline & & $\mathrm{R}$ & VP-ATP & FP-ATN & $\mathrm{D}$ & VP-DTP & FD-DTP & IRD & VP-ITP \\
\hline 41501 & 2 & 10 & 1 & 9 & 9 & 1 & 8 & 9 & 1 \\
\hline 41502 & 1 & 4 & 1 & 3 & 1 & 0 & 1 & 1 & 0 \\
\hline 41503 & 8 & 19 & 8 & 11 & 12 & 7 & 5 & 12 & 7 \\
\hline 41504 & 2 & 7 & 2 & 5 & 2 & 0 & 2 & 2 & 0 \\
\hline 41505 & 2 & 4 & 1 & 3 & 2 & 1 & 1 & 2 & 1 \\
\hline 41506 & 2 & 5 & 2 & 3 & 2 & 2 & 0 & 2 & 2 \\
\hline 41507 & 1 & 1 & 1 & 0 & 1 & 1 & 0 & 1 & 1 \\
\hline 41509 & 10 & 13 & 4 & 9 & 7 & 4 & 3 & 7 & 4 \\
\hline 41510 & 2 & 3 & 2 & 1 & 3 & 2 & 1 & 3 & 2 \\
\hline 41512 & 1 & 2 & 1 & 1 & 2 & 1 & 1 & 2 & 1 \\
\hline 41513 & 2 & 2 & 1 & 1 & 1 & 1 & 0 & 1 & 1 \\
\hline 41514 & 1 & 0 & 0 & 0 & 0 & 0 & 0 & 0 & 0 \\
\hline 41522 & 2 & 7 & 1 & 6 & 2 & 0 & 2 & 2 & 0 \\
\hline 41523 & 1 & 6 & 0 & 6 & 3 & 0 & 3 & 3 & 0 \\
\hline 41716 & 10 & 18 & 10 & 8 & 11 & 8 & 3 & 11 & 8 \\
\hline
\end{tabular}

A Tabela 5.10 mostra a análise realizada para os documentos pré-processados usando o AGRI-BR. Observa-se que, assim como na abordagem de Desambiguação por Pontos, os dados pré-processados com o Rembrandt mostram um melhor desempenho, sobretudo aqueles que usam desambiguação. Por exemplo, no documento “41505”, os dados com Rembrandt reconheceram 2 entidades e só 1 foi corretamente reconhecida. Para os dados com AGRI-BR foram reconhecidas 6 entidades e só 1 foi corretamente reconhecida. Ao longo dos 
Tabela 5.10: Comparação entre entidades corretas e incorretas dos processos não-desambiguado e desambiguado usando o Vocabulário Controlado AGRIBR para os 15 primeiros documentos da coleção para a abordagem de Desambiguação Textual e Estrutural

\begin{tabular}{c|c|cccccccccc}
\hline \hline \multicolumn{1}{c}{ Avaliação com o Vocabulário Controlado AGRI-BRt } \\
\hline & Espec. & \multicolumn{2}{c|}{ Não-desambiguado } & \multicolumn{2}{c}{ Desambiguado } & \multicolumn{2}{c}{$\begin{array}{c}\text { Não-Des. } \\
\text { vs Des. }\end{array}$} \\
\hline & E & R & VP-ATP & FP-ATN & D & VP-DTP & FD-DTP & IRD & VP-ITP \\
\hline 41501 & 2 & 14 & 1 & 13 & 10 & 1 & 9 & 10 & 1 \\
\hline 41502 & 1 & 5 & 0 & 5 & 3 & 0 & 3 & 3 & 0 \\
\hline 41503 & 8 & 29 & 8 & 21 & 15 & 8 & 7 & 15 & 8 \\
\hline 41504 & 2 & 8 & 2 & 6 & 2 & 0 & 2 & 2 & 0 \\
\hline 41505 & 2 & 8 & 1 & 7 & 6 & 1 & 5 & 6 & 1 \\
\hline 41506 & 2 & 6 & 1 & 5 & 5 & 1 & 4 & 5 & 1 \\
\hline 41507 & 1 & 3 & 1 & 2 & 3 & 1 & 2 & 3 & 1 \\
\hline 41509 & 10 & 26 & 8 & 18 & 11 & 6 & 5 & 11 & 6 \\
\hline 41510 & 2 & 14 & 4 & 10 & 7 & 2 & 5 & 7 & 2 \\
\hline 41512 & 1 & 7 & 1 & 6 & 5 & 1 & 4 & 5 & 1 \\
\hline 41513 & 2 & 2 & 1 & 1 & 2 & 1 & 1 & 2 & 1 \\
\hline 41514 & 1 & 2 & 0 & 2 & 2 & 0 & 2 & 2 & 0 \\
\hline 41522 & 2 & 16 & 2 & 14 & 3 & 0 & 3 & 3 & 0 \\
\hline 41523 & 1 & 1 & 0 & 1 & 1 & 0 & 1 & 1 & 0 \\
\hline 41716 & 10 & 19 & 9 & 10 & 12 & 7 & 5 & 12 & 7 \\
\hline & & & & & & & & & \\
\hline
\end{tabular}

experimentos observou-se que todos os dados processados com AGRI-BR tendem a reconhecer uma maior quantidade de entidades, gerando desta forma uma maior proporção de erros.

Ao comparar a abordagem de Desambiguação por Pontos que utilizou o AGRI-BR, apresentada na Tabela 5.3, e a Desambiguação Textual e Estrutural, apresentada na Tabela 5.10, pode-se observar uma mudança no número de entidades reconhecidas e corretamente reconhecidas. Por exemplo, no documento "41716" para o processo não-desambiguado tanto a Desambiguação por Pontos e a Desambiguação Textual e Estrutural reconheceram o mesmo número de entidades e classificaram corretamente o mesmo número de entidades. Por outro lado, se analisam os dados obtidos com o processo desambiguado, a Desambiguação por Pontos reconheceu 14 entidades e clas- 
sificou corretamente 7. A abordagem de Desambiguação Textual e Estrutural reconheceu 12 entidades e classificou corretamente também 7 entidades.

Para obter os resultados mostrados nas Tabelas 5.9 e 5.10 a configuração dos parâmetros foi a mesma que a apresentada no Teste3, conforme mostrado na Tabela 5.11. Essa configuração de parâmetros mostrou obter um melhor desempenho nos processos de desambiguação.

Tabela 5.11: Configuração de parâmetros para a Desambiguação Textual e Estrutural

\begin{tabular}{|c|c|c|c|c|}
\hline \multicolumn{5}{|c|}{ Configuração de Parâmetros } \\
\hline & & Teste 1 & Teste2 & Teste3 \\
\hline \multicolumn{2}{|l|}{ Peso Dica Texto $\alpha$} & 65 & 70 & 80 \\
\hline \multicolumn{2}{|l|}{ Peso Entidade não Ambígua $\beta$} & 95 & 95 & 80 \\
\hline \multicolumn{2}{|l|}{ Valor de Descarte $\delta$} & 40 & 50 & 50 \\
\hline \multirow{4}{*}{ Desambiguação Heurística } & \multirow{4}{*}{$\begin{array}{c}\text { Usina } \\
\text { Município } \\
\text { Micro-Região } \\
\text { Meso-Região }\end{array}$} & 10 & 10 & 10 \\
\hline & & -9 & -9 & -9 \\
\hline & & -8 & -8 & -8 \\
\hline & & -7 & -7 & -7 \\
\hline
\end{tabular}

Nesta seção foi apresentada uma visão geral dos processos de desambiguação e não-desambiguação usando as ferramentas Rembrandt e AGRI-BR. Foi apresentada também uma breve comparação entre as abordagens de Desambiguação por Pontos e a abordagem de Desambiguação Textual e Estrutural. Nas seguintes seções serão descritos os resultados obtidos das avaliações globais e hierárquicos.

\subsubsection{Avaliação Global}

Na Tabela 5.12 é apresentado um resumo das medidas de precisão, cobertura e F-score aplicadas para o conjunto dos 698 documentos, comparando os processos não-desambiguados e desambiguados com a utilização da ferramenta Rembrandt e o AGRI-BR. Os resultados mostram um melhor desempenho dos documentos que foram pré-processados utilizando a ferramenta Rembrandt e passaram pelo processo desambiguação. No caso dos documentos pré-processados com o AGRI-BR, observa-se também melhores resultados no processo desambiguado. De forma que o Rembrandt usando a Desambiguação Textual e Estrutural obteve um F-Score de 0.4977 e o AGRI-BR obteve 
0.3678. Nota-se que nesta abordagem melhoraram-se um pouco os valores de F-Score comparados com a Desambiguação por Pontos que obteve para o Rembrandt 0.4862 e para o AGRI-BR 0.3836.

Tabela 5.12: Avaliação da Precisão, Cobertura e F-Score dos processos nãodesambiguado e desambiguado para a Desambiguação Textual e Estrutural

\begin{tabular}{|c|c|c|c|c|}
\hline & \multicolumn{2}{|c}{ Rembrandt } & \multicolumn{2}{c|}{ AGRI-BR } \\
\hline & Não-desamb. Desamb. Não-desamb. Desamb. \\
\hline Precisão & 0.3157 & $\mathbf{0 . 4 8 2 9}$ & 0.2052 & $\mathbf{0 . 2 7 1 1}$ \\
\hline Cobertura & $\mathbf{0 . 6 9 6 5}$ & 0.5134 & $\mathbf{0 . 8 5 9 5}$ & 0.5717 \\
\hline F-Score & 0.4344 & $\mathbf{0 . 4 9 7 7}$ & 0.3313 & $\mathbf{0 . 3 6 7 8}$ \\
\hline
\end{tabular}

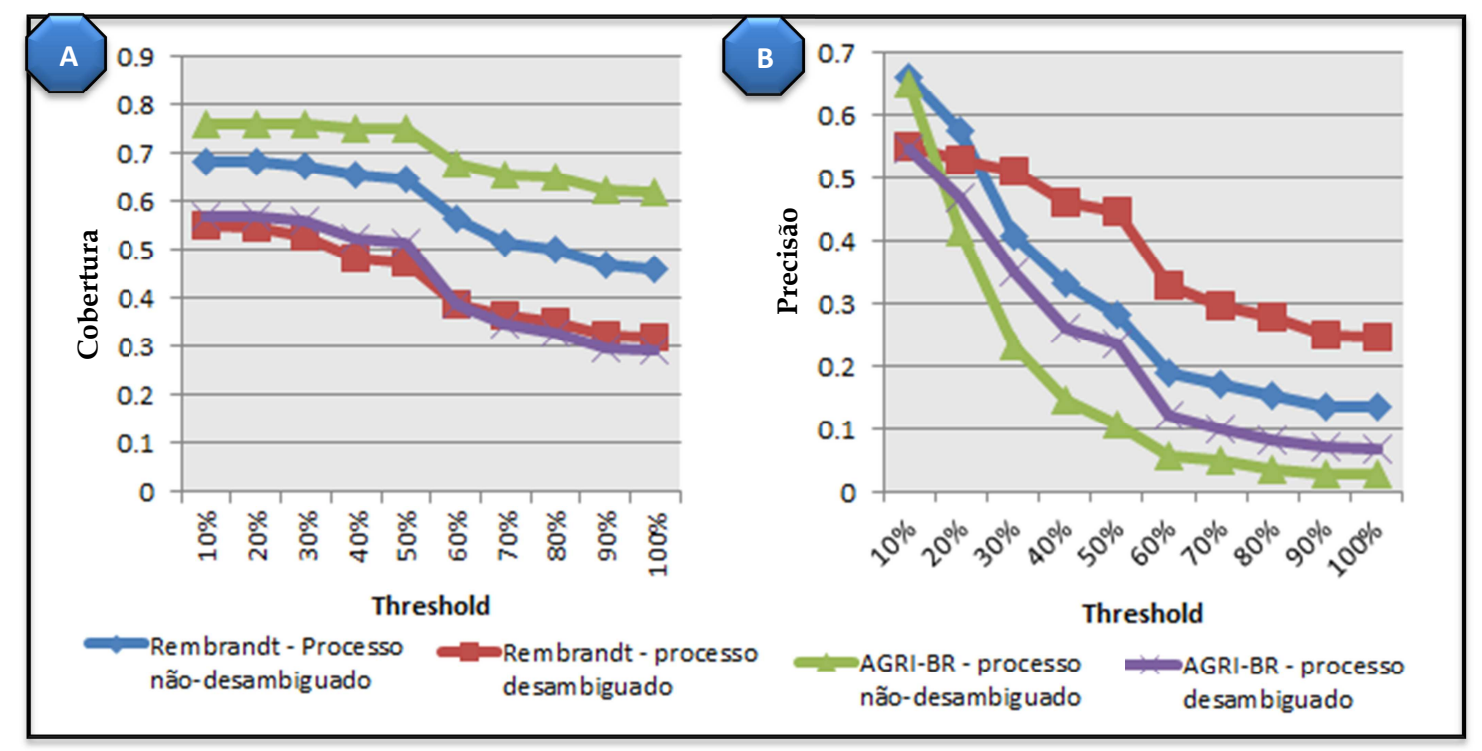

Figura 5.8: Precisão e Cobertura para os processos não-desambiguados e desambiguados usando o Rembrandt e o AGRI-BR na Desambiguação Textual e Estrutural

Na Figura 5.8 é ilustrado o comportamento do processo não-desambiguado e o processo desambiguado usando os dois tipos de pré-processamento definidos. Na Figura 5.8(a) é ilustrado o comportamento dos processos de desambiguação e não-desambiguação comparando a cobertura. A Figura 5.8(b) ilustra o comportamento dos processos de desambiguação e não-desambiguação utilizando a precisão. Como pode ser observado na Figura 5.8(a) o processo que tem uma maior cobertura e recupera uma maior quantidade de entidades é o "AGRI-BR não-desambiguação" seguido pelo "Rembrandt não-desambiguado". Na Figura 5.8(b) observa-se que o "Rembrandt - desambiguado" presenta me- 
lhores taxas de precisão que os outros algoritmos, seguido pelo "Rembrandt não-desambiguado".

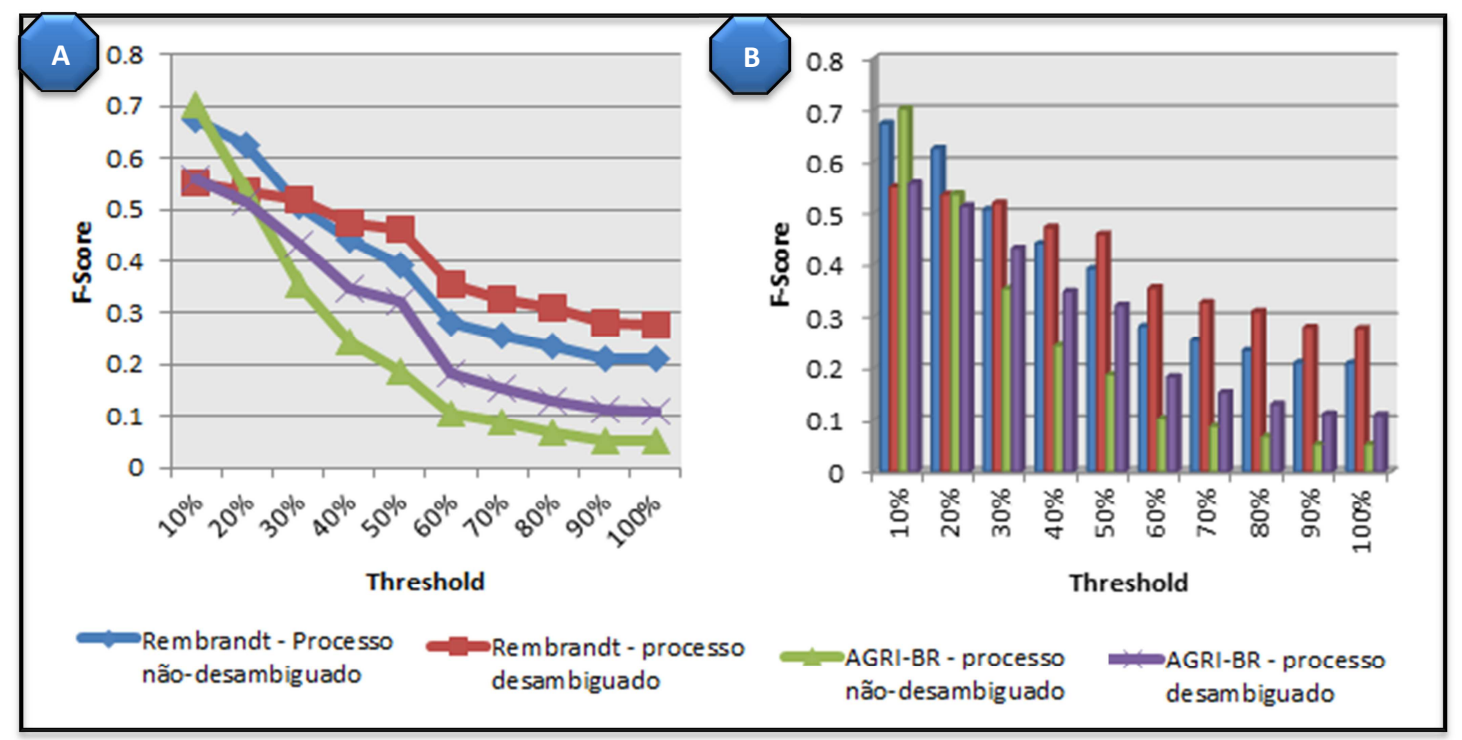

Figura 5.9: F-Score para os processos não-desambiguados e desambiguados usando o Rembrandt e o AGRI-BR na Desambiguação Textual e Estrutural

Na Figura 5.9 é ilustrado o comportamento de todos os processos utilizando a medida F-score. Pode-se observar que nos thresholds de $10 \%, 20 \%$ e $30 \%$ o processos "AGRI-BR - não-desambiguado" e "Rembrandt - não-desambiguado apresentam um comportamento similar. Nos seguintes thresholds os processos começam-se estabilizar e nota-se que o processo que tem um maior F-Score é o "Rembrandt - desambiguado", seguido pelo "Rembrandt - nãodesambiguado" e por último os processos que usaram o AGRI-BR. Na Figura 5.9(b) observa-se que a medida que o F-Score do "Rembrandt - desambiguado" aumenta os demais $F$-Scores diminuem, especialmente dos processados com o AGRI-BR. Se comparados os resultados obtidos com a Desambiguação por Pontos e ilustrados na Figura 5.6, pode-se observar que os resultados para o "AGRI-BR - desambiguado" melhoram nesta abordagem de desambiguação. Acredita-se que a melhoria deve-se à possibilidade de descartar entidades que podem ter sido reconhecidas equivocadamente pelos pré-processamentos com o Rembrandt ou o AGRI-BR.

Da mesma forma que aconteceu com a Desambiguação por Pontos, acreditase que os erros de classificação estão acontecendo com maior frequência em alguma parte da hierarquia. Assim, na próxima seção apresenta-se a avaliação realizada sobre a estrutura hierárquica e a proporção de erros encontrados nesta abordagem de desambiguação. 


\subsubsection{Avaliação por partes da Hierarquia}

Nesta seção é analisada a informação hierárquica dos dados que passaram pela Desambiguação Textual e Estrutural. Nas Tabelas 5.13 e 5.14 são apresentados os valores de acerto e erro para os processos não-desambiguados e desambiguados usando o Rembrandt.

Tabela 5.13: Avaliação hierárquica da coleção de documentos usando Rembrandt para o processo não-desambiguado para a Desambiguação Textual e Estrutural

\begin{tabular}{|c|c|c|c|c|c|}
\hline \multicolumn{6}{|c|}{$\begin{array}{l}\text { Resumo Avaliação Hierárquica (Rembrandt) do conjunto de } \\
\text { documentos não-desambiguados }\end{array}$} \\
\hline & \multirow{2}{*}{$\begin{array}{l}\text { Entidades } \\
\text { Especialista }\end{array}$} & \multicolumn{4}{|c|}{ Processo não-desambiguado } \\
\hline & & Nro Entidades & $\begin{array}{l}\text { Total Ent. } \\
\text { Corretas }\end{array}$ & Erro & \% Erro \\
\hline Macro-Região & 1219 & 747 & 798 & 421 & 34.54 \\
\hline Região & 1152 & 953 & 653 & 499 & 43.32 \\
\hline Estado & 1146 & 1363 & 545 & 601 & 52.44 \\
\hline Meso-Região & 835 & 1463 & 344 & 491 & 58.80 \\
\hline Micro-Região & 823 & 1489 & 312 & 511 & 62.09 \\
\hline Municipio & 792 & 1522 & 192 & 600 & 75.76 \\
\hline Usina & 476 & 621 & 88 & 388 & 81.51 \\
\hline País & 379 & 629 & 148 & 231 & 60.95 \\
\hline
\end{tabular}

Tabela 5.14: Avaliação hierárquica da coleção de documentos usando Rembrandt para o processo desambiguado para a Desambiguação Textual e Estrutural

\begin{tabular}{|c|c|c|c|c|c|}
\hline \multicolumn{6}{|c|}{$\begin{array}{l}\text { Resumo Avaliação Hierárquica (Rembrandt) do conjunto de } \\
\text { documentos desambiguados }\end{array}$} \\
\hline & \multirow{2}{*}{$\begin{array}{l}\text { Entidades } \\
\text { Especialista }\end{array}$} & \multicolumn{4}{|c|}{ Processo Desambiguado } \\
\hline & & Nro Entidades & $\begin{array}{l}\text { Total Ent. } \\
\text { Corretas }\end{array}$ & Erro & \% Erro \\
\hline Macro-Região & 1219 & 350 & 869 & 350 & 28.71 \\
\hline Região & 1152 & 356 & 796 & 356 & 30.90 \\
\hline Estado & 1146 & 455 & 691 & 455 & 39.70 \\
\hline Meso-Região & 835 & 402 & 433 & 402 & 48.14 \\
\hline Micro-Região & 823 & 398 & 425 & 398 & 48.36 \\
\hline Municipio & 792 & 465 & 327 & 465 & 58.71 \\
\hline Usina & 476 & 377 & 99 & 377 & 79.20 \\
\hline Pais & 379 & 209 & 170 & 209 & 55.15 \\
\hline
\end{tabular}


Como observado na Tabela 5.13, referente aos dados pré-processados com o Rembrandt, a maior parte dos erros, considerando o processo não-desambiguado, acontecem na classificação de Usinas, gerando um erro de $81.51 \%$ seguido pelo nível de Município que gerou um erro de $75.76 \%$. Para o processo desambiguado, apresentado na Tabela 5.14, a maior parte dos erros encontrase também no nível de Usina, gerando um erro de $79.20 \%$, seguido pelo nível de Município que gerou $58.71 \%$ de erro. Por outro lado, os níveis que tem menor quantidade de erros para ambos processos encontram-se nos níveis mais superiores da hierarquia que são MacroRegião, Estado e Região. Se comparamos os resultados obtidos com esta metodologia e os resultados da Desambiguação por Pontos referidas nas Tabelas 5.5 e 5.6 observa-se que a percentagem de erro por nível hierárquico é muito parecido, concentrando-se no mesmo nível da hierarquia.

Tabela 5.15: Avaliação hierárquica da coleção de documentos usando o AGRIBR para o processo não-desambiguado para a Desambiguação Textual e Estrutural

\begin{tabular}{c|c|c|c|c|c|}
\hline \multirow{2}{*}{$\begin{array}{c}\text { Resumo Avaliação Hierárquica (AGRI-BR) do conjunto de documentos } \\
\text { não-desambiguados }\end{array}$} \\
\cline { 4 - 7 } & \multirow{2}{*}{$\begin{array}{c}\text { Entidades } \\
\text { Especialista }\end{array}$} & \multicolumn{4}{|c}{ Processo não-desambiguado } \\
\cline { 3 - 7 } & & Nro Entidades & $\begin{array}{c}\text { Total Ent. } \\
\text { Corretas }\end{array}$ & Erro & $\%$ Erro \\
\hline Macro-Região & 1219 & 1249 & 756 & 463 & 37.98 \\
\hline Região & 1152 & 1865 & 594 & 558 & 48.44 \\
\hline Estado & 1146 & 2970 & 439 & 707 & 61.69 \\
\hline Meso-Região & 835 & 3513 & 252 & 583 & 69.82 \\
\hline Micro-Região & 823 & 3640 & 205 & 618 & 75.09 \\
\hline Município & 792 & 3518 & 64 & 728 & 91.92 \\
\hline Usina & 476 & 843 & 63 & 413 & 86.76 \\
\hline Paín & 379 & 564 & 193 & 186 & 49.08 \\
\hline
\end{tabular}

Na Tabela 5.15, referente aos dados pré-processados com o AGRI-BR, a maior parte dos erros, considerando o processo não-desambiguado, acontecem na classificação de Municípios, gerando um erro de $91.92 \%$. Outra parte da hierarquia que está gerando grande parte dos erros é no nivel de Usina que tem $86.76 \%$. Para o processo desambiguado, apresentado na Tabela 5.16, a maior parte dos erros encontra-se também no nível de Usina, gerando um erro de $81.51 \%$. Já o segundo nivel com grande percentagem de erro encontra-se no nível de Município, gerando um erro de $68.94 \%$. Por outro lado, os níveis 
Tabela 5.16: Avaliação hierárquica da coleção de documentos usando o AGRIBR para o processo desambiguado para a Desambiguação Textual e Estrutural

\begin{tabular}{|c|c|c|c|c|c|}
\hline \multicolumn{6}{|c|}{$\begin{array}{c}\text { Resumo Avaliação Hierárquica (AGRI-BR) do conjunto de documentos } \\
\text { desambiguados }\end{array}$} \\
\hline & \multirow{2}{*}{$\begin{array}{l}\text { Entidades } \\
\text { Especialista }\end{array}$} & \multicolumn{4}{|c|}{ Processo Desambiguado } \\
\hline & & Nro Entidades & $\begin{array}{l}\text { Total Ent. } \\
\text { Corretas }\end{array}$ & Erro & \% Erro \\
\hline Macro-Região & 1219 & 976 & 806 & 413 & 33.88 \\
\hline Região & 1152 & 1240 & 715 & 437 & 37.93 \\
\hline Estado & 1146 & 2970 & 584 & 562 & 49.04 \\
\hline Meso-Região & 835 & 2057 & 353 & 482 & 57.72 \\
\hline Micro-Região & 823 & 2110 & 337 & 486 & 59.05 \\
\hline Municipio & 792 & 2099 & 246 & 546 & 68.94 \\
\hline Usina & 476 & 646 & 88 & 388 & 81.51 \\
\hline País & 379 & 268 & 241 & 138 & 36.41 \\
\hline
\end{tabular}

que tem menor quantidade de erros para ambos processos encontram-se nos níveis mais superiores da hierarquia, que são MacroRegião, Estado e Região, assim como nos documentos pré-processados com o Rembrandt.

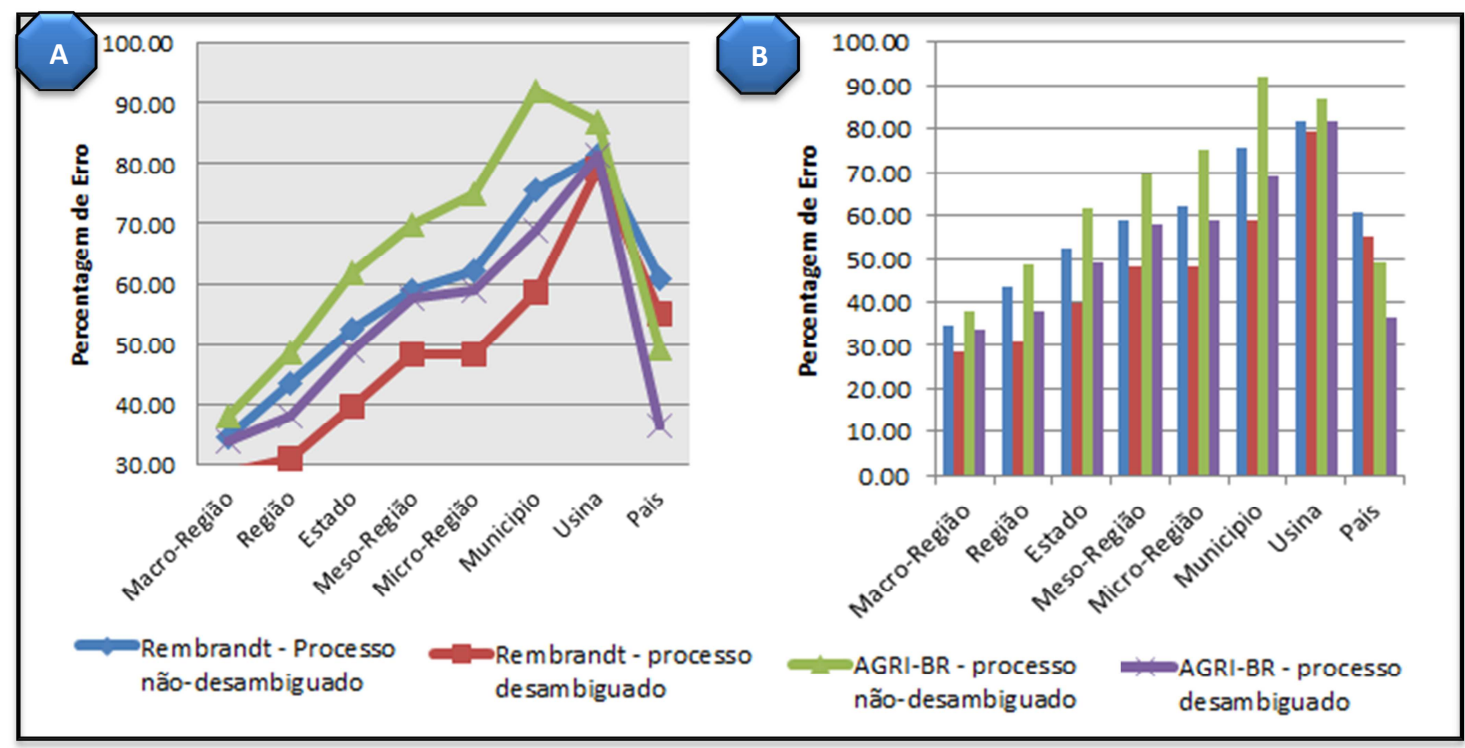

Figura 5.10: Avaliação Hierárquica entre os documentos pré-processados com o Rembrandt e o AGRI-BR para os processos não-desambiguado e desambiguado

Na Figura 5.10 é ilustrada a percentagem de erro obtida em cada nível da hierarquia. Como observado na Figura 5.10(a) o processo que gera a maior quantidade de erros de classificação é o "AGRI-BR - não-desambiguado”, se- 
guido pelo "Rembrandt - não-desambiguado". Já o processo que gera uma menor quantidade de erro é o "Rembrandt - desambiguado". Na Figura 5.10(b) pode-se observar também em que niveis da hierarquia estão acontecendo a maior quantidade de erros.

Os erros de classificação na hierarquia podem ser atribuídos aos seguintes fatos:

- Neste tipo de desambiguação é feita uma eliminação de entidades que podem ter sido não reconhecidas corretamente pelas ferramentas de préprocessamento do Rembrandt ou AGRI-BR. O problema principal está na definição de parâmetros desta abordagem já que, se o valor for muito elevado poderiam-se estar eliminando entidades relevantes para o problema;

- A ontologia geográfica utilizada para esta abordagem de desambiguação foi utilizada apenas como uma base de dados já que ainda não fornece nenhuma informação semântica que permita auxiliar no processo de desambiguação, como algumas características que indiquem uma certa preferência entre entidades.

Com o intuito de comparar as abordagens baseadas em gazetteers ou ontologias geográficas versus uma abordagem de Aprendizado de Máquina elaborouse uma série de experimentos que foram realizados usando a abordagem de classificação hierárquica multirrótulo dos documentos e que será explicada na próxima seção.

\subsection{Avaliação da Abordagem de Aprendizado de Máquina - Classificação hierárquica multirrótulo}

Buscaldi e Rosso (2008) dividem os métodos de desambiguação em três categorias: (1) baseados em mapas, (2) baseados em conhecimento e (3) dirigido a dados ou supervisionados. As duas abordagens mostradas nas seções anteriores estão baseadas em conhecimento devido a que fazem uso de recursos externos tais como gazetteers ou ontologias geográficas para conseguir uma classificação dos documentos. O problema tratado neste projeto está baseado nas abordagens de Desambiguação por Pontos e Desambiguação Textual e Estrutural. Essas abordagens também podem ser descritas como um problema de classificação hierárquica multirrótulo. Na qual, um documento pode ter associados $n$ rótulos na forma de hierarquia. 
Um objetivo desta avaliação é comparar o método de desambiguação baseado em conhecimento contra o método dirigido a dados ou supervisionado. É dizer comparar os resultados da classificação usando a Desambiguação por Pontos e a Desambiguação Textual e Estrutural com uma abordagem de classificação hierárquica multirrótulo.

Um grande problema para fazer uma classificação hierárquica usando técnicas de Aprendizado de Máquina está referida ao corpus. O corpus a ser usado para treinar o classificador hierárquico tem que ser suficientemente grande para poder aprender cada nível da hierarquia. Guanto maior o número de níveis na hierarquia, maior o número de documentos necessários para a tarefa de aprendizado. Neste trabalho, trabalhou-se com 8 níveis hierárquicos e com um corpus marcado de 698 documentos. Devido o grande número de níveis hierárquicos e o pouco volume de documentos marcados tomou-se a decisão de reduzir da hierarquia a 4 níveis para este experimento: (1) Região, (2) Estado, (3) Município e (4) Usina. Como nível básico foram considerados os Países, é dizer a classificação "Brasil" ou "Internacional". Na Figura 5.11 é ilustrado um exemplo da hierarquia utilizada para este experimento. Como observado na Figura 5.11, foi representada uma estrutura hierárquica de 5 níveis. Cada entidade dentro de cada nível têm um código associado, esse código representa o rótulo de classe de cada entidade dentro da hierarquia.

Para a realização deste experimento tiveram que ser feitas as seguintes mudanças:

- Redução do nível de hierarquias de todos os documentos.

- Geração dos documentos no formato ".arff”, no qual representa-se a hierarquia com 1 ou 0 . Utiliza-se 1 se o exemplo tem marcada a classe na hierarquia e 0 caso contrário.

- Limpeza dos dados e dos níveis hierárquicos com ajuda da ferramenta Weka (Hall et al., 2009). Inicialmente os dados consideravam todos os municípios, usinas, regiões e estados existentes obtendo dessa forma aproximadamente 8 mil atributos por documento. A limpeza consistiu em eliminar aqueles municípios ou regiões que não foram considerados na anotação do especialista em nenhum documento. Deixando dessa forma uma hierarquia de 281 categorias aproximadamente.

- Análise manual das notícias para a classificação dos níveis de município e usina. 


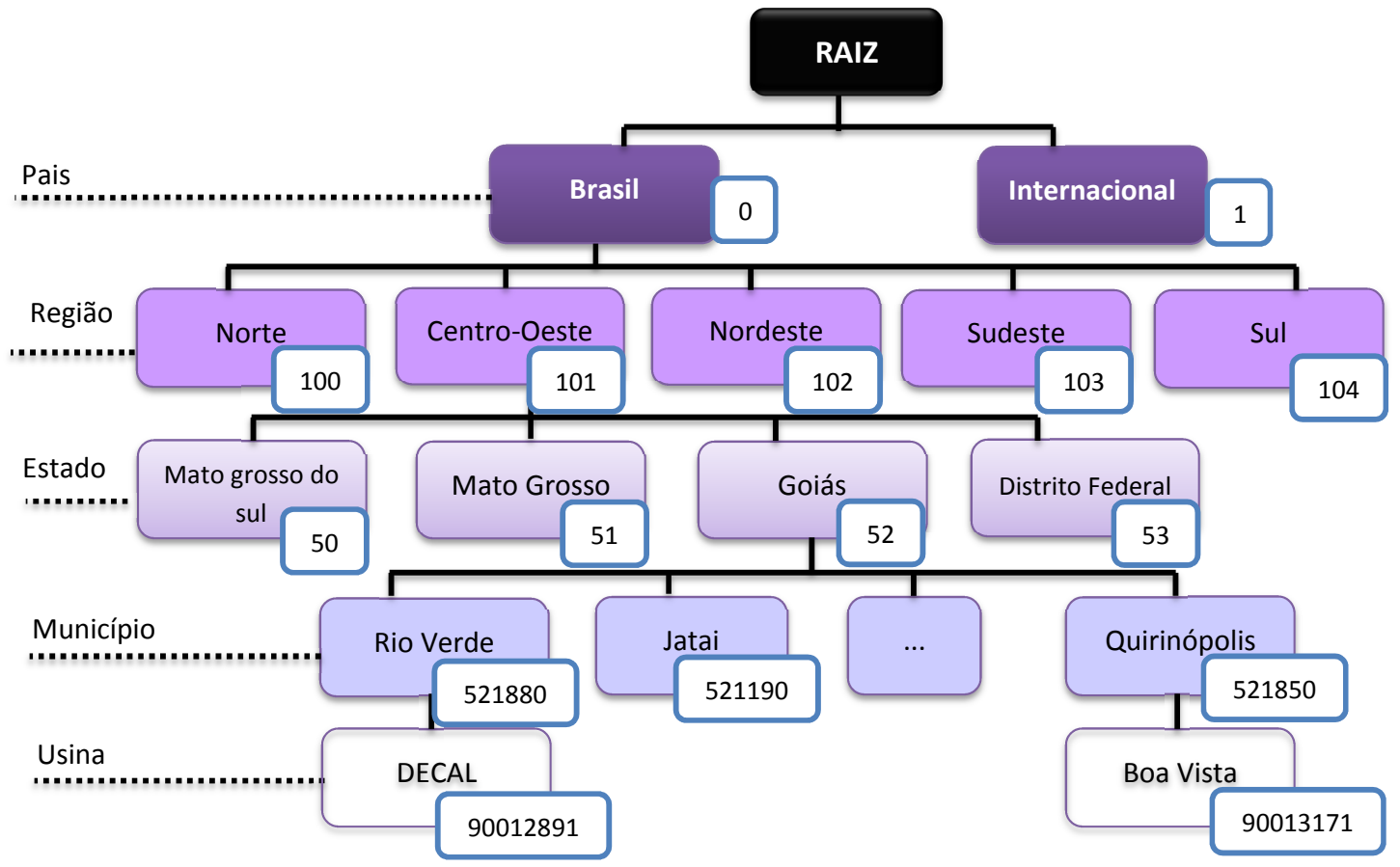

Figura 5.11: Exemplo da hierarquia utilizada para a abordagem de classificação hierárquica multirrótulo

Os experimentos foram divididos em duas partes, a primeira parte visa classificar os documentos considerando só 2 níveis da hierarquia: Região e Estado. A segunda parte visa classificar os documentos considerando os 4 níveis propostos no início. Na Tabela 5.17 são apresentados os resultados obtidos para a primeira parte dos experimentos. Os experimentos foram realizados em Java, usando Weka (Hall et al., 2009) e Mulan (Tsoumakas et al., 2011), com o algoritmo J48 como base para a classificação.

Como pode-se observar na Tabela 5.17, existem alguns valores de $F$-score que estão baixos chegando em alguns casos a serem 0 . Nota-se que os dois primeiros níveis Label $O$ e Label 1 que correspondem a classificação do "Brasil" ou "Internacional" obtiveram bons resultados devido à posição hierárquica que eles ocupam. Enquanto vai-se descendo na hierarquia os resultados tendem a diminuir. Esse incremento ou diminuição dos valores deve-se em maior parte à quantidade de exemplos apresentados ao classificador para aprender essa classe.

Na Tabela 5.18 é apresentada uma lista das 11 primeiras classes da hierarquia e o número de exemplos associados a essa classe. Nota-se que mesmo sendo dos primeiros níveis da hierarquia tem-se em alguns casos um baixo número de exemplos para treinamento. O pior caso acontece quando existe só 
Tabela 5.17: Resultados da classificação hierárquica multirrótulo para as 10 primeiras classes

\begin{tabular}{l|c|c|c}
\hline \multicolumn{4}{c}{ Classificação Hierárquica multirrótulo } \\
\hline Classe & F-Score & Precisão & Cobertura \\
\hline Label O - Brasil & 0.968 & 0.943 & 0.9909 \\
\hline Label 1 - Internacional & 0.531 & 0.5968 & 0.4934 \\
\hline Label 2 - Norte & 0.3857 & 0.4 & 0.375 \\
\hline Label 3 - Centro Oeste & 0.7427 & 0.8584 & 0.68 \\
\hline Label 4 - Nordeste & 0.6386 & 0.7143 & 0.5948 \\
\hline Label 5 - Sudeste & 0.7151 & 0.7332 & 0.7041 \\
\hline Label 6 - Sul & 0.5849 & 0.7111 & 0.5292 \\
\hline Label 7 - Acre & 0.3666 & 0.4 & 0.35 \\
\hline Label 8 - Alagoas & 0 & 0 & 0 \\
\hline Label 9 - Amapa & 0.2866 & 0.3666 & 0.2583 \\
\hline Label 10 - Amazonas & 0.7285 & 0.7357 & 0.7344 \\
\hline
\end{tabular}

Tabela 5.18: Exemplificação da quantidade de exemplos de treinamento e teste para cada classe da hierarquia

\begin{tabular}{l|c|c|c}
\hline \multicolumn{4}{|c}{ Quantidade de Exemplos por classe } \\
\hline Classe & Exemplos & Classe & Exemplos \\
\hline Label O & 659 & Label 6 & 77 \\
\hline Label 1 & 123 & Label 7 & 3 \\
\hline Label 2 & 19 & Label 8 & 11 \\
\hline Label 3 & 94 & Label 9 & 3 \\
\hline Label 4 & 127 & Label 10 & 1 \\
\hline Label 5 & 256 & Label 11 & 16 \\
\hline
\end{tabular}

um exemplo para o classificador aprender a classe, como o caso da Label 10 que tem um único exemplo o qual pode ser utilizado ou para treinamento ou para teste.

A segunda parte dos experimentos é testar a classificação usando os 4 níveis da hierarquia previamente marcados. Devido a quantidade de exemplos por classe, como mostrado na Figura 5.12 e 5.13, assim como a quantidade de caminhos geográficos reconhecidos para cada documento e a complexidade da estrutura hierárquica dos caminhos, não permitiram a realização deste experimento.

Na Figura 5.12 é ilustrada a distribuição de exemplos para as classes de País, Região e Estado. Como observado, existe uma grande quantidade de 


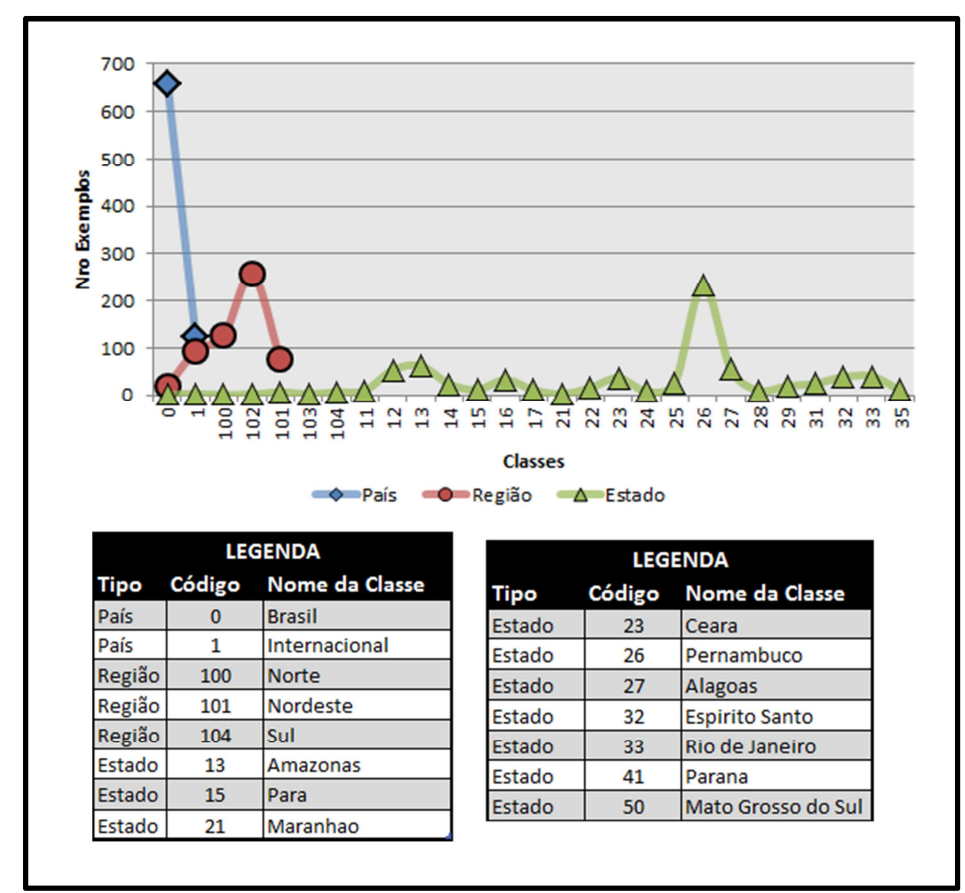

Figura 5.12: Distribuição de exemplos para as classes de País, Região e Estado

exemplos atribuídos à classe País que é a base da hierarquia. Nota-se uma grande diminuição de exemplos comparando País e Região, sendo que várias classes da Região tem associados 1 ou 0 exemplos. A medida que vai-se descendo na hierarquia, encontram-se menos exemplos para que o classificador possa aprender, como mostra a Figura 5.13. Nessa figura, observa-se que o número médio de documentos para treinar não ultrapassa os 60 exemplos. Observa-se também que a maior parte das classes tem menos de 10 exemplos para treinar ou testar.

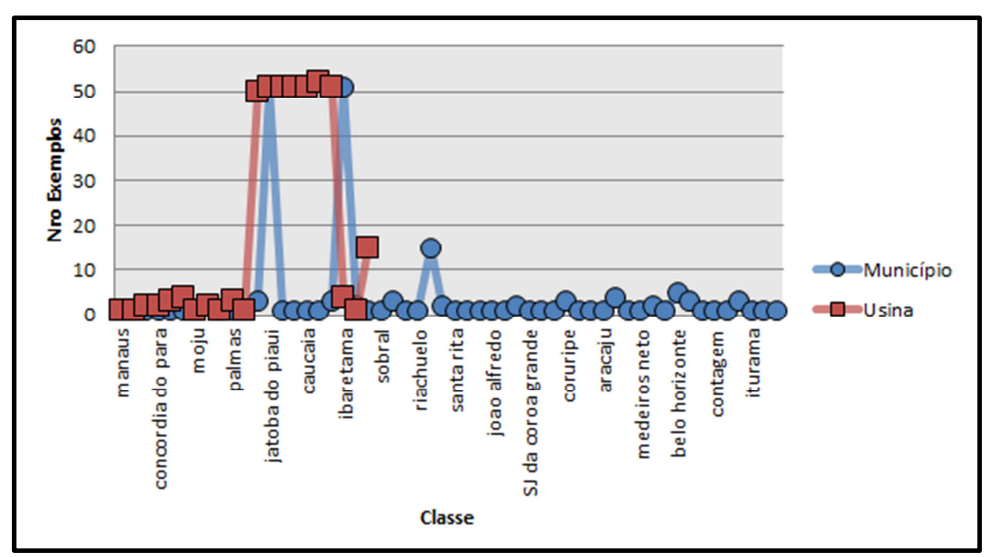

Figura 5.13: Distribuição de exemplos para as classes de Município e Usina

Na Figura 5.14 é ilustrada a distribuição dos exemplos para cada classe que 

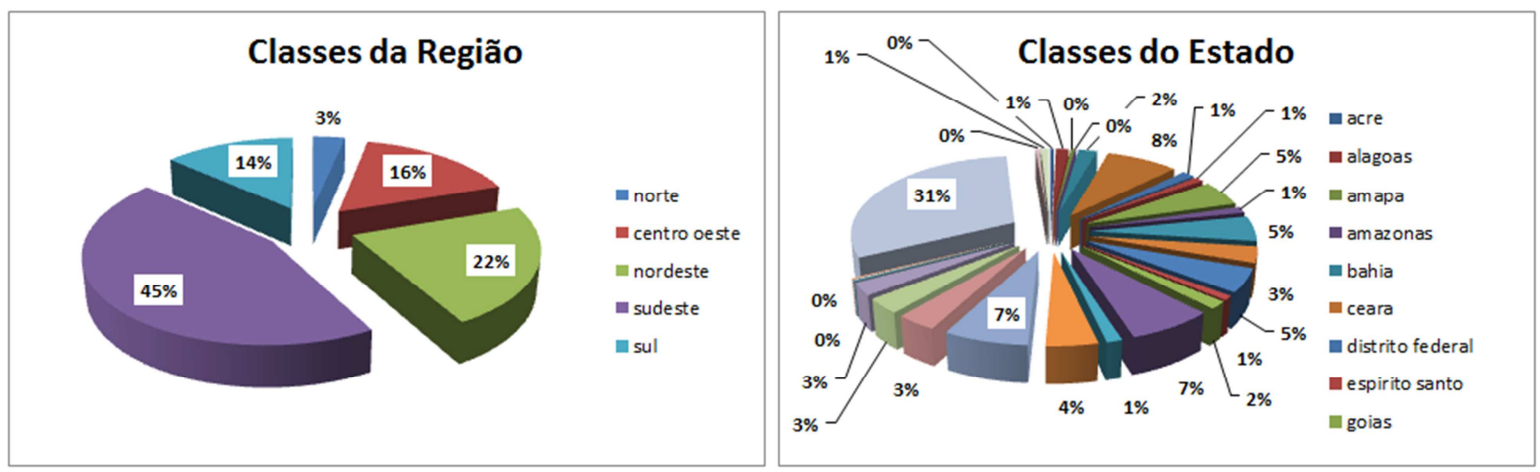

Figura 5.14: Percentagem da distribuição de exemplos para as classes de Região e Estado

compõe a Região e Estado. Pode-se observar que a distribuição dos exemplos para cada uma das classes é desbalanceado, e várias classes chegam a ter 0\% de exemplos associados. Se plotar os gráficos de Município e Usina os exemplos ficam mais dispersos ainda e a distribuição de exemplos diminui muito, excepto para os Municípios e Usinas que tem uma tendência a aparecer nos documentos, tais como todas as usinas de Cosan e São Martinho, assim como também os municípios de Piracicaba, Ribeirão Preto, São Paulo, entre outros.

A abordagem de Aprendizado de Máquina pode ser muito útil para classificar os documentos de forma hierárquica e considerando a localização geográfica dos documentos. No entanto, precisa-se de uma quantidade grande de exemplos por classe da hierarquia para que o classificador consiga aprender de forma correta como classificar os documentos. Neste experimento usaramse como descritores as palavras que compõem cada documento (bag-of-words). Uma outra possivel abordagem para construir os descritores é usando um thesauro agrícola e um thesauro geográfico do Brasil. Dessa forma o classificador poderia ter descritores mais precisos para aprender.

A ideia principal deste projeto está baseada na construção de duas formas de desambiguadores, seja fazendo uso de um gazetteer ou de uma ontologia geográfica. Nas seções iniciais foram mostrados os experimentos relacionados com cada desambiguador construído e após uma comparação com uma abordagem de Aprendizado de Máquina. Para poder demostrar qual desambiguador tem melhor desempenho para o problema proposto neste mestrado foi importante fazer uma comparação entre os dois classificadores, a qual será descrita na próxima seção. 


\subsection{Comparação entre a Desambiguação por Pon- tos e a Desambiguação Textual e Estrutural usando o Paired T-Teste}

Após a avaliação individual dos dois métodos de desambiguação, é de interesse determinar qual método tem um melhor comportamento para o problema de desambiguação de múltiplos caminhos geográficos. Como os melhores resultados foram obtidos usando os processos de desambiguação, basearemos os testes estatísticos desta seção considerando o Rembrandt e o AGRI-BR no processo desambiguado. Na Tabela 5.19 são apresentados os valores de F-score obtidos para cada processo com cada abordagem de desambiguação. Como observado, os valores de F-Score usando o Rembrandt para cada um dos processos de desambiguação não apresenta uma grande diferença entre eles.

Tabela 5.19: F-Score para os documentos pré-processados com o Rembrandt e AGRI-BR no processo desambiguado usando a Desambiguação por Pontos e a Desambiguação Textual e Estrutural

\begin{tabular}{c|c|c}
\hline & Rembrandt & AGRI-BR \\
\hline Desambiguação por Pontos (DePP) & 0.4862 & 0.3836 \\
\hline Desambiguação Textual e Estrutural (DeTE) & 0.4977 & 0.3678 \\
\hline \hline
\end{tabular}

Na Figura 5.15 é apresentado o comportamento dos dois desambiguadores utilizando a medida $F$-Score, para comparar o desempenho de ambos. Como observado, existe uma semelhança entre o comportamento de ambos. Nos thresholds de $60 \%$ e $70 \%$ eles têm práticamente os mesmos valores. No final dos thresholds nota-se que o processo Desambiguação Textual e Estrutural (DeTE) melhora um pouco os resultados. Assim, para determinar o método de desambiguação mais significante para este problema, utilizou-se a medida estatística Paired T-Teste, descrito na seguinte seção.

Para a realização deste experimento foi utilizada uma amostra de 698 documentos, os quais foram usados para testar cada um dos processos de desambiguação. A amostra considera o F-Score obtido por cada documento para cada método de desambiguação. O objetivo do experimento foi:

- Analisar o método de Desambiguação por Pontos e o método de Desambiguação Textual e Estrutural; 


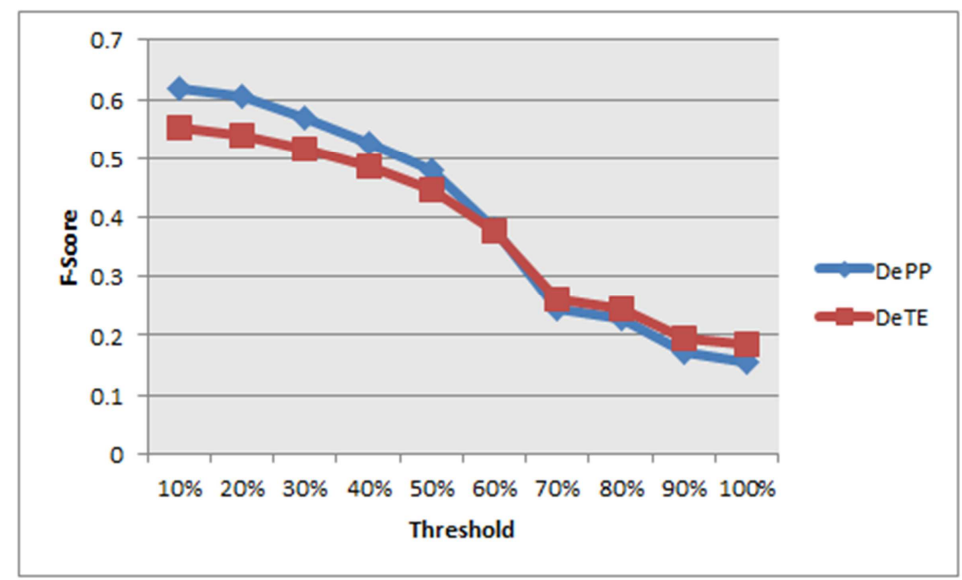

Figura 5.15: Comparação do F-Score entre a Desambiguação por Pontos (DePP) e a Desambiguação Textual e Estrutural (DeTE)

- Com respeito ao desempenho obtido com cada classificador, usando a medida F-Score;

Para executar este teste foram elaboradas duas hipóteses com relação ao desempenho de cada classificador com o conjunto de documentos usados como amostra:

- Hipótese nula $\left(H_{0}\right)$ : Não existe diferença estatisticamente significante entre os dois métodos de desambiguação.

- Hipótese alternativa $\left(H_{1}\right)$ : Existe uma diferença estatisticamente significante entre os dois métodos de desambiguação.

O valor crítico $\alpha$ foi estabelecido em $5 \%$ e usando $n-1$ graus de libertade, em que $n$ representa o número de amostras utilizadas para o teste, o $t$-value para rejeitar ou aceitar a hipótese nula é de 2.326 .

Na Tabela 5.20, as duas primeiras linhas mostram um exemplo dos 8 primeiros valores das amostras utilizadas para fazer a avaliação. A terceira linha $d_{i}$ calcula as diferenças entre as duas amostras, o qual será utilizado para calcular o valor $t_{0}$.

Calculando os valores de distância média $(\vec{d})$ e de desvio padrão $\left(S_{d}\right)$ das amostras é calculado o valor do $t_{0}$, como apresentado na Tabela 5.21. No final dos testes estabeleceu-se o valor de $t_{0}=2.1411$. Para rejeitar a hipótese nula verifica-se a verdade ou falsidade da Equação 5.1. Em que $t_{\alpha}, f$ é a maior percentagem do ponto de distribuição $t$ com $f$ graus de liberdade.

$$
\text { Rejeitar } H_{0} S E\left|t_{0}\right|>t_{\alpha / 2, n-1}
$$


Tabela 5.20: Amostra de documentos utilizadas para o teste estatístico Paired t-teste

\begin{tabular}{c|c|c|c|c|c|c|c|c}
\hline \multicolumn{7}{c}{8 primeiras amostras do Paired t-teste } \\
\hline & Doc1 & Doc2 & Doc3 & Doc4 & Doc5 & Doc6 & Doc7 & Doc8 \\
\hline DePP & 0.1818 & 0 & 0.8 & 0 & 0.8 & 0.8 & 1 & 0.35 \\
\hline DeTE & 0.1818 & 0 & 0.7 & 0 & 0.5 & 1 & 1 & 0.47 \\
\hline$d_{i}$ & 0 & 0 & 0.1 & 0 & 0.3 & -0.2 & 0 & -0.11 \\
\hline
\end{tabular}

Tabela 5.21: Valores calculados para o Paired t-teste

\begin{tabular}{c|c}
\hline$n$ & 698 \\
\hline$\vec{d}$ & 0.0212 \\
\hline$S_{d}$ & 0.2627 \\
\hline$t_{0}$ & 2.1411 \\
\hline
\end{tabular}

No teste realizado tem-se que $|2.1411|>t_{0.05 / 2,697} \Rightarrow|2.1411|>t_{0.025,697} \Rightarrow$ $|2.1411|>2.326=F A L S O$. Como o resultado da Equação 5.1 foi falso não podemos rejeitar a hipótese nula. Estabelecendo assim, que não existe uma diferença estatisticamente significante entre os métodos de desambiguação.

\subsection{Considerações Finais}

Neste capítulo foram mostrados os diversos testes feitos para avaliar as abordagens propostas. Foram realizadas avaliações globais, as quais consideram a classificação como um tudo. Após foram feitas avaliações hierárquicas para cada método com a intenção de determinar em que parte da classificação hierárquica estava-se produzindo a maior quantidade de erros. Após, detalharam-se os experimentos realizados utilizando uma abordagem de Aprendizado de Máquina, mostrando alguns problemas que foram encontrados. Finalmente, realizou-se um teste estatístico para determinar se existia uma diferença estatisticamente significante entre os dois métodos de desambiguação. Assim, na seguinte seção são apresentadas as conclusões, os principais resultados, as contribuições, as principais limitações e os trabalhos futuros. 



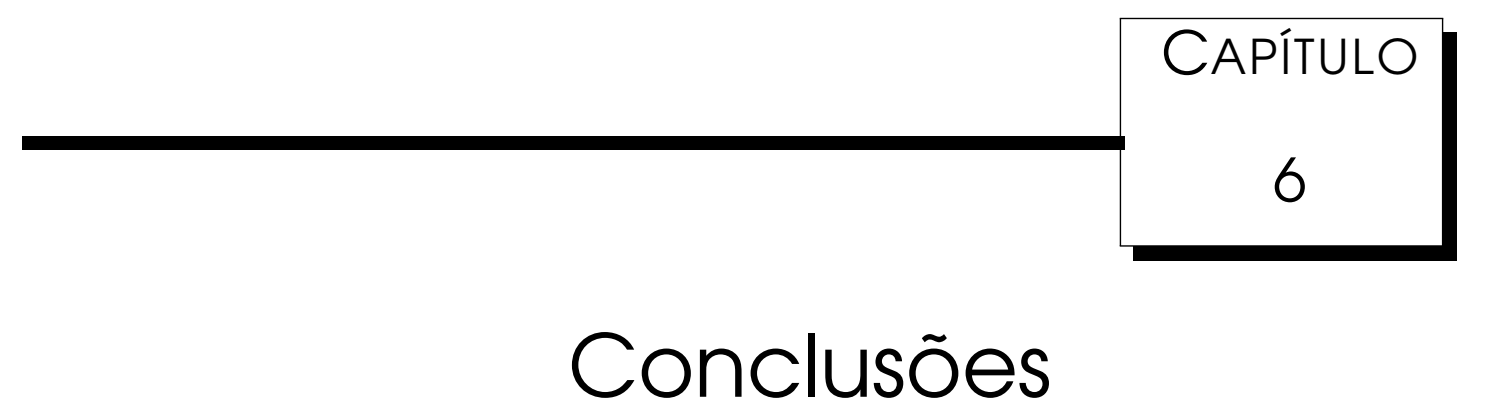

Neste trabalho foram expostos os principais fundamentos da Recuperação de Informação Geográfica, descrevendo-se em detalhe as etapas de geo-parsing e geo-coding. Descreveu-se ainda o estado da arte em técnicas que abordam o problema de Resolução de Topônimos. Entre as técnicas existentes é comum o uso de elementos externos como gazetteers ou ontologias que auxiliem no processo de identificação de entidades geográficas.

Foram descritos os métodos e técnicas elaboradas para os processos de desambiguação das entidades geográficas nos documentos, considerando as coordenadas geográficas ou a estrutura hierárquica das entidades. Apresentouse a metodologia que visa identificar e determinar a cobertura espacial dos documentos, denominada SpatialCIM. Da metodologia, foram detalhados os aspectos arquiteturais e os principais algoritmos de desambiguação implementados, e os experimentos realizados para a avaliação dos algoritmos.

Os resultados obtidos pelos processos de desambiguação, indicam que seu uso contribui significativamente na localização espacial dos documentos. Em particular, a aplicação dos processos de desambiguação melhoram a precisão e cobertura da classificação espacial dos documentos. As abordagens de (1) Desambiguação por Pontos e (2) Desambiguação Textual e Estrutural permitiram classificar, com uma precisão e cobertura relativamente boa, os documentos considerando a estrutura hierárquica das entidades brasileiras.

Assim, com os resultados obtidos é possivel responder as questões de pesquisa elaboradas no Capítulo 1: 
1. A técnica de desambiguação selecionada influência na localização espacial dos documentos?. Para responder esta pergunta foram estudados diversos métodos de desambiguação na literatura. Após isso, foram analisados e implementados dois métodos de desambiguação, os quais usam duas fontes diferentes de conhecimento externo. Esses métodos foram adaptados para permitir reconhecer entidades brasileiras, considerando a estrutura geo-política do Brasil. Para isso, foi implementado um gazetteer Brasileiro que considera a estrutura geo-política das entidades e as coordenadas geográficas associadas. Também foi adaptada uma ontologia geográfica do Brasil, para que considera-se os mesmos níveis hierárquicos considerados no gazetteer. Após, foram elaborados experimentos que permitiam a comparação entre as duas abordagens de desambiguação: (1) Desambiguação por Pontos e (2) Desambiguação Textual e Estrutural, mostrando que não existe uma diferença estatisticamente significante entre a aplicação da abordagem (1) ou (2) para a desambiguação dos topônimos. Também foram comparadas as duas abordagens com um processo de classificação de Aprendizado de Máquina e mostraramse os principais problemas associados com a abordagem de Aprendizado de Máquina. Mostrando desta forma, que das duas técnicas de desambiguação selecionadas e propostas neste trabalho, não tem uma influência estatisticamente significante na localização espacial dos documentos;

2. Os processos de reconhecimento de entidades mencionadas influenciam os processos de desambiguação?. Para responder esta pergunta, foram estudadas as formas de reconhecimento de entidades mencionadas nos textos, assim como também os problemas existentes nessa área. Assim, foram analisadas diferentes ferramentas que permitem o reconhecimento de entidades em português. Entre os problemas, foi detectado o tempo de processamento das ferramentas linguísticas. Assim, foi analisada a possibilidade de reconhecer as entidades utilizando recursos que não considerem todo o contexto do documento. Para isso, foi implementado um vocabulário controlado. Após, foram realizados diversos experimentos que visaram avaliar a influência da ferramenta de Reconhecimento de entidades utilizado. Para esse propósito foram selecionadas e avaliadas a ferramenta linguística Rembrandt e o recurso linguístico AGRI$\mathrm{BR}$. Os resultados mostraram que o reconhecimento de entidades feito pelo Rembrandt melhora a classificação espacial das duas abordagens de desambiguação. Mostrando desta forma, que o processo utilizado para 
o reconhecimento de entidades mencionadas nos textos influenciam os processos de desambiguação;

3. A desambiguação de topônimos está influenciada pelo número de topônimos reconhecidos para os documentos?. Para responder esta pergunta, os documentos marcados pelo especialista foram inicialmente analisados para determinar a quantidade de entidades marcadas por documento. Selecionou-se uma quantidade de documentos e aplicou-se os dois processos de desambiguação propostos. Assim, inicialmente foi feita uma análise da influência do número de entidades para os resultados de desambiguação. Após, foram testados documentos com poucas entidades reconhecidas e documentos com muitas entidades reconhecidas. Os resultados mostraram que a quantidade de entidades por documento não influência nos processos de desambiguação.

\subsection{Principais Resultados e Contribuições}

A contribuição principal deste trabalho consistiu em especificar uma metodologia que permita descobrir a cobertura espacial dos documentos e implementar dois sistemas que permitam realizar a desambiguação dos documentos usando duas abordagens diferentes.

Neste trabalho, foi proposta a metodologia SpatialCIM que está composta de três etapas principais: reconhecimento de entidades geográficas, expansão de dados e desambiguação. Foram apresentadas também duas abordagens de desambiguação que consideram a hierarquia das entidades: (1) Desambiguação por Pontos e (2) Desambiguação Textual e Estrutural. Para realizar a desambiguação por pontos foi criado um gazeteer Brasileiro que segue a hierarquia "País, Macro-Região, Região, Estado, Meso-Região, Micro-Região, Município e Usina” e contém as coordenadas geográficas de cada entidade. Já para realizar a Desambiguação Textual e Estrutural foi adaptada uma ontologia geográfica do Brasil que considera a mesma hierarquia que o gazetteer.

A partir dos experimentos realizados pôde-se perceber que a classificação espacial dos documentos que passaram pelos processos de desambiguação são aqueles que apresentam um melhor desempenho. Percebe-se também que a classificação espacial de documentos que usa a ferramenta Rembrandt para reconhecer as entidades geográficas apresenta um melhor desempenho que os dados processados com o AGRI-BR. Embora os experimentos tenham sido realizados utilizando documentos em português, outros documentos em 
diferentes línguas podem ser usados, bastando para que isso seja possivel usar uma ferramenta que permita reconhecer entidades em outras línguas.

Neste projeto de mestrado, contribui-se com processos de desambiguação que levam em consideração a estrutura hierárquica do Brasil. No Capítulo 2 foram apresentados os principais processos e componentes para a Recuperação de Informação Geográfica. Foram analisadas também as etapas de (1) geo-parsing, na qual mostraram-se os principais processos e as principais ferramentas que permitem o reconhecimento de entidades mencionadas em português, e (2) geo-coding, na qual exploraram-se alguns dos problemas de ambiguidade que podem estar presentes nos documentos, assim como também as principais estratégias para resolver esses problemas. No Capítulo 3 foram apresentados uma série de trabalhos relacionados com a Resolução de Topônimos que usam métodos baseados em conhecimento, ou seja, que fazem uso de elementos externos como gazetteers, Sistemas de Informação Geográficos ou ontologias para resolver os problemas de ambiguidade. Nesses trabalhos foram observadas uma série de etapas e técnicas de resolução de ambiguidade comum a todos. Assim, no Capítulo 4 foi proposta e detalhada a metodologia SpatialCIM que propõe três etapas para permitir descobrir a cobertura espacial dos documentos. Detalhou-se também as duas abordagens de desambiguação propostas neste trabalho, as quais visam realizar a desambiguação dos documentos considerando a hierarquia geo-política do Brasil. Por fim, foram feitas uma série de avaliações sobre as duas abordagens de desambiguação propostas: (1) Desambiguação por Pontos e (2) Desambiguação Textual e Estrutural, e o efeito dos Reconhecedores de Entidades nos resultados, apresentados no Capítulo 5.

Para a realização deste trabalho, foram desenvolvidas 3 ferramentas e 3 recursos que permitiram a obtenção dos resultados apresentados. As ferramentas desenvolvidas foram: (1) a ferramenta denominada BraGeoPs, que permitiu ao especialista fazer uma marcação dos caminhos geográficos associados a cada documento. Essa ferramenta permitiu também, marcar os caminhos de forma a serem usados por um classificador hierárquico multirrótulo; (2) a ferramenta denominada DePP, que implementa a Desambiguação por Pontos proposta neste trabalho. Essa ferramenta permitiu a classificação automática dos documentos considerando as coordenadas geográficas associadas; e (3) a ferramenta denominada DeTE, que implementa a Desambiguação Textual e Estrutural proposta neste trabalho. Essa ferramenta permitiu a classificação automática dos documentos considerando como base a estrutura hierárquica 
das entidades reconhecidas e implementando uma desambiguação textual e heurística. Para o funcionamento das ferramenta, foi necessária a criação ou adaptação de três recursos externos. Em primeiro lugar, foi criado o vocabulário controlado AGRI-BR como uma alternativa para reconhecer as entidades mencionadas nos documentos. Para trabalhar com as coordenadas geográficas das entidades, usadas pela ferramenta DePP, foi criado um gazetteer que considera a hierarquia das entidades Brasileiras. Essa hierarquia está dada por "País, Macro-Região, Região, Estado, Meso-Região, Micro-Região, Município e Usina”. Por outro lado, para a ferramenta DeTE, foi adaptada uma ontologia geográfica do Brasil. A ontologia original foi obtida do trabalho de Venâncio et al. (2003), e foi adaptada para considerar os mesmos níveis hierárquicos considerados pelo gazetteer. Assim, o gazetteer Brasileiro, a ontologia geográfica do Brasil, e o vocabulário controlado AGRI-BR são os três recursos implementados que permitiram a obtenção dos resultados apresentados. As ferramentas desenvolvidas assim como os recursos estão sendo aplicados no âmbito do projeto TIENA. É importante ressaltar que os resultados obtidos com as ferramentas e recursos, servem como entrada para outros processos de visualização e classificação taxonômica dentro da Embrapa.

A partir dos resultados obtidos depois de avaliar as abordagens, é possivel concluir que os processos de desambiguação ajudam na classificação espacial dos documentos, incrementando a precisão e cobertura dos mesmos. Pode-se afirmar também que as ferramentas utilizadas no reconhecimento de entidades dos documentos influência os resultados dos desambiguadores. Finalmente, o uso de técnicas de desambiguação de topônimos levam a encontrar uma melhor localização espacial dos documentos.

Algumas das contribuições tiveram seus resultados publicados em congressos científicos da área de Inteligência Artificial e Informação Geoespacial. Foram duas publicações relacionadas diretamente a este projeto de mestrado: (1) Em (Portugal Vargas et al., 2012a) foi apresentada a metodologia SpatialCIM e foi analisado se o processo de Desambiguação por Pontos têm um melhor desempenho nos documentos que foram classificados usando a desambiguação com aqueles documentos que foram classificados sem usar a desambiguação. Mostrou-se que o processo de desambiguação melhora a precisão e cobertura dos documentos classificados; (2) Em (Portugal Vargas et al., 2012b) foi analisado o impacto que das ferramentas de reconhecimento de entidades mencionadas Rembrandt e AGRI-BR no processo de Desambiguação por Pontos, proposto neste projeto. Mostrou-se que na Desambiguação 
por Pontos, a ferramenta Rembrandt influencia de forma positiva os resultados, aumentando a precisão e cobertura, conseguindo dessa forma uma maior quantidade de acertos.

Para complementar o presente trabalho as principais limitações e os trabalhos futuros são sugeridos, conforme ilustrado nas seguintes seções.

\subsection{Principais Limitações}

Embora o desenvolvimento deste projeto de mestrado tenha cumprido os objetivos propostos, deve-se observar a limitação referida à coleção de documentos textuais utilizadas. Foi utilizada apenas um domínio de documentos, a cana-de-açúcar. Outros tipos de documentos devem ser estudados para verificar a aplicabilidade das abordagens de desambiguação, propostas neste projeto, para documentos textuais de outros tipos de domínio.

As abordagens de Desambiguação por Pontos e Desambiguação Textual e Estrutural, propostas neste projeto, possuem diversas funções. Entretanto, por ser uma abordagem inicial ainda tem várias limitações de aplicação, das quais destacam-se:

- Localidade reconhecidas restritas às regiões administrativas Brasileiras, contendo a hierarquia "País, Macro-Região, Região, Estado, Meso-Região, Micro-Região, Município, Usina”;

- Processo de Reconhecimento de entidades restrito a conteúdos em português se utiliza-se a ferramenta Rembrandt ou o vocabulário AGRI-BR;

- O gazetter Brasileiro desenvolvido restrito a nomes de entidades e coordenadas brasileiras.

A limitação funcional da abordagem está dada pela atribuição de valores $\alpha, \beta$ e $\delta$ para o processo de Desambiguação Textual e Estrutural que podem influenciar a eliminação ou não de entidades.

\subsection{Trabalhos Futuros}

Foram pensadas várias formas de dar continuidade a este trabalho. Começando pela união das abordagens propostas, de forma que, primeiro seja feita uma desambiguação textual e eliminação de entidades que estejam baixo um limiar. Após, com as entidades resultantes fazer uma Desambiguação por 
Pontos. Eliminando dessa forma entidades que podem ter sido reconhecidas de forma errada.

Adicionalmente, podem ser incorporados à metodologia e aos processos de desambiguação elementos linguísticos que permitam refinar ainda mais as entidades e os caminhos geográficos extraídos. Permitindo analisar outros elementos não geográficos que deem indícios de localidade. Por exemplo, em vários documentos observa-se nomes de pessoas ou lugares turísticos que podem ajudar a relacionar o contexto das entidades para uma melhor desambiguação.

Uma outra modificação interessante é a adaptação do gazetter para que inclua mais tipos de informações que possam ajudar nos processos de desambiguação. Por exemplo, população, cidades principais, cidades mais relevantes referentes com outras do mesmo estado.

Incorporar o uso do repositório REPENTINO (Sarmento et al., 2006) como parte do Banco de Dados geográfico, para ajudar nos processos de desambiguação e reconhecimento de entidades. O REPENTINO é um repositório público que contém exemplos de entidades com nome. Esses exemplos encontramse divididos por várias categorias conceptuais, e cada categoria tem subcategorias organizadas na forma de árvore. Dessa forma, podem-se utilizar a estrutura hierárquica das entidades como se fosse uma ontologia e os dados das entidades geográficas para ajudar a reconhecer entidades mencionadas nos textos. Adicionalmente, podem ser incorporados ao REPENTINO dados tais como coordenadas geográficas para melhorar o processo de Desambiguação por Pontos. 



\section{Referências Bibliográficas}

Amancio, M. A. (2011). Elaboração textual via definição de entidades mencionadas e de perguntas relacionadas aos verbos em textos simplificados do português. Dissertação de mestrado, Universidade de São Paulo - Instituto de Ciências de Computação e Matemática Computacional. Citado nas páginas 22 e 23.

Amelunxen, C. (2009). An approach to geocoding based on volunteered spatial data. Dissertação de mestrado, Universidad. Prof. Dr. Josef Strobl - Germany. Citado na página 17.

Amitay, E., Har'El, N., Sivan, R., e Soffer, A. (2004). Web-a-where: geotagging web content. In Proceedings of the 27th annual international ACM SIGIR conference on Research and Development in Information Retrieval, páginas 273-280. Citado nas páginas 1 e 15.

Aranha, C. e Passos, E. (2006). A tecnologia de mineração de textos. RESI Revista Eletrônica de Sistemas de Informação, 5:1-8. Citado na página 8.

Aranha, C. N. (2007). Uma abordagem de pré-processamento automático para Mineração de Textos em português: Sob o enfoque da inteligencia computacional. Dissertação de mestrado, PUC-Rio, Rio de Janeiro - RJ. Citado nas páginas xi, 20, 23, e 24 .

Baeza-Yates, R. A., Ciaramita, M., Mika, P., e H., Z. (2008). Towards semantic search. Proceedings of Natural Language and Information Systems, 5039:411. Citado na página 1.

Bejan, C. A. (2007). Deriving chronological information from texts through a graph-based algorithm. In Proceedings of the Twentieth International Florida 
Artificial Intelligence Research Society Conference, páginas 259-260. AAAI Press. Citado na página 55.

Bensalem, I. e Kholladi, M.-K. (2010). Toponym disambiguation by arborescent relationships. Journal of Computer Science, 6:653-659. Citado nas páginas viii, 3, 52, e 63.

Brachman, R. J. e Anand, T. (1996). The process of knowledge discovery in databases. In Advances in knowledge discovery and data mining, páginas 37-57. Citado na página 1.

Broder, A. (2007). The next generation web search and the demise of the classic IR model. In Proceedings of the 29th European conference on IR research (ECIR). Springer-Verlag. Citado na página 30.

Buscaldi, D. e Magnini, B. (2010). Grounding toponyms in an italian local news corpus. In Proceedings of the 6th Workshop on Geographic Information Retrieval, páginas 1-5. ACM. Citado nas páginas viii, 3, 8, 41, e 61.

Buscaldi, D. e Rosso, P. (2008). A conceptual density-based approach for the disambiguation of toponyms. International Journal of Geographical Information Science, 22:301-313. Citado nas páginas viii, 3, 33, 49, 52, 53, 62, e 113 .

Campelo, C. E. C. e Baptista, C. d. S. (2009). A model for geographic knowledge extraction on web documents. Advances in Conceptual Modeling Challenging Perspectives, 5833:317-326. Citado nas páginas viii, 3, 19, 49, 63, 74, e 75.

Cardoso, N. (2008). Rembrandt - reconhecimento de entidades mencionadas baseado em relações e análise detalhada do texto. In Encontro do Segundo HAREM (Avaliação de Reconhecedores de Entidades Mencionadas). In International Conference on Computational Processing of the Portuguese Language. Citado nas páginas xi, 26, 27, 28, 68, e 88.

Cardoso, N. (2011). Evaluating geographic information retrieval. SIGSPATIAL Special, 3:46-53. Citado nas páginas 1 e 2.

Ceci, F., Cardoso da Silva, D., Sell, D., e Gonçalves, A. (2010). Towards a semi-automatic approach for ontology maintenance. International Conference on Information Systems and Technology Management (CONTECSI), 7:3673-3695. Citado na página 21. 
Chen, H. (2001). Knowledge Management Systems: A Text Mining Perspective. Knowledge Computing Corporation. Citado na página 8.

Clough, P., Sanderson, M., e Joho, H. (2004). Extraction of semantic annotations from textual web pages. Relatório técnico, University of Sheffield. Citado nas páginas 2 e 29.

Câmara, G., Monteiro, A. M., e Medeiros, J. S. (2000). Fundamentos epistemológicos da ciência da geoinformação. In Introdução ao Geoprocessamento. Citado na página 2 .

Conrado, M. S., Marcacini, R. M., Moura, M. F., e Rezende, S. O. (2009). O efeito do uso de diferentes formas de geração de termos na compreensibilidade e representatividade dos termos em coleções textuais na língua portuguesa. In II Workshop on Web and Text Intelligence (WTI), páginas 1-10, São Carlos, SP-Brazil. Citado na página 12.

Correia de Oliveira, D. (2010). Extraction and Classification of Named Entities. Dissertação de mestrado, Instituto Superior Técnico - Universidade Técnica de Lisboa. Citado nas páginas xiii, 24, 25, e 26.

Davis, C. A., Fonseca, F. T., e Borges, K. A. V. (2003). A flexible addressing system for approximate geocoding. In Anais GeoInfo 2003, V Simpósio Brasileiro de Geoinformática. Citado na página 18.

De Alencar, R. O., Davis, C. A., e Gonçalves, M. A. (2010). Geographical classification of documents using evidence from Wikipedia. In Proceedings of the 6th Workshop on Geographic Information Retrieval. ACM. Citado nas páginas viii, 3, 43, e 62 .

De Vasconcelos Borges, K. A. (2006). Uso de uma Ontologia de Lugar Urbano para Reconhecimento e Extração de Evidências Geo-espaciais na Web. Dissertação de mestrado, Universidade Federal de Minas Gerais. Citado nas páginas viii, $3,34,45$, e 62 .

D’hondt, J., Verhaegen, P.-A., Vertommen, J., Cattrysse, D., e Dufllou, J. R. (2011). Topic identification based on document coherence and spectral analysis. Information Sciences, 181:3783-3797. Citado na página 2.

Ebecken, N., Lopes, M. C., Costa, M., e Rezende, S. (2005). Sistemas Inteligentes: fundamentos e aplicações, chapter Mineração de Textos. Manole. Citado na página 28. 
Egenhofer, M. J. e Franzosa, R. (1991). Point-set topological spatial relations. In International Journal of Geographic Information Systems. Citado na página 16.

Farazi, F., Maltese, V., Giunchiglia, F., e Ivanyukovich, A. (2011). A faceted ontology for a semantic geo-catalogue. In The Semanic Web: Research and Applications - 8th Extended Semantic Web Conference. Citado na página 2.

Fayyad, U. M., Piatetsky-Shapiro, G., Smyth, P., e R., U. (1996). From data mining to knowledge discovery: an overview. Advances in knowledge discovery and data mining, 1:1-37. Citado na página 1.

Ferreira, L. e Teixeira, A. (2008). REMMA - reconhecimento de entidades mencionadas do medalert. In Desafios na avaliação conjunta do reconhecimento de entidades mencionadas: Actas do Encontro do Segundo HAREM (Avaliação de Reconhecedores de Entidades Mencionadas). Citado na página 25.

Finch, L. e Gardner, M. (2009). Diversidad en la terminología agrícola de las américas. COMUNIICA. Citado na página 28.

Fuchs, C. (1987). L'ambiguité et la praphrase: opérations linguistiques, processus cognitifs, traitements automatisés. Centre de publications de l’Université de Caen. Citado na página 2.

Garbin, E. e Mani, I. (2005). Disambiguation toponyms in news. Human Language Technology Conference (HLT-EMNLP), 1:363-370. Citado na página 29.

Goldberg, D. W. (2008). A geocoding best practices guide. Relatório técnico, North American Association of Central Cancer Registries. Citado na página 17.

Goldberg, D. W., Wilson, J. P., e Knoblock (2007). From text to geographic coordinates: The current state of geocoding. Journal of the Urban and Regional Information Systems Association, 19:33-46. Citado na página 17.

Gomes, R. M. (2009). Desambiguação de sentido de palavras dirigida por técnicas de agrupamento sob o enfoque da mineração de textos. Dissertação de Mestrado, Pontifícia Universidade Católica do Rio de Janeiro. Citado na página 65. 
Gouvêa, C. (2009). Uma Abordagem para o Enriquecimento de Gazetteers a partir de Notícias visando o Georreferenciamento de Textos na Web. Dissertação de mestrado, Universidade Católica de Pelotas, Centro Politécnico. Citado nas páginas xi, 16, 18, e 30 .

Grishman, R. e Sundheim, B. (1996). Message understanding conference - 6: A brief history. Proceedings of the 16th conference on Computational linguistics, 1:466-471. Citado na página 20.

Hall, M., Frank, E., Holmes, G., Pfahringer, B., Reutemann, P., e Witten, I. H. (2009). The WEKA data mining software: an update. ACM SIGKDD Explorations Newsletter, 1:10-18. Citado nas páginas 114 e 115.

Ide, N. e Véronis, J. (1998). Introduction to the special issue on word sense disambiguation: the state of the art. Computational Linguistics, 24:2-40. Citado na página 31 .

Jones, C. B., Abdelmoty, A. I., e Fu, G. (2003). Maintaining ontologies for geographical information retrieval on the web. On The Move to Meaningful Internet Systems 2003: CoopIS, DOA, and ODBASE, 2888 / 2003:934-951. Citado na página 44.

Jones, C. B. e Purves, R. S. (2008). Geographical Information Retrieval. International Journal of Geographical Information Science, 22:219-228. Citado na página 1.

Konchady, M. (2006). Text Mining Application Programming. Charles River Media, Inc. Citado na página 22.

Kozareva, Z. (2006). Bootstrapping named entity recognition with automatically generated gazetteer lists. Proceedings of the Eleventh Conference of the European Chapter of the Association for Computational Linguistics: Student Research Workshop, 7:15-21. Citado na página 22.

Kripke, S. (1980). Naming and Necessity. Cambridge, Mass. : Harvard University Press. Citado na página 21.

Larson, R. R. (1996). Geographic information retrieval and spatial browsing. GIS and Libraries: Patrons, Maps and Spatial Information, 2:81-124. Citado na página 15. 
Larson, R. R. e Frontiera, P. (2004). Geographic information retrieval (gir): searching where and what. In Proceedings of the 27th annual international ACM SIGIR conference on Research and development in information retrieval. Citado nas páginas xi e 18.

Lee, C.-H., Yang, H.-C., e Shih-Hao, W. (2011). An image annotation approach using location references to enchace geographic knowledge discovery. Experts Systems Applications, 38:13792-13802. Citado na página 2.

Leidner, J. L. (2006). An evaluation dataset for the toponym resolution task. Computers, Environment and Urban Systems, 30:400-417. Citado nas páginas 2, 22, 28, e 29.

Leidner, J. L. (2008). Toponym Resolution in Text: Annotation, Evaluation and Applications of Spatial Grounding of Place Names. Universal Press. Citado nas páginas viii, $3,4,40,61$, e 72 .

Leidner, J. L. e Lieberman, M. D. (2011). Detecting geographical references in the form of place names and associated spatial natural language. SIGSPATIAL Special, 3:5-11. Citado na página 17.

López, A., Somodevilla, M. J., Vilariño, D., Pineda, I. H., e De Celis, C. P. (2012). Toponym disambiguation by ontology in spanish: Geographical proximity between place names in the same context. Advances in information Sciences and Service Sciences (AISS), 4:282-289. Citado nas páginas viii, 3, 34,58 , e 63.

Magalhaes, R. e Moura, M. (2010). Busca e análise de notícias agrícolas sobre cana-de-açúcar. In Mostra de Estagiários e bolsistas da Embrapa Informática Agropecuária. Citado na página 90.

Mantratzis, C., Orgun, M. A., e Cassidy, S. (2005). Separating XHTTML content from navigation clutter using DOM-structure. In Hypertext 2005, Proceedings of the 16th ACM Conference, páginas 145-147. ACM. Citado na página 2.

Martins, B. e Calado, P. (2011). Learning to rank for geographic information retrieval. Proceedings of the 6th Workshop on Geographic Informatino Retrieval GIR, 1:1083-1084. Citado na página 1. 
Martins, C. A. (2004). Uma abordagem para pré-processamento de dados textuais em algoritmos de aprendizado. Dissertação de Mestrado, Instituto de Ciências Matemáticas e de Computação - ICMC-USP. Citado na página 11.

McCurley, K. (2001). Geospatial mapping and navigation of the web. In Proceedings of the 10th international conference on World Wide Web, páginas 221-229. ACM. Citado nas páginas 1 e 15.

Metz, J. (2012). Abordagens para aprendizado semissupervisionado multirótulo e hierárquico. Tese de Doutorado, Instituto de Ciências Matemáticas e de Computação - ICMC-USP. Citado nas páginas xi, xiii, 13, e 14.

Mikheev, A., Moens, M., e Grover, C. (1999). Named Entity Recognition without Gazetteers. In Proc. of the Ninth International Conference of the European Chapter of the Association for Computational Linguistics (EACL'99), páginas 1-8. Citado nas páginas xi e 20.

Nadeau, D. (2007). Semi-Supervised Named Entity Recognition: Learning to Recognize 100 Entity Types with Little Supervision. Dissertação de mestrado, Ottawa-Carleton Institute for Computer Science. School of Information Technology and Engineering - University of Ottawa. Citado nas páginas 21 e 22 .

Overell, S. (2009). Geographic Information Retrieval: Classification, Disambiguation and Modelling. Tese de Doutorado, University of London - Imperial College. Citado na página 1.

Overell, S. e Rüger, S. (2008). Using co-occurrence models for placename disambiguation. International Journal of Geographical Information Science, 22:265-287. Citado na página 33.

Overell, S., Ruger, S., e Magalhaes, J. (2006). Place disambiguation with cooccurrence models. In Proceedings of the Working notes of the Cross Language Evaluation Forum Workshop. Citado nas páginas viii, 3, 38, e 60.

Palmer, D. D. e Day, D. S. (1997). A statistical profile of the named entity task. In Proceedings of the fifth conference on Applied natural language processing, páginas 190-193. Association for Computational Linguistics. Citado na página 22 . 
Pianta, E., Girardi, C., e Zanoli, R. (2008). The textpro tool suite. In Proceedings of the Sixth International Conference on Language Resources and Evaluation. Citado na página 41.

Portugal Vargas, R. N., Moura, M. F., Speranza, E. A., Rodriguez, E., e Oliveira Rezende, S. (2012a). Discovering the Spatial Coverage of the Documents through the SpatialCIM Methodology. In 15th AGILE International Conference on Geographic Information Science. Citado na página 127.

Portugal Vargas, R. N., Moura, M. F., Speranza, E. A., Rodriguez, E., e Oliveira Rezende, S. (2012b). The SpatialCIM methodology for spatial document coverage disambiguation and the entity recognition process aided by linguistic techniques. In Geospatial Information and Documents (Geo-Doc). Citado na página 127.

Rezende, S. O. (2003). Sistemas Inteligentes - Fundamentos e Aplicações. Manole, Barueri. Citado nas páginas xi, 8, 9, 10, e 11.

Ribeiro Machado, I. M. (2011). Um Gazetteer Ontológico para Recuperação de Informação Geográfica. Dissertação de mestrado, Universidade Federal de Minas Gerais. Citado nas páginas viii, xiii, 3, 55, 56, e 63.

Roberts, K., Bejan, C. A., e Harabagiu, S. M. (2010). Toponym disambiguation using events. In Proceedings of the Twenty-Third International Florida Artificial Intelligence Research Society Conference. AAAI Press. Citado nas páginas viii, 2, 3, 33, 53, e 63.

Santos, D. e Cardoso, N. (2006). HAREM, a primeira avaliação conjunta de sistemas de reconhecimento de entidades mencionadas para português: documentação e actas do encontro. Linguateca. Citado na página 24.

Santos, D. e Cardoso, N. (2007). Reconhecimento de entidades mencionadas em português: Documentação e actas do HAREM, a primeira avaliação conjunta na área. Linguateca. Citado nas páginas 21, 22, e 27.

Santos, D. e Chaves, M. (2006). The place of place in geographical ir. In Proceedings of GIR06 the 3rd Workshop on Geographic Information Retrieval(GIR), páginas 5-8. Citado na página 15.

Sarmento, L., Pinto, A. S., e Cabral, L. (2006). Computational Processing of the Portuguese Language: 7 th International Workshop, PROPOR, chapter RE- 
PENTINO - A Wide-Scope Gazetteer for Entity Recognition in Portuguese. Springer Verlag. Citado nas páginas 20, 21, e 129.

Silva, L. B. d. (2006). Ambiguidades da língua portuguesa: recorte classificatório para a elaboração de um modelo ontológico. Dissertação de Mestrado, Universidade de Brasília - Departamento de Ciência da Informação e Documentação. Citado na página 2.

Smith, D. e Crane, G. (2001). Disambiguating Geographic Names in a Historical Digital Library. In Research and Advanced Technology for Digital Libraries, páginas 127-136. Springer Berlin Heidelberg. Citado nas páginas vii, 34,42 , e 60.

Soares, M. V., Prati, R. C., e Monard, M. C. (2008). Pretext ii: Descrição da reestruturacão da ferramenta de pré-processamento de textos. Relatório técnico, ICMC-USP, São Carlos - SP. Citado na página 88.

Spaccapietra, S., Cullot, N., Parent, C., e Vangenot, C. (2004). On spatial ontologies. In Proceedings of the sixth Brazilian Symposium on GeoInformatics. Citado na página 44 .

Stuckenschmidt, H. e Van Harmelen, F. (2004). Information Sharing on the Semantic Web. Springer-Verlag. Citado nas páginas 44 e 45.

Tan, A. H. (1999). Text mining: The state of the art and challenges. In Workshop on Knowledge Discovery from Advanced Databases, páginas 6570. Citado na página 8.

Tsoumakas, G., Katakis, I., e Vlahavas, I. (2010). Mining multi-label data. In Data Mining and Knowledge Discovery Handbook, páginas 667-685. Springer US. Citado na página 14.

Tsoumakas, G., Spyromitros-Xioufis, E., Vilcek, J., e Vlahavas, I. (2011). Mulan: A java library for multi-label learning. Journal of Machine Learning Research, 12:2411-2414. Citado nas páginas 88 e 115.

Venâncio, L. R., Fileto, R., e Medeiros, C. B. (2003). Aplicando ontologias de objetos geográficos para facilitar navegação em GIS. In GeoInfo. Citado nas páginas xi, 5, 81, 82, e 127.

Volz, R., Kleb, J., e Mueller, W. (2007). Towards ontology-based disambiguation of geographical identifiers. In Proceedings of the WWW2007 Workshop 
I3: Identity, Identifiers, Identification, Entity-Centric Approaches to Information and Knowledge Management on the Web. Citado nas páginas viii, 3, 47, e 62 .

Wohlin, C., Runeson, P., Höst, M., Ohlsson, M. C., Regnell, B., e Wesslén, A. (2000). Experimentation in software engineering: an introduction. Kluwer Academic Publishers. Citado na página 88.

Xingguang, W., Yi, Z., Min, C., Xing, L., Hao, Y., e Yu, L. (2010). An evidencebased approach for toponym disambiguation. In The 18th International Conference on Geoinformatics: GIScience in Change, Geoinformatics 2010, páginas 1-7. IEEE. Citado nas páginas viii, 3, 42, e 61.

Yi, L., Alistair, M., Nicola, S., e Lawrence, C. (2006). Exploring probabilistic toponym resolution for geographical information retrieval. In Proceedings of the 3rd ACM Workshop On Geographic Information Retrieval. Citado nas páginas viii, 3, 36, e 60 .

Zubizarreta, A., de la Fuente, P., Cantera, J., Arias, M., Cabrero, J., Garcia, G., Llamas, C., e Vegas, J. (2008). A georeferencing multistage method for locating geographic context in web search. In Proceeding of the 17th ACM conference on Information and knowledge management, páginas 1485-1486. ACM. Citado nas páginas viii, 39, e 61. 